\title{
GROUP COORDINATION PROCESSES AND DETERMINANTS OF LEADER- SHIP IN RED-FRONTED LEMURS (EULEMUR RUFIFRONS)
}

\author{
Dissertation \\ zur Erlangung des mathematisch-naturwissenschaftlichen Doktorgrades \\ „Doctor rerum naturalium“ \\ der Georg-August-Universität Göttingen
}

im Promotionsstudiengang

Behaviour and Cognition

der Georg-August University School of Science (GAUSS)

vorgelegt von

Anna Lucia Sperber

aus Erlangen

Göttingen, 2018 


\section{Betreuungsausschuss}

Dr. Claudia Fichtel

Abteilung Verhaltensökologie \& Soziobiologie, Deutsches Primatenzentrum GmbH, Kellnerweg 4, 37077

Göttingen

Prof. Dr. Margarete Boos

Sozial- und Kommunikationspsychologie, Georg-Elias-Müller-Institut für Psychologie, Gosslerstraße 14, 37073 Göttingen

PD Dr. Oliver Schülke

Abteilung Verhaltensökologie, Johann-Friedrich-Blumenbach Institut für Zoologie and Anthropologie, Kellnerweg 6, 37077 Göttingen

\section{Mitglieder der Prüfungskommission}

Referentin: Dr. Claudia Fichtel

Korreferentin: Prof. Dr. Margarete Boos

Weitere Mitglieder der Prüfungskommission

PD Dr. Oliver Schülke

Abteilung Verhaltensökologie, Johann-Friedrich-Blumenbach Institut für Zoologie and Anthropologie, Kellnerweg 6, 37077 Göttingen

Prof. Dr. Julia Ostner

Abteilung Verhaltensökologie, Johann-Friedrich-Blumenbach Institut für Zoologie and Anthropologie, Kellnerweg 6, 37077 Göttingen

Prof. Dr. Eckhard Heymann

Abteilung Verhaltensökologie \& Soziobiologie, Deutsches Primatenzentrum GmbH, Kellnerweg 4, 37077 Göttingen

PD Dr. Christian Roos

Abteilung Primatengenetik, Deutsches Primatenzentrum GmbH, Kellnerweg 4, 37077

Tag der mündlichen Prüfung: 14. Dezember 2018 
"And the voice said,

'We want you to go to Madagascar. [...] The plane leaves in two weeks, we would like you to be on it.'

Now I -assuming they've got the wrong number - said 'yes!' before they could discover their mistake.

But in fact, it turned out that they decided,

'Well, here is somebody who doesn't know anything about lemurs [...], anything about Madagascar, let's send him.'

So I started to try and find out something about it, and it turns out it's very interesting."

Douglas Adams 


\section{Contents}

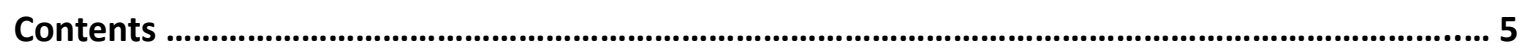

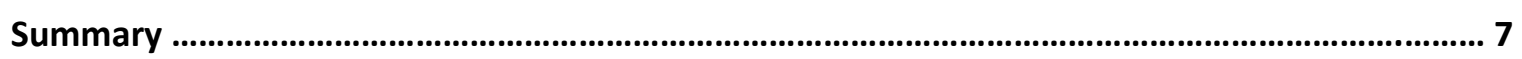

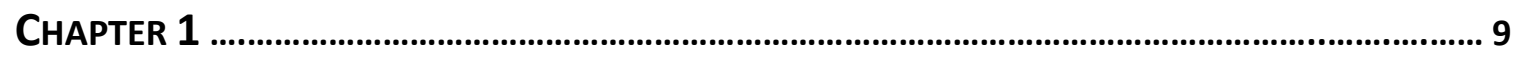

General Introduction

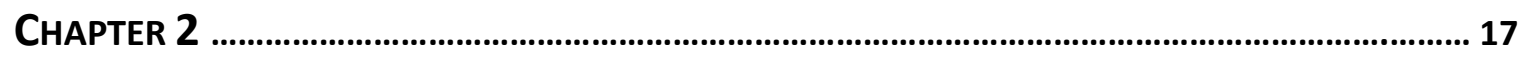

Grunt to go - Vocal coordination of group movements in red-fronted lemurs

With Lynne M. Werner, Peter M. Kappeler \& Claudia Fichtel

ChAPTER 3

Who leads? Characterising initiators of collective movements in wild red-fronted lemurs

With Peter M. Kappeler \& Claudia Fichtel

\section{CHAPTER 4}

Should I stay or should I go?

Individual movement decisions during group departures in red-fronted lemurs

With Peter M. Kappeler \& Claudia Fichtel

ChAPTER 5

\section{General Discussion}

Bibliography

Acknowledgments

Declaration 


\section{Summary}

For animals to enjoy the benefits of group living it is vital that they coordinate their activities despite divergent needs. The challenge this poses becomes apparent when animals are moving between resources. In this thesis I investigated several aspects that determine a group's movement coordination: the coordination of departure time, the characteristics of initiators and the joining process. The subjects of my studies were four groups of wild red-fronted lemurs (Eulemur rufifrons). in Kirindy Forest, Western Madagascar. I combined observations of naturally occurring group movements with audio recordings of focal individuals. Additionally, I conducted behavioural observations and experiments to assess affiliative bonds and individual personality.

I found that group movements were preceded by a pre-departure period, in which subsequent initiators and followers increased the rate at which they produced close calls ("grunts"). These observations suggest that grunts indicate the individual's readiness to move and may provide the basis for a shared decision on departure time. In addition, initiators grunted more than followers, even when comparing them at their respective departures which hints that grunts may also have a recruitment function. Although animals of both sexes and age classes initiated group movements, individuals differed in their initiation frequency. Initiation frequency depended on personality, with a positive effect of exploration and a sex-dependent effect of sociability. Joining was determined by the follower's age, sex, affiliative relationships and proximity to others at departure. Females made up the vanguard of the departing group, while juveniles took protected central positions and males brought up the rear. Dyads with stronger affiliative bonds departed in closer succession, and individuals followed group mates more quickly when they were closer to them at departure. These findings demonstrate that local rules and individual needs can combine to determine individual departure decisions.

This thesis clarifies important aspects of collective departures in an egalitarian primate species in its natural habitat. It identifies a close call as a possible feed-back mechanism to coordinate departure time, demonstrates that leadership likelihood is influenced by individual personality and illustrates the determinants and mechanisms of the joining process. It thus contributes to our understanding of how groups achieve collective action and brings us a step closer to identifying the general principles of group coordination and collective decision making. 


\section{ChAPTER 1}

\section{General Introduction}

\section{Collective decisions}

"If you want to go fast, go alone. If you want to go far, go together."

Overused though this proverb may be, it cuts straight to the dilemma of living in a group: To be a part of something bigger you must be willing to compromise. Individuals garner numerous benefits from living in a group, such as reduced individual predation risk, joint resource defence, cooperative foraging, shared vigilance, and information transfer (Alexander, 1974; Bertram, 1978; Silk, 2007; Terborgh, 1983; van Schaik, 1983; Wrangham, 1980; Zemel \& Lubin, 1995). However, animals living in a group also incur costs due to increased pathogen transmission and intra-group conflicts over resources, which limits the maximal size of groups (Alexander, 1974; Bertram, 1978). A further problem jeopardising group cohesion are inter-individual conflicts in goals. Depending on their age, sex and physiological and reproductive state, group members often differ in their time budgets and dietary needs, which results in conflicting interests within a group (Alonso \& Alonso, 1993; Boinski, 1988; Fragaszy, 1990; Ginnett \& Demment, 1997; Rothman, Dierenfeld, Hintz, \& Pell, 2008; Sauther, 1994; Scantlebury, Russell, Mcllrath, Speakman, \& Clutton-Brock, 2002). Individuals cannot simply follow their own interests if they want to continue reaping the benefits of group living. To stay cohesive, a group must coordinate individual interests. Group members have to reach a consensus decision (Conradt \& Roper, 2005), which leads to collective action. Due to the conflicting interests, collective actions will come at a price, the "consensus cost", which amounts to the fitness disadvantages individuals incur by compromising with the other group members (Conradt \& Roper, 2003, 2005). If these costs are higher than the benefits of staying with the group, they can result in group fission (Kerth, Ebert, \& Schmidtke, 2006; King, 
Douglas, Huchard, Isaac, \& Cowlishaw, 2008; Pyritz, Fichtel, Huchard, \& Kappeler, 2013).There are two ways in which groups can reduce consensus costs: within one single event or across several events over time. First, in many species decisions are shared, with multiple group members participating in the decision-making process (Bourjade \& Sueur, 2010; Conradt \& Roper, 2005, 2007; but see King et al., 2008; Lusseau \& Conradt, 2009). Second, only a minority of species exhibits "consistent leadership", with one individual consistently leading collective actions (Conradt \& Roper, 2005). This individual is then usually the highest ranking in a strict hierarchy (Rasa, 1987; Schaller, 1963). The majority of species exhibits "variable leadership", i.e. leader identity varies across time and contexts (Conradt \& Roper, 2005). Although some general mechanisms of how groups achieve collective actions have been identified, the topic still poses important unanswered questions and thus requires further study.

\section{Collective movements as a model for collective action}

Differences in needs between individuals often express themselves as differences in spatial goals, e.g. remaining safely in a resting spot or venturing out to a foraging site. Thus, natural group movements between resources provide an excellent opportunity to study the fundamental mechanisms of how groups achieve coordination and collective action. Not only do group movements occur across a wide range of animal species (Petit \& Bon, 2010), which provides a basis for comparative approaches, they also occur frequently, in most species every day. Group movements are also operationally accessible with visible stages and results, which allows studying the mechanisms behind a collective decision. Furthermore, group movements provide an ecologically relevant context, since individuals must weigh the advantages and disadvantages of different actions that differ in their risks and rewards (see "Initiators of group movements" below), which allows us insight into the factors determining leader- and followership. On account of these advantages, group movements are the main context in which group coordination has been studied in non-human animals (Boinski \& Garber, 2000; Fichtel, Pyritz, \& Kappeler, 2011; Pyritz, King, Sueur, \& Fichtel, 2011; Sueur, Deneubourg, \& Petit, 2011) and are also of interest for researchers of human collective behaviour (Boos, Pritz, Lange, \& Belz, 2014; Dyer et al., 2008; Dyer, Johansson, Helbing, Couzin, \& Krause, 2009; Faria, Krause, \& Krause, 2010).

Collective movements have been defined by Petit \& Bon (2010) as "a group of animals that decide to depart[...], move together in the same direction [...] and maintain cohesion until the group stops moving or starts a new activity, all resulting in a change of location." (Petit \& Bon, 2010, p. 635). In this thesis I will concentrate on the beginning of collective movements, addressing three stages, which will be introduced in detail in the sections ahead. First, the time directly 
before departure, in which a shared decision can be made. Second, the initiation, where one group member takes on the role of initiator by moving away from the group. And third, the joining process, in which the other group members decide on their individual departure, as they might, or might not, join the initiator by moving off in the same direction and thus become followers (King, 2010; Petit \& Bon, 2010). In this thesis, I equate a successful initiation that attracts followers with leadership, in line with the definition of leadership as behaviours that determine the type, timing and duration of group activities (Krause \& Ruxton, 2002).

\section{Coordination of departure time}

The basis for a shared movement decision are so-called "notifying behaviours" (Kummer, 1968) or "preliminary behaviours" (Sueur \& Petit, 2008b). They are produced in a "pre-departure period" directly before the movement and show the individuals' needs, giving them the possibility to influence the movement decision in their favour (Petit \& Bon, 2010). The movement direction can be determined by voting, as group members can indicate their preferred spatial goal (Kummer, 1968; Prins, 1996; Ramos, Petit, Longour, Pasquaretta, \& Sueur, 2015; Seltmann, Majolo, Schülke, \& Ostner, 2013; Sueur, Deneubourg, \& Petit, 2010; Sueur et al., 2011). In this thesis, however, I will focus on the coordination of departure time. Group members can express their readiness to move (Fischer \& Zinner, 2011; Rendall, Seyfarth, Cheney, \& Owren, 1999; Seeley \& Tautz, 2001; Stewart \& Harcourt, 1994; Visscher \& Seeley, 2007; Watts, 2000) and the rate of these displays, particularly those of the subsequent initiator, have been shown to affect the recruitment success of a subsequent initiation (Bourjade, Thierry, Maumy, \& Petit, 2009; Ramseyer, Boissy, Dumont, \& Thierry, 2009; Ramseyer, Thierry, Boissy, \& Dumont, 2009; Sueur \& Petit, 2008b) . The timing of departure can even be decided precisely via quorum (Bousquet, Sumpter, \& Manser, 2011; Walker, King, McNutt, \& Jordan, 2017).

Notifying behaviours can be directed at all senses and different behaviours are often combined to reach several senses at once. Notifying behaviours can be olfactory or tactile, as sniffing and grooming in carnivores (Smith, Estrada, et al., 2015). They can also be visual, ranging from simple intention movements in ungulates and several primate species (Bourjade et al., 2009; Seltmann et al., 2013; Sueur \& Petit, 2008b) to head tossing and bobbing in geese and swans (Black, 1988; Raveling, 1969). In environments with low visibility, e.g. in dense forests, acoustic notifying behaviours are particularly apt (Bradbury \& Vehrencamp, 2011). Their use is thus widespread, especially in primates. The most common acoustic signals are vocalisations, but exceptions exist, e.g. the "buzz run" in which honey bees (Apis mellifera) buzz their wings to initiate movement (Rittschof \& Seeley, 2008). In the movement context, acoustic signals are not only used 
in the pre-departure period but are often also employed at initiation (Evans, 1982; Radford, 2004) or for leading the moving group (Boinski, 1996; Boinski, Moraes, Kleiman, Dietz, \& Baker, 1994).

The vocalisations used in the movement context can be specific to this context, as the "moving call" used by meerkats (Suricata suricatta) when voting to change foraging patch (Bousquet et al., 2011). Specific movement calls have been studied in a wide range of species from bees to birds to primates (Boinski, 1991, 1993, 1996; Boinski \& Campbell, 1995; Boinski et al., 1994; Leca, Gunst, Thierry, \& Petit, 2003; Seeley \& Tautz, 2001; Sueur, 2011; Visscher \& Seeley, 2007; Warrington, McDonald, Sager, \& Griffith, 2014). However, the vocalisations used can also be multi-contextual, meaning that they also have functions outside the movement context. One example is the "cackling call" in green woodhoopoes (Phoeniculus purpureus), which also functions as an alarm call (Radford, 2004). The use of multi-contextual calls, despite being widespread, has rarely been described quantitatively (Duplaix, 1980; Evans, 1982; Fichtel \& Manser, 2010; Fischer \& Zinner, 2011; Rendall et al., 1999; Stewart \& Harcourt, 1994; Watts, 2000). This topic warrants further study, since detailing the production and effects of notifying behaviours in species with different group sizes, social organisations and habitats can help us understand the mechanisms at work in reaching a consensus decision.

\section{Initiators of group movements}

As rare as consistent despotic leadership is, equally distributed leadership is just as rare. Usually, certain group members initiate collective movements more often than others (Conradt \& Roper, 2005). What characterises these frequent initiators? To answer this question, it is necessary to consider the costs and benefits incurred by the initiator of a movement. A primary benefit of initiating a group movement is the chance to follow one's own needs without leaving behind the safety of the group (Conradt \& Roper, 2009). On top of that, being in the van can increase foraging success due to the "finder's advantage" (DeBlois \& Rose, 1996; Di Bitetti \& Janson, 2001; Krause, 1993; Krause, Reeves, \& Hoare, 1998; Vickery, Giraldeau, Templeton, Kramer, \& Chapman, 1991). Still, initiating also has drawbacks. The initiator runs the risk of being at least temporarily separated from the group, thus losing the benefits it provides. Moreover, the vanguard of a moving group runs a higher risk of predation (Bumann, Krause, \& Rubenstein, 1997; Krause, Ruxton, \& Rubenstein, 1998).

For an animal to initiate a movement, the benefits have to outweigh the costs. The balance can be tipped towards initiating by an increased interest in the reward. Hungry individuals or individuals with generally higher physiological needs, such as lactating females, have been observed to lead group movements more often (Fischhoff et al., 2007; Furrer, Kunc, \& Manser, 2012; 
Krause, 1993; Nakayama, Johnstone, \& Manica, 2012; Öst \& Jaatinen, 2013). Furthermore, knowledge of an attractive resource can be a great incentive, as trained individuals lead naïve group mates to food resources in experimental studies in fish (Köhler, 1976; Reebs, 2000), sheep (Ovis aries) (Pillot et al., 2010) and meerkats (Bousquet \& Manser, 2011).The scales can also be tipped by a reduction of the costs of initiating. The risk of separation from the group is smaller for high-ranking and socially central individuals, who can rely on their social power to guarantee that the group will follow (Jacobs, Sueur, Deneubourg, \& Petit, 2011; King et al., 2008; King, Sueur, Huchard, \& Cowlishaw, 2011; Ramseyer et al., 2009, 2009; Ramseyer, Petit, \& Thierry, 2009b; Seltmann et al., 2013; Sueur et al., 2011; Sueur, Petit \& Deneubourg, 2009). Furthermore, a bigger body size and superior strength make individuals less vulnerable to predator attack, which is among the reasons for adults leading more often than subadults in many species (Boinski, 1991; Fernández, Kowalewski, \& Zunino, 2013; Pyritz, Kappeler, \& Fichtel, 2011; Sueur \& Petit, 2008b; Van Belle, Estrada, \& Garber, 2013).

One trait that can shift an animal's whole perception of the costs and benefits of an action is its personality, i.e. consistent inter-individual differences in behaviour (Bergmüller \& Taborsky, 2010; Réale, Reader, Sol, McDougall, \& Dingemanse, 2007; Sih, Bell, \& Johnson, 2004; Wolf \& Krause, 2014; Wolf \& Weissing, 2012). Particularly an individual's boldness, its willingness to prioritise reward over risk, has been linked with leadership across species (Briard, Dorn, \& Petit, 2015; Harcourt, Ang, Sweetman, Johnstone, \& Manica, 2009; Leblond \& Reebs, 2006; Nakayama et al., 2012; Ward, Thomas, Hart, \& Krause, 2004). Leaders are also marked by high levels of exploration, i.e. a positive reaction to novelty, and by general high activity (Beauchamp, 2000; Kurvers et al., 2009; Ramseyer, Boissy, Thierry, \& Dumont, 2009; Schuett \& Dall, 2009). Moreover, an animal's sociability determines its perceived cost of leaving the group behind and can thus lead to less sociable individuals initiating more often (Arnold, 1977; Conradt, Krause, Couzin, \& Roper, 2009; Della-Rossa, Chadœuf, Boissy, \& Dumont, 2013; Ramseyer et al., 2009).

How these characteristics interact and what their relative effects are on leadership remains unclear, particularly since several leadership-boosting traits often coincide within one individual. To tease apart these factors, it is necessary to study species with different social systems and different trait combinations. Furthermore, most of the studies on the effect of personality traits on leadership have been conducted in captivity, with personality tested while individuals were isolated from the group, although social context can strongly impact behaviour (Webster \& Ward, 2011). The few studies conducted in the wild solely explored the connection between leadership and boldness and produced conflicting results (Berger, 1977; Öst \& Jaatinen, 2013; Réale \& Festa-Bianchet, 2003). Thus, studies in the wild that measure personality in a natural social context 
and relate it to the role individuals take in group movements would help further our understanding of the determinants of leadership and how they are shaped by social and ecological factors

\section{Joining process}

After initiation, one question arises: Why and when do group members choose to join a movement? The joining process of a group movement is often determined by mimetism, a positive feedback mechanism, in which one animal leaving makes it more probable for others to leave as well (Deneubourg \& Goss, 1989; King \& Sueur, 2011; Petit \& Bon, 2010). In individualised groups, mimetism is hardly ever anonymous, i.e. based solely on the number of individuals leaving (but see Petit, Gautrais, Leca, Theraulaz, \& Deneubourg, 2009). Rather, mimetism is selective and the decision to follow is influenced by the characteristics of the initiator or other predecessors.

It is common for individuals to preferentially follow those group members they share a strong social bond with. This affiliative mimetism has been reported in primates, but also in domestic horses (Equus caballus) and other domestic animals (Briard et al., 2015; Jacobs, Sueur, et al., 2011; King et al., 2008; King, Sueur, et al., 2011; Ramseyer et al., 2009, 2009, 2009; Ramseyer, Petit, et al., 2009b; Seltmann et al., 2013; Sueur et al., 2009, 2011). What has been studied far less in the context of group departures, is the influence of distance, in that individuals will join a group movement when those in spatial proximity do. Still, spatial mimetism has been observed in Humbug damselfish (Dascyllus aruanus), in anonymous human groups, as well as in domestic sheep and geese (Anser domesticus) (Faria et al., 2010; Ramseyer et al., 2009; Ramseyer, Petit, \& Thierry, 2009a; Ward et al., 2013). When it is considered at all, spatial proximity is often conflated with affiliation (King, Sueur, et al., 2011). An attempt to find independent measures for these factors would be beneficial for determining their relative effects.

As mentioned above (see "Initiators of group movements"), different positions in the travel order carry different risks and benefits. Thus, as individuals differ in their vulnerability and nutritional needs, their decision on when to leave will also be affected by these individual traits (Fichtel, 2012; Holekamp, Boydston, \& Smale, 2000; Prins, 1989; Wright, 1998) How the influence of individual traits interacts with general following process remains largely unexplored.

\section{Study species red-fronted lemurs (Eulemur rufifrons)}

Malagasy primates (Lemuriformes) offer an excellent study system for questions about social behaviour, since group living in lemurs is the result of convergent evolution with other primates (Kappeler, 1999). Thus, studying group coordination processes in lemurs presents a valuable opportunity for comparing mechanisms and identifying general principles at work in this context. 
Red-fronted lemurs are medium-sized, cathemeral primates. They are primarily arboreal, but also use the ground for foraging and travelling. They live in small multi-male multi-female groups and are relatively egalitarian and socially tolerant (Mittermeier et al., 2010; Pereira, Kaufman, Kappeler, \& Overdorff, 1990). Lacking a strict dominance hierarchy and sexual size dimorphism, red-fronted lemurs are a particularly informative study species for the determinants of leadership and following processes. Group movements occur several times a day and are most often initiated by adult females. Leadership is distributed, as initiator identity varies between events, but some individuals initiate movements more frequently than others (Erhart \& Overdorff, 1999; Pyritz, Kappeler, et al., 2011). Studying the differences between frequent initiators and followers in this species can thus help us determine the characteristics of leaders when affiliative bonds, age and sex are not confounded with dominance rank. These same circumstances are also beneficial for studying the factors affecting the joining process. On top of that, variable leadership and high social tolerance are often associated with shared decision making (Petit \& Bon, 2010; Pyritz, Kappeler, et al., 2011; Ramseyer et al., 2009, 2009; Seltmann et al., 2013; Sueur \& Petit, 2008b). It is thus likely that red-fronted lemurs are using notifying behaviours to coordinate departure. A candidate vocalisation, a multi-contextual call, has already been identified (Pereira \& Kappeler, 1997; Pflüger \& Fichtel, 2012). On the whole, red-fronted lemurs offer an excellent system for studying several aspects of group movements that will benefit from more attention.

\section{Aims and structure of this thesis}

The aim of this thesis is to further the understanding of the mechanisms of group coordination and collective decision making, with particular focus on inter-individual differences. To this end, the next three chapters chronicle the complete departure process for group movements in redfronted lemurs, exploring the use of notifying behaviours in the pre-departure period and at departure, identifying traits characterising frequent initiators and investigating the factors and processes affecting joining decisions. All chapters are based on the analysis of behavioural and experimental data collected in the field in Madagascar. Chapter $\mathbf{2}$ focuses on the coordination of departure time with notifying behaviours. I investigate the potential function of a multi-contextual call as an indicator of the motivation to move and as a recruitment tool. Chapter $\mathbf{3}$ takes a closer look at the initiators of group movements. In this chapter, I determine the influence of sex, age, sociability, activity, boldness and exploration on initiation frequency. Individual personality is quantified with measures from behavioural observations and field experiments. Chapter 4 examines the factors that influence the joining process of a movement. I test age and sex as likely determinants of departure order, but also consider potential mimetic effects of proximity to other group 
1 General Introduction

members at departure and affiliative relationships of dyads. In Chapter 5 I summarise and discuss the results of the thesis and give an outlook on future directions of collective movement research. 


\section{Chapter 2}

\section{Grunt to go - Vocal coordination of group movements in red-fronted lemurs}

Anna Lucia Sperber, Lynne M. Werner, Peter M. Kappeler, Claudia Fichtel

Ethology, 2017, Volume 123, Issue 12, Pages 894-905

https://doi.org/10.1111/eth.12663

Authors' contributions

ALS, PMK \& CF designed the study, ALS \& LW collected and analysed the data, ALS drafted the manuscript, CF and PMK participated in writing the manuscript 


\section{ABSTRACT}

To remain cohesive as a group, individuals must coordinate their movements between resources. In many species, vocalisations are used in this context. While some species have specific movement calls, others use calls which are also employed in different contexts. The use of such multicontextual calls has rarely been studied quantitatively, especially during both the pre-departure and departure period associated with collective decisions. We thus investigated the use of close calls ("grunts") for the coordination of collective movements in four groups of wild red-fronted lemurs (Eulemur rufifrons) in Kirindy Forest, Western Madagascar. Group movements are started by an initiator, who moves away from the group and is joined by followers setting out in the same direction. We observed collective movements and recorded vocalisations from 18 focal individuals (54 movements recorded for followers, 21 for initiators). The grunt rate of both initiators and followers was higher in the pre-departure period than in a control context (i.e., during foraging). Initiators of collective movements grunted more often than followers in the pre-departure period as well as at individual departure. The latter difference was due to the initiators' grunt rates increasing earlier than the followers' and remaining at an elevated level for longer. These observations suggest that grunts serve to coordinate the departure by indicating the individual's readiness to move. The pre-departure period, in which both initiators and followers showed an elevated grunt rate, may provide the basis for a shared decision on departure time. The difference in initiator and follower call rates suggests that grunts may have a recruitment function, but playback experiments are required to test this potential function. Overall, our study describes how multicontextual close calls can function as movement calls, with changes in call rate providing a potential feedback mechanism for the timing of group movements. This study thus contributes to a more detailed understanding of the mechanisms of group coordination and collective decision making.

Keywords: collective movements, Eulemur, group coordination, primates, vocalisations 


\section{INTRODUCTION}

Living in a group has costs, but also many benefits (Alexander, 1974; Silk, 2007; Terborgh, 1983; van Schaik, 1983; Wrangham, 1980). To reap the benefits of group-living, animals must stay cohesive during movements between resources. As group members often differ in their time budgets and needs according to their sex, age and reproductive state (Alonso \& Alonso, 1993; Boinski, 1988; Fragaszy, 1990; Sauther, 1994; Scantlebury et al., 2002), they may have conflicting interests at a given time. Thus, concerted movements come at a price-, the "consensus cost" (Conradt \& Roper, 2005).

To reduce this consensus cost, movement decisions in many species are shared, with multiple group members participating in the decision-making process (Bourjade \& Sueur, 2010; Conradt \& Roper, 2005, 2007; but see King et al., 2008; Lusseau \& Conradt, 2009). In order to influence a movement decision, group members can indicate their readiness to move as well as their preferred movement direction. These so-called notifying (Kummer, 1968) or preliminary behaviours (Sueur \& Petit, 2008b) are exhibited in a pre-departure period, which directly precedes the group movement. The timing of departure can thus be decided with a quorum or threshold rule (Bousquet et al., 2011), whereas the movement direction can result from a voting process (Kummer, 1968; Prins, 1996; Ramos et al., 2015; Seltmann et al., 2013; Sueur et al., 2010, 2011).

Notifying behaviours, particularly those shown by the initiator of a collective movement, can further affect the recruitment success of an initiation, i.e., whether the initiator is followed, by how many group members and how quickly. This is commonly linked with initiators expressing notifying behaviours at a higher rate than other group members during the pre-departure period (Black, 1988; Ramseyer et al., 2009, 2009) and at the time of departure (Evans, 1982; Sueur \& Petit, 2010). Finding differences between initiators and followers in a behaviour occurring in the pre-departure period or at departure could thus allow inferring a recruitment function of said behaviour.

Notifying behaviours can include all communication modalities and combinations thereof. While olfactory and tactile notifying behaviours have only rarely been reported (Smith, Estrada, et al., 2015), the use of visual and acoustic behaviours is ubiquitous. Visual notifying behaviours can simply show the readiness to move (Black, 1988), but can also be used to indicate the desired movement direction. This can be done by orienting towards (Ramseyer et al., 2009, 2009; Warrington et al., 2014) or walking in the desired direction (Seltmann et al., 2013; Sueur et al., 2011; Sueur \& Petit, 2008b). Acoustic signals are advantageous in environments impeding the 
visual monitoring of group members, such as dense forests, or when groups are widely spread out (Bradbury \& Vehrencamp, 2011).

Acoustic signals may be employed during the pre-departure period as well as at initiation, and can be specific to the movement context or multi-contextual, i.e., also used in other contexts, such as regulation of social interactions (Pflüger \& Fichtel, 2012) or as a warning call (Radford, 2004). Specific movement calls have been observed in several species, including apostlebirds (Struthidea cinerea) (Warrington et al., 2014), meerkats (Suricata suricatta) (Bousquet et al., 2011), golden lion tamarins (Leontopithecus rosalia) (Boinski et al., 1994), Central American squirrel monkeys (Saimiri oerstedi) (Boinski, 1991, 1996) and white-faced capuchins (Cebus capucinus) (Boinski, 1993; Boinski \& Campbell, 1995; Leca et al., 2003).

The movement function of multi-contextual calls can be communicated in different ways, depending on the period in which they are used. In the pre-departure period, a distinct increase in the rate of close calls heralds the impending group movement in giant otters (Pteronura brasiliensi) (Duplaix, 1980), mountain gorillas (Gorilla gorilla berengei) (Stewart \& Harcourt, 1994; Watts, 2000) and Chacma baboons (Papio ursinus) (Fischer \& Zinner, 2011). Additionally, calls can be paired with visual cues, resulting in a combination specific to the movement context, as in African elephants (Loxodonta africana) (O'Connell-Rodwell et al., 2012; Poole, Payne, Langbauer, \& Moss, 1988). At initiation, on the other hand, calls are coupled with the clear visual cue of moving away from the group, which provides contextual information (Evans, 1982; Radford, 2004). While multi-contextual calls appear to be a widespread means of movement coordination (Fichtel \& Manser, 2010), this function has often been described anecdotally or as part of the vocal repertoire, but quantitative analyses are rare. Here, we study the use and function of multi-contextual calls in the context of collective movements in a group-living primate.

Studying group coordination in Malagasy primates (Lemuriformes) offers an interesting comparative perspective, as they evolved group living independently from other primates (Kappeler, 1999). Although lemurs use vocalisations for intergroup spacing and intragroup cohesion (e.g., Braune, Schmidt, \& Zimmermann, 2005; Fichtel \& Hilgartner, 2013; Patel \& Owren, 2012; Ramanankirahina, Joly, Scheumann, \& Zimmermann, 2016; Rasoloharijaona, Randrianambinina, Braune, \& Zimmermann, 2006), their role in decision-making processes during collective group movements has rarely been considered. We therefore studied the use of vocalisations as notifying behaviours during collective decision-making of group movements in redfronted lemurs (Eulemur rufifrons).

Red-fronted lemurs are medium-sized, cathemeral, forest-dwelling primates, which are primarily arboreal, but also frequent the ground, mostly to forage and travel. They are relatively 
egalitarian and socially tolerant, and live in small multimale, multifemale groups (Mittermeier et al., 2010; Pereira et al., 1990). Group movements are mostly initiated by adult females, but leader identity varies between events (Erhart \& Overdorff, 1999; Pyritz, Kappeler, et al., 2011). This variable leadership makes red-fronted lemurs a suitable study species: As the constant monitoring of all potential initiators would be cognitively very demanding, the existence of notifying behaviours is likely (Sueur \& Petit, 2008b). An absence of visual displays in this species has already been noted (Fichtel et al., 2011), and although red-fronted lemurs possess a rich vocal repertoire (Fichtel \& Kappeler, 2002; Pereira \& Kappeler, 1997; Pflüger \& Fichtel, 2012), no specific movement call has been identified. However, the grunt, a "close call," is frequently produced in the movement context and during foraging (Pereira \& Kappeler, 1997), and the grunt rate increases with the risk of separation, suggesting that it may serve to maintain cohesion (Pflüger \& Fichtel, 2012). This study therefore addressed the following questions: Do red-fronted lemurs use grunts to coordinate the departure time of collective movements in a shared decision? and Do grunts have a recruitment function? Answering these questions will provide new insights into the mechanisms of group coordination and decision making, particularly for the use of multi-contextual calls in the movement context. 


\section{MATERIAL AND METHODS}

\section{Study site and subjects}

This study was conducted in Kirindy Forest, Western Madagascar, at the field site of the German Primate Center. The study site is situated in a dry, semi-deciduous forest within a forestry concession operated by the Centre National de Formation, d'Etudes et de Recherche en Environnement et Foresterie (CNFEREF) (Kappeler \& Fichtel, 2012a). The population of red-fronted lemurs has been part of a long-term study, and study animals are individually marked with nylon or radio collars and are well habituated to observers (Kappeler \& Fichtel, 2012b). We studied four groups consisting of 6-11 individuals.

\section{Data collection}

Data were collected in August 2014 and from September to October 2015, mainly between 8:00 $-11: 00$ and 14:00 - 17:00 h, as groups usually rest during midday (Kappeler \& Erkert, 2003). One focal group was observed per half-day, and morning and afternoon observation sessions were balanced among groups. Observations were recorded with a Psion handheld computer and processed in Excel (Microsoft Office).

\section{Group movements}

Group movement events were recorded with all-occurrences sampling. We followed the definitions of Pyritz et al. (2011, p. 1332): an initiator was defined as an individual who, after being "stationary for $\geq 4 \mathrm{~min}$, moves $\geq 15 \mathrm{~m}$ away from [the other] group members in a directed manner without pausing." An initiation attempt was considered successful if at least one follower (apart from dependent offspring) was recruited. The definition of a follower was slightly modified from an individual who arrives in the vicinity of the leading individual $\leq 10 \mathrm{~min}$ after termination, to an individual who leaves $\leq 10 \mathrm{~min}$ after the initiator and whose "movement diverges $\leq 45^{\circ}$ from the trajectory of the movement of the initiator" (Pyritz, Kappeler, et al., 2011, p. 1332). A termination was defined as the moment "when the leading individual was again stationary for $\geq 4$ min" (Pyritz et al., 2011, p. 1332). During initiations, we noted the identities of initiators and followers and the timing of their departures. We included only successful initiations in the analysis, as the number of unsuccessful initiations was too small to allow statistical analyses (see also Pyritz et al., 2011). Furthermore, we disregarded group movements caused by intergroup conflicts. We treated all group movements as independent events for statistical analyses. 


\section{Audio recordings}

Simultaneously with group movement observations, we made audio recordings of 18 adult individuals in four groups in 2014 and in three groups in 2015. All vocalisations of focal animals were recorded during 30 min sessions with a Marantz PMD 660 CF-Recorder and a Sennheiser ME 80 directional microphone. Each session also included continuous recording of the focal animal's behaviour (resting, foraging, locomotion and social interactions) associated with each call. We recorded vocalisations for $87 \mathrm{hr}$, including 75 recorded group movement events (54 follower recordings, 21 initiator recordings). We identified grunts by visual inspection of the spectrogram using Cool Edit 2000 (Syntrillium Software Corporation).

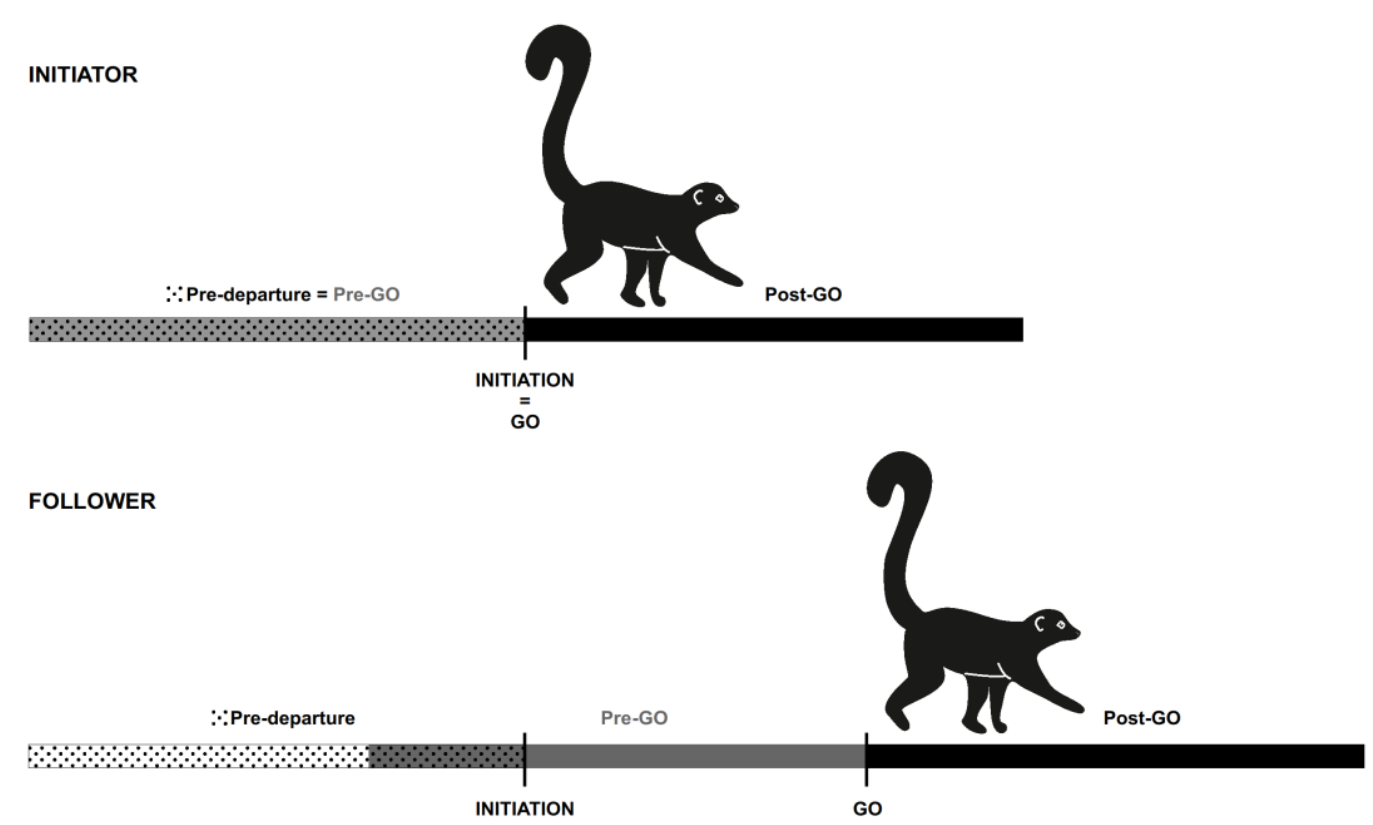

Figure 2.1: Schematic depiction of the movement periods for which grunt rates were recorded. Initiator recordings (top): $150 \mathrm{~s}$ before and after starting to move, follower recordings (bottom): 150 s before and after starting to move and 150s before initiation. In followers, the pre-departure and the pre-go period can overlap; in initiators, they are identical.

Based on the data from group movement observations, we considered vocalisations in four periods of interest: the pre-departure period (time before initiation), the pre- and post-go periods (time before and after an animal starts moving, Fig. 2.1) and a control period outside of the group movement context, that is, while foraging. A pilot study had revealed that grunt rates started to increase approximately $150 \mathrm{~s}$ before initiation. We thus considered this to be the relevant time window for the pre-departure period and, for comparability, used the same length for the pre-go and post-go period as well as for the control. We counted grunts for each $10 \mathrm{~s}$ interval to examine the dynamics of the grunt rate and calculated the average grunt rate per period. Time intervals with high levels of background noise or with the focal animal out of sight were excluded 
from the analyses. Only observations with at least eight usable intervals per period were included in the subsequent analyses (pre-departure follower: $n=50$, pre-go follower: $n=54$, post-go follower: $n=50$, pre-go initiator: $n=21$, post-go initiator: $n=19$, control: $n=22$; in total 33 periods were excluded).

Identifying the pre-departure period in recordings of followers was not directly possible because a potential initiation could only be identified when an individual had moved at least $7 \mathrm{~m}$ away from the group, meaning that the exact departure time of the initiator could not be recorded. We therefore inferred from recordings of initiators the median of the time between the initiator's departure and initiation identification ( $26 \mathrm{~s}, \mathrm{IQR}=18.6, \mathrm{n}=26)$ and used this value to estimate the potential departure time of the initiator in all follower recordings.

\section{Statistical analyses}

All analyses were conducted in $\mathrm{R}$ version 3.0.2. Models were chosen according to lowest Akaike information criterion (AIC) (Akaike, 1973) and tested against null models with a chi-square-test. The significance level was set at 0.05 .

To test for differences in grunt rates between initiators, followers and the different periods, our general procedure was the following: first, we fit linear mixed effects models (LMM using package ImerTest (Bates, Mächler, Bolker, \& Walker, 2015; Kuznetsova, Bruun Brockhoff, \& Haubo Bojesen Christensen, 2015), excluding the intercept to allow for an easier comparison of the effects (Bretz, Hothorn, \& Westfall, 2010; Hothorn, 2016). Then we used multiple comparisons (package multcomp (Hothorn, Bretz, \& Westfall, 2008)) to test for differences between the effects of the periods, initiators and followers. As an initiator's pre-departure and pre-go periods are inevitably identical and they could overlap in followers as well, we constructed two separate models for our tests, to avoid entering overlapping data twice in different contexts.

\section{Pre-departure period}

Our first aim was to test whether the grunt rate in the pre-departure period was higher than in a non-movement context, and whether there was a difference between initiators and followers. If movement decisions are shared, not only the initiators' but also the followers' grunt rates should be higher in the pre-departure period. We, therefore, fit a model with grunt rate as the response (square-root- transformed to improve model fit), and roles as well as periods as levels of one fixed factor (initiator pre-departure, follower pre-departure, foraging control). Individual identity was included as a random factor. Multiple comparisons were used to test the effect of an initiator in the pre-departure period against that of a follower in the pre-departure period and both against the foraging control. 


\section{Pre- and post-go periods}

To assess whether the initiators' and followers' grunt rates differed when the animals presumably have an equal motivation to move, we examined them at the point of their respective departures, comparing their pre- and post-go periods. The model was fit with the square-root-transformed grunt rate as the response, regressed on a fixed factor with the following four categories: initiator pre- and post-go and follower pre- and post-go. Individual identity was included as a random factor. Multiple comparisons were used to test for differences between initiator and follower effects in both the pre-and post-go periods.

To examine in more detail differences in grunt rate between followers and initiators at departure, we fit a time window model. We split the 150-s pre-go and post-go periods into three 50-s subperiods and calculated the respective mean grunt rates. Observations were only included when at least four 10-s intervals per subperiod were available (sample sizes for subperiods: initiator pre-go 1, 2, 3: $n=18,20,21$; post-go 1, 2, 3: $n=17,18,18$; follower pre-go 1, 2, 3: $n=52,53$, 53; and follower post-go 1, 2, 3: $n=46,45,47$ ). We fit a LMM with grunt rate (square-root-transformed) as the response and context (control, subperiods of follower and initiator) as a fixed effect, including individual identity and movement event as random factors. Using multiple comparisons, we compared initiator and follower grunt rates within a subperiod with each other and with the foraging control.

\section{Sex effect}

As by chance all recorded initiators were female, a difference in grunt rate between initiators and followers as well as the foraging control could be due to a sex difference in calling behaviour. To control for this sex effect, we fit a LMM using the control and the recordings of followers with the square-root-transformed grunt rate as the response, sex as a fixed effect and period (control, predeparture period, pre- and post-go periods) and individual ID as random effects. 


\section{RESULTS}

\section{Pre-departure period}

We found significant differences in grunt rates between the pre-departure period and the foraging control, as well as between initiators and followers (Fig. 2.2 and Table 2.1). Both initiators and followers grunted significantly more often during the pre-departure period than during the foraging control. Initiators grunted significantly more often than followers during the pre-departure period.

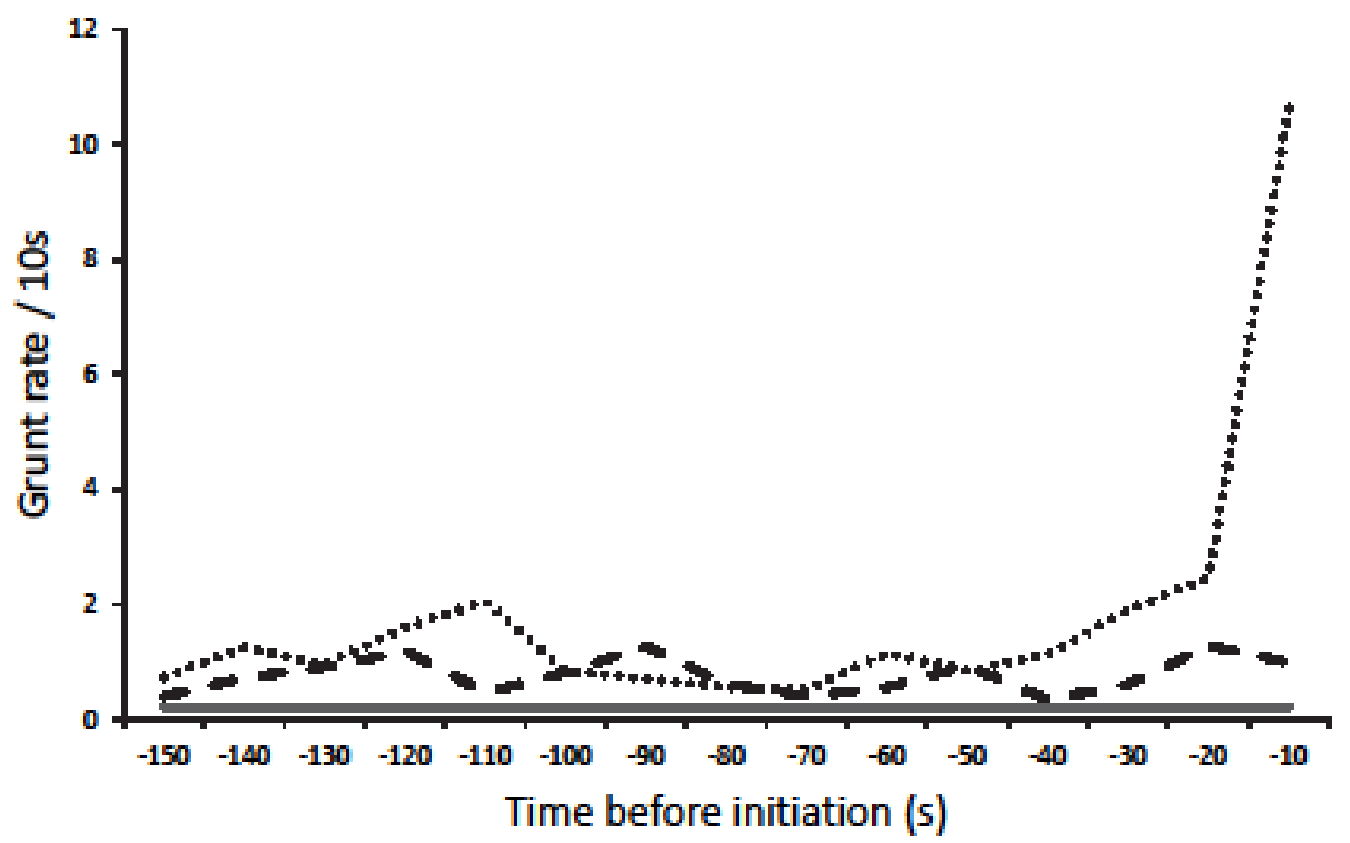

..... Initiators $(n=18) \quad$ - Followers $(n=47)=$ Control $(n=22)$

Figure 2.2: Grunt rates of initiators and followers in the pre-departure period and in the foraging control. For the pre-departure period, the mean grunt rate is given per 10-s interval (sample size varies between intervals; stated is the minimum sample size). For the control, the overall mean grunt rate is shown.

\section{Pre- and post-go periods}

Initiators grunted more often than followers at the time when each individual started moving, both during the pre-go and during the post-go period (Fig. 2.3 and Table 2.1). 


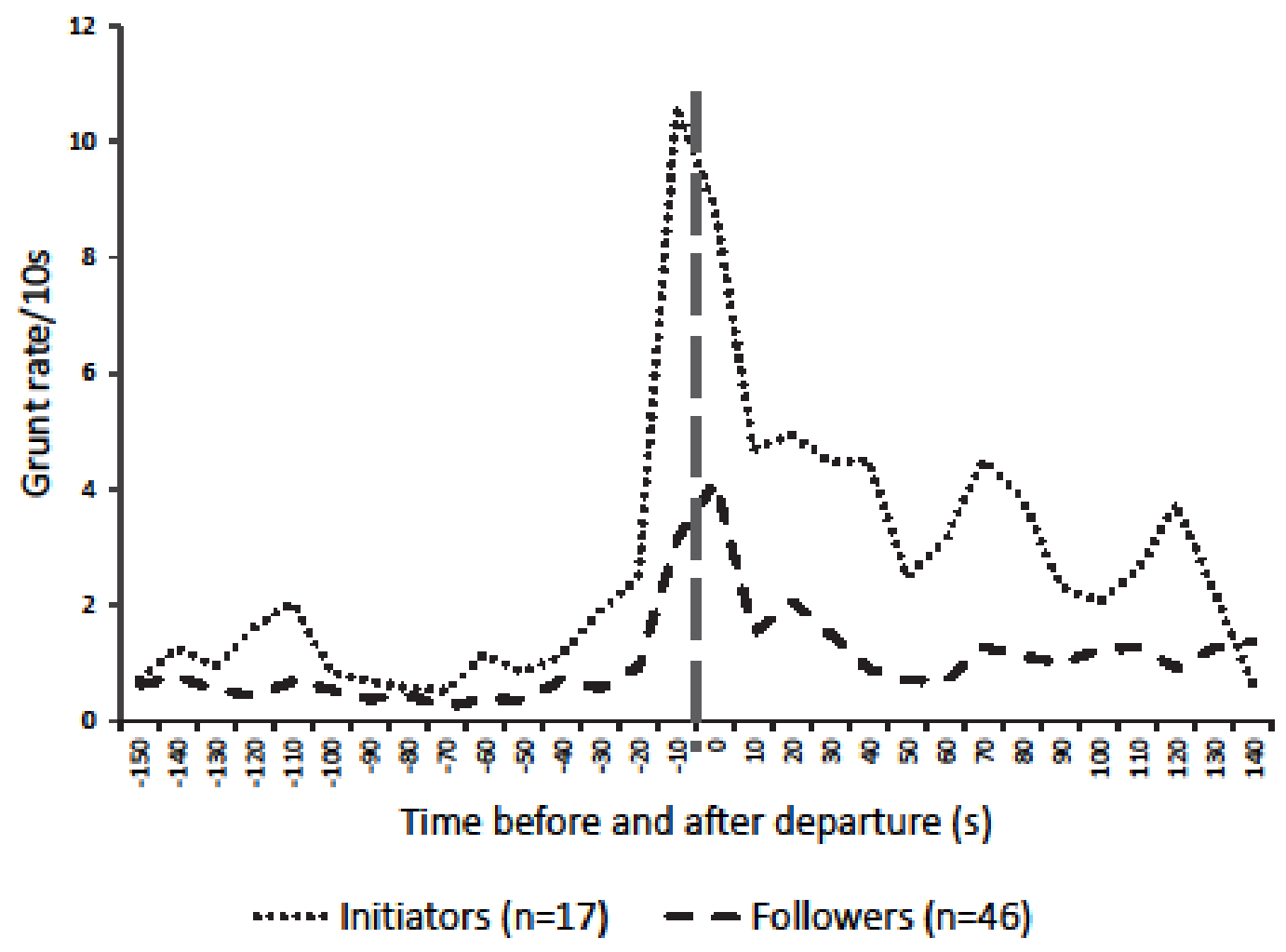

Figure 2.3 Grunt rates of initiators and followers before and after starting to move (pre-and post-go periods). Dashed grey line indicates the time of departure. Sample size varies between 10 -s intervals; stated is the minimum sample size.

Initiators increased their grunt rate above foraging level before starting to move and kept it at an elevated level for the whole post-go period, whereas followers exceeded the foraging grunt rate only in the subperiod directly after they started moving. Initiators grunted significantly more often than followers in the subperiod directly before departure and in the first two post-go subperiods (Fig. 2.4 and Table 2.2).

Table 2.1: Results from multiple comparisons of the effects from the pre-departure model and the pre-go/post-go model, showing the influence of different contexts on the grunt rate of redfronted lemurs.

\section{Pre-departure period}

follower - control

Estimate $\mathrm{Cl}$ lower $\mathrm{Cl}$ upper Std. Error $\mathrm{z}$ value $\operatorname{Pr}(>|z|)$

initiator - control

0.32

0.02

0.62

0.13

2.51

0.03

initiator-follower

0.96

0.60

1.31

0.15

6.25

$<0.001$

0.64

0.33

0.94

0.13

4.80

$<0.001$

Test against null model: $\chi^{2}=34.00, \mathrm{df}=2, \mathrm{p}<0.001$

Pre-go \& post-go period

initiator - follower pre-go

0.73

0.42

1.05

0.14

$5.19<0.001$

initiator - follower post-go

0.58

0.28

0.88

0.13

$4.29<0.001$

Test against null model: $\chi^{2}=53.83, \mathrm{df}=3, \mathrm{p}<0.001$ 


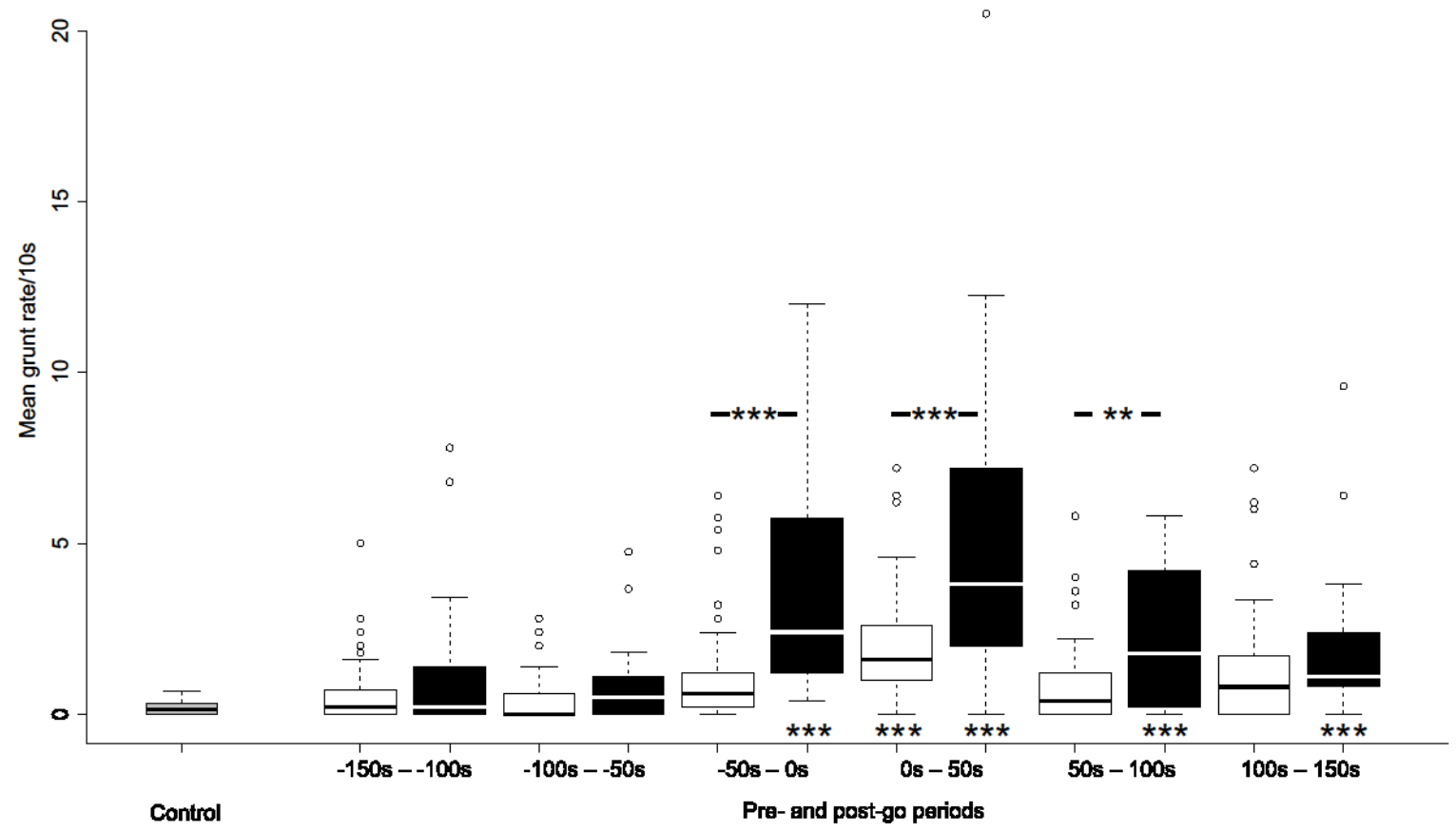

Figure 2.4: Grunt rates of red-fronted lemurs in the foraging control (light grey, left side) and in the six pre-go and post-go subperiods (right side) of followers (white) and initiators (black). Asterisks at the bottom indicate a significant difference to the foraging control; asterisks at the top indicate a significant difference between initiators and followers in the respective subperiod. $* * *$ $=p<0.001, * *=p<0.01$

Table 2.2: Results from multiple comparisons of the effects from the time window model, splitting the pre- and post-go periods into six sub-periods. The model estimates the influence of different contexts on the grunt rate of red-fronted lemurs.

$\begin{array}{lllllll}\begin{array}{l}\text { Test } \\ \text { Initiator-control }\end{array} & \text { Estimate } & \text { Cl lower } & \text { Cl upper } & \text { Std. Error } & z \text { value } & \operatorname{Pr}(>|z|) \\ \text {-150s--100s } & 0.46 & -0.17 & 1.09 & 0.22 & 2.10 & 0.33 \\ \text {-100s--50s } & 0.36 & -0.25 & 0.98 & 0.21 & 1.71 & 0.61 \\ \text {-50s-0s } & 1.34 & 0.74 & 1.95 & 0.21 & 6.40 & <0.001 \\ \text { 0s-50s } & 1.76 & 1.11 & 2.40 & 0.22 & 7.94 & <0.001 \\ \text { 50s-100s } & 1.07 & 0.44 & 1.70 & 0.22 & 4.92 & <0.001 \\ \text { 100s-150s } & 0.89 & 0.26 & 1.52 & 0.22 & 4.09 & <0.001 \\ \text { Follower- control } & & & & & & \\ \text {-150s--100s } & 0.13 & -0.37 & 0.64 & 0.17 & 0.76 & 1.00 \\ \text {-100s--50s } & 0.05 & -0.45 & 0.56 & 0.17 & 0.30 & 1.00 \\ \text {-50s-0s } & 0.49 & -0.02 & 0.99 & 0.17 & 2.80 & 0.06 \\ \text { 0s-50s } & 0.92 & 0.41 & 1.44 & 0.18 & 5.19 & <0.001 \\ \text { 50s-100s } & 0.34 & -0.17 & 0.86 & 0.18 & 1.91 & 0.45 \\ \text { 100s-150s } & 0.49 & -0.02 & 1.00 & 0.18 & 2.75 & 0.07 . \\ \text { Initiator-follower } & & & & & & \\ \text {-150s--100s } & 0.33 & -0.21 & 0.87 & 0.19 & 1.74 & 0.58 \\ \text {-100s--50s } & 0.31 & -0.21 & 0.83 & 0.18 & 1.72 & 0.59 \\ \text {-50s-0s } & 0.85 & 0.34 & 1.37 & 0.18 & 4.82 & <0.001 \\ \text { 0s-50s } & 0.83 & 0.27 & 1.40 & 0.19 & 4.29 & <0.001 \\ \text { 50s-100s } & 0.73 & 0.18 & 1.28 & 0.19 & 3.83 & 0.0019 \\ \text { 100s-150s } & 0.40 & -0.14 & 0.95 & 0.19 & 2.13 & 0.31\end{array}$

Test against null model: Chi $^{2}$-test, $\chi^{2}=146, \mathrm{df}=12, \mathrm{p}<0.001$ 


\section{Sex effect}

We found a significant effect of sex on grunt rates (estimate: 0.36 , SE: 0.14 , df: $17.63, t=2.53, p=$ .02 , model better than the null model: $\chi^{2}=5.79, \mathrm{df}=1, p=.02$ ), with males grunting more often than females in the control and the following context (Fig. 2.5).

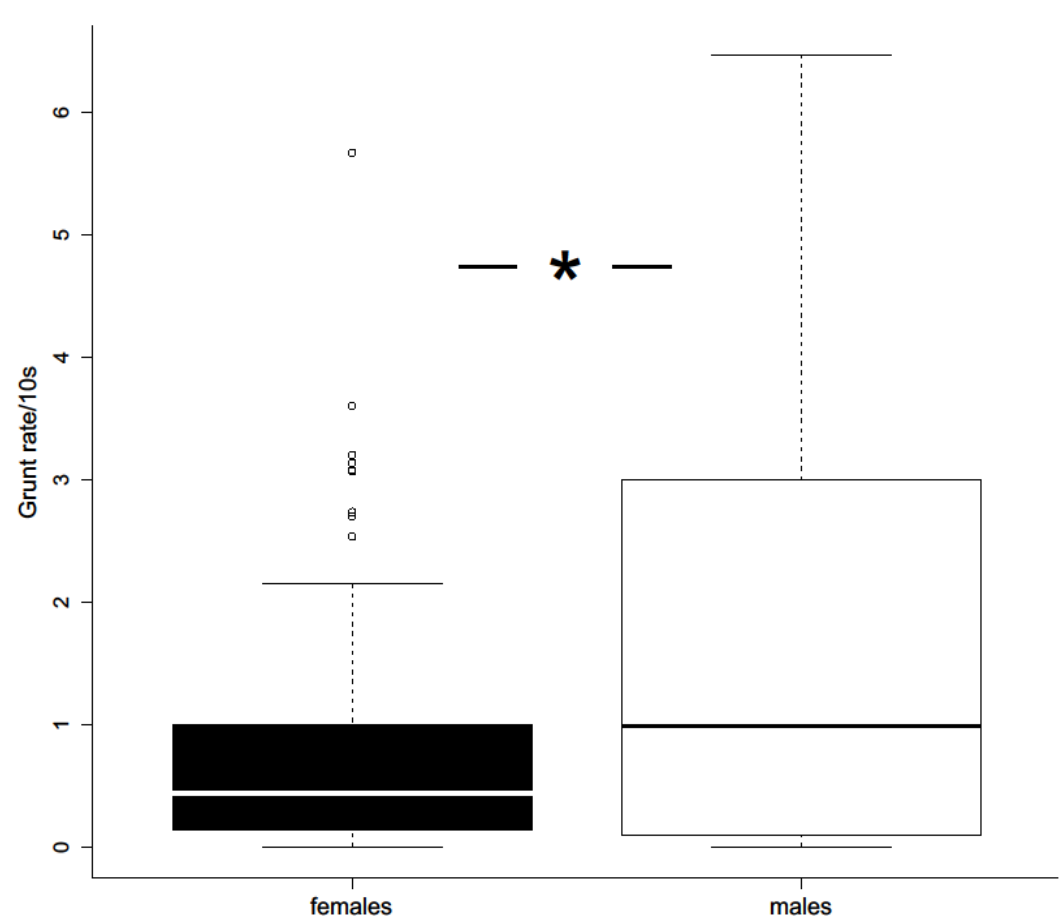

Figure 2.5: Grunt rates of male and female red-fronted lemurs in the foraging and following contexts. Males (white) grunted significantly more than females (black). ${ }^{*}=p<0.05$ 


\section{DISCUSSION}

We examined the use of vocalisations in the coordination of collective movements in red-fronted lemurs. To this end, we investigated the potential role of close calls, that is, grunts, as a notifying behaviour and as a recruitment tool. Call rates of initiators as well as followers increased in the pre-departure period and persisted at peak levels during departure. Furthermore, initiators had higher grunt rates than followers in the pre-departure period as well as in the pre-and post-go periods. Thus, grunts may play an important role in the coordination of group movements in redfronted lemurs by indicating the caller's readiness to move and by recruiting others to join.

\section{Coordination of departure time}

Both initiators and followers grunted more often in the pre-departure period than in the foraging control. Thus, red-fronted lemurs' grunts can be classified as notifying behaviours (Black, 1988; Evans, 1982; Ramseyer et al., 2009, 2009; Sueur \& Petit, 2010). As not only the initiator's, but also the followers' grunt rates increased before initiation, decisions on departure time in red-fronted lemurs might be shared. The presence of a pre-departure period is an important hint for shared decision-making (Bourjade \& Sueur, 2010). Furthermore, shared movement decisions are common in species which resemble red-fronted lemurs in their variable leadership (Pyritz, Kappeler, et al., 2011; Ramseyer et al., 2009, 2009; Seltmann et al., 2013; Sueur \& Petit, 2008b) and their egalitarian social style (Petit \& Bon, 2010). We could record only one individual at a time, but we observed a general increase in grunt rates throughout the group before initiations, so that it was often possible for a human observer to predict an impending group movement. However, we could not determine whether decision-making was based on a quorum.

\section{Recruitment function}

Grunt rates in the pre-departure period were higher for initiators than for followers, which is akin to other species in which notifying behaviours in the pre-departure period affect recruitment success (Black, 1988; Ramseyer et al., 2009, 2009). Still, the difference between initiator and followers in the pre-departure period could be caused by a difference in the motivation to move, as the initiator is closer to leaving. In red-fronted lemurs, however, the grunt rates of initiators and followers differed even when considering them at their respective departures, that is, situations in which they should in principle experience the same motivation to move. Initiators showing higher rates of notifying behaviours at departure have been linked to a recruitment function in primates and birds (Evans, 1982; Sueur \& Petit, 2010). Hence, the observed difference may indicate a recruitment function of grunts in red-fronted lemurs. However, whether receivers use other group 
members' grunts to make a decision on joining the movement has to be examined in more detail with specific playback experiments (e.g., Gall \& Manser, 2017).

\section{Sex effect on grunt rates}

As by chance all recorded movement initiations were carried out by females, the observed difference in grunt rate between initiators and followers as well as the foraging control might be due to a sex difference. However, during non-initiator conditions males grunted more often than females. Thus, the higher grunt rate of initiators is not solely a consequence of their sex. The sex difference in grunt rate is interesting in itself and might be explained by males having less social "power" than females. Even though red-fronted lemurs do not exhibit female dominance as reported for other lemur species (Pereira et al., 1990), females still have greater influence on group activities, for example, by initiating the majority of group movements (Erhart \& Overdorff, 1999; Pyritz, Kappeler, et al., 2011). If male callers have indeed less influence, they may compensate this handicap by producing calls at a higher rate. Similarly, in Canada geese (Branta canadensis) (Raveling, 1969), the duration of the pre-departure period was longer and the rate of notifying behaviours was higher when the adult male of the family, the individual most powerful in directing collective movements, did not participate.

\section{Coordination of group movements across taxa}

To outline the current state of research, we present an overview of studies of collective movements which report on notifying behaviours in the pre-departure period and at departure (Table 2.3). We included only studies which explicitly examined whether the behaviours are used in the coordination of group movements, disregarding repertoires and anecdotal reports. Reviewing these studies revealed that there are eight species reported to use solely visual cues. In six of these species, these cues are inherent to the act of moving away from the group, for example, intention movements and pausing while departing, rather than distinct behaviours like head movements. Of the nine species reported to use only vocal cues, four species use specific movement calls, while five species, including red-fronted lemurs, employ multi-contextual calls. The use of multi-contextual calls for movement coordination thus appears to be equally common as the use of specific calls. In seven species, a combination of visual and acoustic cues has been reported. This strategy may even be more common than represented here, as acoustic cues acting in concert with visual ones might be easily overlooked. In particular, early work on birds concentrated solely on the visually conspicuous head movements while barely mentioning the accompanying vocalisations 
(Black, 1988; Raveling, 1969); especially if the vocalisation is not a specific movement call, but a frequently produced close call, its relevance may be underestimated.

Table 2.3: Overview of quantitative studies of notifying behaviours in the pre-departure period and at departure. Species marked with * appear in more than one category, "I $>F$ " means the initiator shows more notifying behaviours than the followers.

\begin{tabular}{|c|c|c|c|c|c|c|}
\hline $\begin{array}{l}\text { Behav- } \\
\text { iour type }\end{array}$ & Species & Visual cue & $\begin{array}{l}\text { Acoustic } \\
\text { cue }\end{array}$ & Function & References & Comments \\
\hline \multicolumn{7}{|c|}{ Visual only } \\
\hline & \multirow[t]{2}{*}{$\begin{array}{l}\text { Barbary ma- } \\
\text { caques (Macaca } \\
\text { sylvanus) }\end{array}$} & $\begin{array}{l}\text { Intention move- } \\
\text { ments, glancing } \\
\text { back }\end{array}$ & & $\begin{array}{l}\text { Pre-departure } \\
\text { (voting) }\end{array}$ & $\begin{array}{l}\text { Seltmann et al., } \\
2013\end{array}$ & $\begin{array}{l}\text { voting for movement } \\
\text { direction }\end{array}$ \\
\hline & & $\begin{array}{l}\text { Initiator pausing } \\
\text { while departing }\end{array}$ & & Recruitment & $\begin{array}{l}\text { Seltmann et al., } \\
2016\end{array}$ & \\
\hline & $\begin{array}{l}\text { Cattle } \\
\text { (Bos taurus) }\end{array}$ & $\begin{array}{l}\text { Group orientation } \\
\text { and dispersion, vigi- } \\
\text { lance, head move- } \\
\text { ments; initiator } \\
\text { pausing and restart- } \\
\text { ing }\end{array}$ & & $\begin{array}{l}\text { Pre-depar- } \\
\text { ture, recruit- } \\
\text { ment }\end{array}$ & $\begin{array}{l}\text { Ramseyer, } \\
\text { Thierry, et al., } \\
2009\end{array}$ & $\begin{array}{l}\mathrm{I}>\mathrm{F} \text { in the pre-depar- } \\
\text { ture period }\end{array}$ \\
\hline & $\begin{array}{l}\text { Chacma ba- } \\
\text { boons* } \\
\text { (Papio ursinus) }\end{array}$ & Moving away & - & Initiation & $\begin{array}{l}\text { King, Sueur, } \\
\text { Huchard, \& } \\
\text { Cowlishaw, } \\
2011\end{array}$ & $\begin{array}{l}\text { Initiation success not } \\
\text { affected by pre-de- } \\
\text { parture grunts or } \\
\text { backward glances }\end{array}$ \\
\hline & $\begin{array}{l}\text { Domestic sheep } \\
\text { (Ovis aries) }\end{array}$ & $\begin{array}{l}\text { Group orientation, } \\
\text { group vigilance, } \\
\text { head movements, } \\
\text { stillness \& number } \\
\text { of steps }\end{array}$ & & $\begin{array}{l}\text { Pre-depar- } \\
\text { ture, recruit- } \\
\text { ment }\end{array}$ & $\begin{array}{l}\text { Ramseyer, } \\
\text { Boissy, et al., } \\
2009\end{array}$ & $\begin{array}{l}\mathrm{I}>\mathrm{F} \text { in the pre-depar- } \\
\text { ture period }\end{array}$ \\
\hline & $\begin{array}{l}\text { Humbug dam- } \\
\text { selfish (Dascyl- } \\
\text { lus aruanus) }\end{array}$ & $\begin{array}{l}\text { Activity = mean dis- } \\
\text { tance swum per } \\
\text { unit time }\end{array}$ & & $\begin{array}{l}\text { Pre-depar- } \\
\text { ture, initiation } \\
\text { success }\end{array}$ & $\begin{array}{l}\text { Ward et al., } \\
2013\end{array}$ & \\
\hline & $\begin{array}{l}\text { Przewalski hor- } \\
\text { ses } \\
\text { (Equus ferus } \\
\text { przewalskii) }\end{array}$ & $\begin{array}{l}\text { Intention move- } \\
\text { ments, pausing }\end{array}$ & & $\begin{array}{l}\text { Pre-depar- } \\
\text { ture, recruit- } \\
\text { ment }\end{array}$ & $\begin{array}{l}\text { Bourjade, } \\
\text { Thierry, } \\
\text { Maumy, \& } \\
\text { Petit, 2009 }\end{array}$ & \\
\hline & \multirow{2}{*}{$\begin{array}{l}\text { Rhesus ma- } \\
\text { caques } \\
\text { (Macaca mu- } \\
\text { latta) }\end{array}$} & $\begin{array}{l}\text { Intention move- } \\
\text { ments, glancing } \\
\text { back }\end{array}$ & & $\begin{array}{l}\text { Pre-depar- } \\
\text { ture, recruit- } \\
\text { ment }\end{array}$ & $\begin{array}{l}\text { Sueur \& Petit, } \\
2008\end{array}$ & \\
\hline & & $\begin{array}{l}\text { Pausing and looking } \\
\text { back while moving } \\
\text { away }\end{array}$ & $\begin{array}{l}- \\
\text { (no loud } \\
\text { calls) }\end{array}$ & Recruitment & $\begin{array}{l}\text { Sueur \& Petit, } \\
2010\end{array}$ & I $>$ F at departure \\
\hline & \multirow[t]{3}{*}{$\begin{array}{l}\text { Tonkean ma- } \\
\text { caques (Macaca } \\
\text { tonkeana) }\end{array}$} & $\begin{array}{l}\text { Intention move- } \\
\text { ments, glancing } \\
\text { back; } \\
\text { Walking away } \\
\text { quickly and pausing } \\
\text { frequently }\end{array}$ & & $\begin{array}{l}\text { Pre-depar- } \\
\text { ture; } \\
\text { Initiating, re- } \\
\text { cruitment }\end{array}$ & $\begin{array}{l}\text { Sueur \& Petit, } \\
2008\end{array}$ & \\
\hline & & $\begin{array}{l}\text { Intention move- } \\
\text { ments, glancing } \\
\text { back }\end{array}$ & & $\begin{array}{l}\text { Pre-departure } \\
\text { (voting) }\end{array}$ & $\begin{array}{l}\text { Sueur et al., } \\
2011\end{array}$ & $\begin{array}{l}\text { voting for movement } \\
\text { direction }\end{array}$ \\
\hline & & $\begin{array}{l}\text { Pausing and looking } \\
\text { back while moving } \\
\text { away }\end{array}$ & & Recruitment & $\begin{array}{l}\text { Sueur \& Petit, } \\
2010\end{array}$ & $\mathrm{I}>\mathrm{F}$ at departure \\
\hline
\end{tabular}


Table 2.3 continued:

\begin{tabular}{|c|c|c|c|c|c|c|}
\hline $\begin{array}{l}\text { Behav- } \\
\text { iour type }\end{array}$ & Species & Visual cue & $\begin{array}{l}\text { Acoustic } \\
\text { cue }\end{array}$ & Function & References & Comments \\
\hline \multicolumn{7}{|c|}{ Vocalisations only } \\
\hline \multicolumn{7}{|l|}{ specific } \\
\hline & $\begin{array}{l}\text { Chacma ba- } \\
\text { boons* } \\
\text { (Papio ursinus) }\end{array}$ & & Loud call & $\begin{array}{l}\text { Pre-depar- } \\
\text { ture, no influ- } \\
\text { ence on initia- } \\
\text { tion success }\end{array}$ & Sueur, 2011 & \\
\hline & $\begin{array}{l}\text { Golden lion } \\
\text { tamarins (Leon- } \\
\text { topithecus rosa- } \\
\text { lia) }\end{array}$ & & Wah-wah & $\begin{array}{l}\text { Initiating, } \\
\text { leading }\end{array}$ & $\begin{array}{l}\text { Boinski et al., } \\
1994\end{array}$ & \\
\hline & $\begin{array}{l}\text { Honey bees* } \\
\text { (Apis mellifera) }\end{array}$ & & $\begin{array}{l}\text { Worker } \\
\text { piping }\end{array}$ & Pre-departure & $\begin{array}{l}\text { Seeley \& Tautz, } \\
\text { 2001; Visscher } \\
\text { \& Seeley, } 2007\end{array}$ & \\
\hline & $\begin{array}{l}\text { Meerkats } \\
\text { (Suricata suri- } \\
\text { catta) }\end{array}$ & & $\begin{array}{l}\text { Moving } \\
\text { call }\end{array}$ & $\begin{array}{l}\text { Pre-departure } \\
\text { (quorum) }\end{array}$ & $\begin{array}{l}\text { Bousquet et al., } \\
2011\end{array}$ & \\
\hline \multicolumn{7}{|c|}{ multi-contextual } \\
\hline & $\begin{array}{l}\text { Black-billed } \\
\text { gulls } \\
\text { (Larus bulleri) } \\
\end{array}$ & & Loud call & $\begin{array}{l}\text { Initiating, Ini- } \\
\text { tiation suc- } \\
\text { cess } \\
\end{array}$ & Evans, 1982 & I > F at departure \\
\hline & $\begin{array}{l}\text { Chacma ba- } \\
\text { boons* } \\
\text { (Papio ursinus) }\end{array}$ & & $\begin{array}{l}\text { Grunt } \\
\text { (close } \\
\text { call) }\end{array}$ & Pre-departure & $\begin{array}{l}\text { Fischer \& } \\
\text { Zinner, 2011; } \\
\text { Rendall, } \\
\text { Seyfarth, } \\
\text { Cheney, \& } \\
\text { Owren, 1999 } \\
\end{array}$ & \\
\hline & $\begin{array}{l}\text { Mountain goril- } \\
\text { las } \\
\text { (Gorilla gorilla } \\
\text { berengei) }\end{array}$ & & $\begin{array}{l}\text { Grunt } \\
\text { (close } \\
\text { call) }\end{array}$ & Pre-departure & $\begin{array}{l}\text { Stewart \& } \\
\text { Harcourt, 1994; } \\
\text { Watts, } 2000\end{array}$ & \\
\hline & $\begin{array}{l}\text { Red-fronted le- } \\
\text { murs } \\
\text { (Eulemur rufi- } \\
\text { frons) }\end{array}$ & & $\begin{array}{l}\text { Grunt } \\
\text { (close } \\
\text { call) }\end{array}$ & $\begin{array}{l}\text { Pre-depar- } \\
\text { ture, initiat- } \\
\text { ing, probably } \\
\text { recruitment }\end{array}$ & This paper & \\
\hline & $\begin{array}{l}\text { Verreaux's sifa- } \\
\text { kas (Pro- } \\
\text { pithecus } \\
\text { verreauxi) }\end{array}$ & & - & - & $\begin{array}{l}\text { Trillmich et al., } \\
2004\end{array}$ & $\begin{array}{l}\text { Variant of grumble } \\
\text { vocalisation specifi- } \\
\text { cally before depar- } \\
\text { ture, but no move- } \\
\text { ment coordination } \\
\text { function }\end{array}$ \\
\hline & $\begin{array}{l}\text { Wood hoopoes } \\
\text { (Phoeniculus } \\
\text { purpureus) }\end{array}$ & & $\begin{array}{l}\text { Cackling } \\
\text { call (loud } \\
\text { call) }\end{array}$ & $\begin{array}{l}\text { Initiating, Ini- } \\
\text { tiation suc- } \\
\text { cess }\end{array}$ & Radford, 2004 & \\
\hline
\end{tabular}


Table 2.3 continued:

\begin{tabular}{|c|c|c|c|c|c|c|}
\hline $\begin{array}{l}\text { Behav- } \\
\text { iour type }\end{array}$ & Species & Visual cue & $\begin{array}{l}\text { Acoustic } \\
\text { cue }\end{array}$ & Function & References & Comments \\
\hline \multicolumn{7}{|c|}{ Combination } \\
\hline \multirow[t]{5}{*}{$\begin{array}{l}\text { With spe- } \\
\text { cific calls }\end{array}$} & $\begin{array}{l}\text { Canada geese } \\
\text { (Branta cana- } \\
\text { densis) }\end{array}$ & Head tossing & $\begin{array}{l}\text { "Low gut- } \\
\text { tural vo- } \\
\text { calisa- } \\
\text { tion" } \\
\text { (close } \\
\text { call) }\end{array}$ & Pre-departure & Raveling, 1969 & $\begin{array}{l}\text { At take-off vocalisa- } \\
\text { tions change to loud } \\
\text { honking }\end{array}$ \\
\hline & $\begin{array}{l}\text { Domestic geese } \\
\text { (Anser domesti- } \\
\text { cus) }\end{array}$ & Wing flaps & $\begin{array}{l}\text { "guttural } \\
\text { vocalisa- } \\
\text { tion" ref- } \\
\text { erencing } \\
\text { Raveling } \\
1969\end{array}$ & $\begin{array}{l}\text { Pre-depar- } \\
\text { ture, initiat- } \\
\text { ing, recruit- } \\
\text { ment }\end{array}$ & $\begin{array}{l}\text { Ramseyer, } \\
\text { Petit, \& Thierry, } \\
2009\end{array}$ & \\
\hline & $\begin{array}{l}\text { Squirrel mon- } \\
\text { keys } \\
\text { (Saimiri oer- } \\
\text { stedi) }\end{array}$ & $\begin{array}{l}\text { Intention move- } \\
\text { ments (sometimes) }\end{array}$ & $\begin{array}{l}\text { Twitter } \\
\text { call }\end{array}$ & $\begin{array}{l}\text { Initiating, } \\
\text { leading }\end{array}$ & $\begin{array}{l}\text { Boinski, 1991, } \\
1996\end{array}$ & \\
\hline & $\begin{array}{l}\text { White-faced } \\
\text { capuchins } \\
\text { (Cebus capuci- } \\
\text { nus) }\end{array}$ & $\begin{array}{l}\text { Moving away } \\
\text { slowly, backward } \\
\text { glances }\end{array}$ & $\begin{array}{l}\text { Trill } \\
\text { (loud call) }\end{array}$ & $\begin{array}{l}\text { Initiating, ini- } \\
\text { tiation suc- } \\
\text { cess, trills also } \\
\text { for leading }\end{array}$ & $\begin{array}{l}\text { Boinski, 1993; } \\
\text { Boinski \& } \\
\text { Campbell, 1995; } \\
\text { Leca et al., 2003 }\end{array}$ & \\
\hline & $\begin{array}{l}\text { Whooper swans } \\
\text { (Cygnus cygnus) } \\
\text { \& Bewick's } \\
\text { swans } \\
\text { (C. columbianus } \\
\text { bewickii) }\end{array}$ & Head bobbing & $\begin{array}{l}\text { "Distinct } \\
\text { four syl- } \\
\text { labic vo- } \\
\text { calisa- } \\
\text { tion" } \\
\text { (probably } \\
\text { loud call) }\end{array}$ & $\begin{array}{l}\text { Pre-depar- } \\
\text { ture, recruit- } \\
\text { ment }\end{array}$ & Black, 1988 & $\begin{array}{l}\text { I>F in the pre-depar- } \\
\text { ture period }\end{array}$ \\
\hline $\begin{array}{l}\text { With un- } \\
\text { specific } \\
\text { calls }\end{array}$ & $\begin{array}{l}\text { African ele- } \\
\text { phants (Lox- } \\
\text { odonta Afri- } \\
\text { cana) }\end{array}$ & $\begin{array}{l}\text { Intention move- } \\
\text { ment, lifting one } \\
\text { leg, flapping ears }\end{array}$ & rumble & $\begin{array}{l}\text { pre-depar- } \\
\text { ture, initiat- } \\
\text { ing?, leading? }\end{array}$ & $\begin{array}{l}\text { O'Connell- } \\
\text { Rodwell et al., } \\
\text { 2012; Poole et } \\
\text { al., } 1988\end{array}$ & $\begin{array}{l}\text { O'Connell-Rodwell et } \\
\text { al. defined a "depar- } \\
\text { ture period" to begin } \\
\text { with the first occur- } \\
\text { rence of the notifying } \\
\text { behaviour and to in- } \\
\text { clude initiation and } \\
\text { the departure of the } \\
\text { whole group. It is } \\
\text { thus not possible to } \\
\text { discern whether the } \\
\text { notifying behaviour is } \\
\text { used throughout the } \\
\text { different stages or } \\
\text { only in parts. }\end{array}$ \\
\hline \multirow{2}{*}{$\begin{array}{l}\text { With } \\
\text { other } \\
\text { acoustic } \\
\text { cues }\end{array}$} & $\begin{array}{l}\text { Bottlenose dol- } \\
\text { phins (Tursiops } \\
\text { truncatus) }\end{array}$ & \multicolumn{2}{|c|}{ Side flops } & Initiating & Lusseau, 2006 & \\
\hline & $\begin{array}{l}\text { Honey bees* } \\
\text { (Apis mellifera) }\end{array}$ & $\begin{array}{l}\text { "Buzz run": run- } \\
\text { ning, bumping into } \\
\text { others, wiggling } \\
\text { movement }\end{array}$ & $\begin{array}{l}\text { Buzzing } \\
\text { the wings }\end{array}$ & Initiating & $\begin{array}{l}\text { Rittschof \& } \\
\text { Seeley, } 2008\end{array}$ & \\
\hline
\end{tabular}

When considering the use of notifying behaviours, it becomes clear that they are mostly specific to either the pre-departure or initiation period. Pre-departure behaviours may simply cease when an individual starts moving (Black, 1988) or be replaced by discrete initiation signals (Raveling, 1969; Rittschof \& Seeley, 2008). However, in red-fronted lemurs, we could show close call rates starting to rise in a pre-departure period, peaking at departure and then declining slowly. Pre-departure notifying behaviours may thus persist throughout initiation and joining, taking on 
the function of initiation signals when combined with the visual cue of moving away from the group. This persistence of notifying behaviours might also be found in two Old World primate species, gorillas (Stewart \& Harcourt, 1994) and Chacma baboons (Fischer \& Zinner, 2011), which, like red-fronted lemurs, show elevated rates of close calls in the pre-departure period. However, the studies on these species did not report the call rates at and after departure and, therefore, could not demonstrate a potential initiation function. Thus, further studies are needed to determine whether the combined function as pre-departure and initiation calls is more common than currently considered and whether it appears as a convergence in taxa which have evolved group living independently.

\section{Conclusions}

Vocal coordination of collective actions is widespread across species and plays a key role when visual cues are insufficient. Our study provides further support for the notion that vocal coordination does not necessarily require a specific movement call, but that multi-contextual calls can fulfil this function. We show that red-fronted lemurs use close calls to coordinate collective movements. Close call rates indicate movement motivation in a pre-departure period, permitting a shared decision on departure time, and likely play a role in the recruitment of followers. Redfronted lemurs thus converge with other group-living species regarding the behavioural mechanisms underlying the coordination of group movements, indicating that vocalisations are a widely used means of coordinating collective activities.

\section{ACKNOWLEDGMENTS}

We are grateful to the Malagasy Ministère de l'Environnement et des Eaux et Forêts, the Departement de Biologie, Ecologie et Conservation Animale de l'Université d'Antananarivo, and the Centre National de Formation, d'Etudes et de Recherche en Environnement et Foresterie de Morondava for supporting our research in Kirindy Forest. We would also like to thank Sophie Kirberg, Bianca Kögl and Hannah Kleine-Weber for their vital support in data collection and Holger Sennhenn-Reulen for his help with the statistical analysis. Furthermore, we would like to thank Andrew King and two anonymous reviewers for their constructive and helpful comments on this manuscript. 
2 Vocal coordination of group movements 


\section{ChAPTER 3}

\section{Who leads? Characterising initiators of collective movements in wild red-fronted lemurs}

Anna Lucia Sperber, Peter M. Kappeler, Claudia Fichtel

In preparation for submission

Authors' contributions

ALS, PMK \& CF designed the study, ALS collected and analysed the data and drafted the manuscript, CF and PMK participated in writing the manuscript 


\section{ABSTRACT}

Leadership of group movements is rarely restricted to one individual, yet at the same time it is hardly ever equally distributed across group members. How individual traits lead to these differences in leadership likelihood remains to be determined. We therefore investigated collective movements in four wild groups of red-fronted lemurs (Eulemur rufifrons) in Kirindy Forest, Madagascar, relating an individual's sociability, activity, boldness and exploration to its movement initiation frequency. We recorded 167 initiations and conducted focal observation $(9-15 \mathrm{~h}$ per individual) to assess individual sociability and activity. We conducted novel object tests to assess exploration tendencies and obtained two measures for boldness, one with a flight initiation distance test and one during exposed drinking at water holes. All personality measures were acquired in the natural social context. Leadership was variable; almost all adults successfully initiated group movements. However, in three out of four groups individuals differed significantly in their number of initiations. Personality predicted leadership: Exploration had a positive effect on initiation frequency, whereas the effect of sociability was divergent: negative for males and positive for females. This study reports the effect of individual personality on leadership in an egalitarian primate species, thus contributing to our understanding of what characterises leaders of collective movements as well as the general principles of group coordination and decision making.

Key words: collective movements, leadership, personality, primates, Eulemur 


\section{INTRODUCTION}

Staying cohesive as a group is essential for reaping the benefits of group living (Alexander, 1974; Fairbanks \& Dobson, 2007; Hass \& Valenzuela, 2002; Landeau \& Terborgh, 1986; Pulliam, 1973; Silk, 2007; Terborgh, 1983; van Schaik, 1983; Wrangham, 1980). However, coordinating activities is a constant challenge, as group members may have differing needs and time budgets depending on their sex, age and reproductive state (Alonso \& Alonso, 1993; Boinski, 1988; Fragaszy, 1990; Rothman et al., 2008; Sauther, 1994; Scantlebury et al., 2002). This challenge becomes apparent in movements between resources. In this context, the costs of compromising and foregoing your own optimal action, the "consensus costs" (Conradt \& Roper, 2005), are commonly minimised by groups having variable leadership. This means that different individuals lead on different occasions, as opposed to consistent leadership with one exclusive leader. Still, leadership is rarely equally distributed; in most species, certain individuals lead group movements more often than others (Conradt \& Roper, 2003, 2005). What characterises these frequent leaders?

To answer this question, one must consider the consequences that initiating a movement has for the initiator. An obvious benefit of leading is the ability to impose one's own interests on the rest of the group, thus being able to fulfil one's needs while remaining safely within the group (Conradt \& Roper, 2009). Furthermore, the position in the van of the group can be favourable for foraging success, since it grants first access to resources, resulting in the "finder's advantage" of finding more and higher quality food than the followers (DeBlois \& Rose, 1996; Di Bitetti \& Janson, 2001; Fischhoff et al., 2007; Krause, 1993; Krause, Reeves, et al., 1998; Vickery et al., 1991). However, initiating also has disadvantages, as animals in the van suffer from increased predation risk by ambush predators (Bumann et al., 1997; Krause, Ruxton, et al., 1998). Thus, individuals have to trade off the costs and benefits of taking the lead.

In animal research, leadership was originally considered a by-product of a high dominance rank (Alexander, 1974). However, modelling approaches (Conradt et al., 2009; Couzin, Krause, Franks, \& Levin, 2005; King, Johnson, \& Van Vugt, 2009) and empirical studies have identified several other factors promoting leadership. We provide an overview of studies on the characterising traits of leaders of group movements in Table 3.1 (see at the end of the chapter). Apart from dominance rank, leadership can also be affected by age, sex, task-relevant knowledge or knowledge of the habitat, individual physiological needs, personality and social integration. Hungry individuals or individuals with generally higher physiological needs, such as lactating females, have been observed to lead group movements more often (Fischhoff et al., 2007; Furrer et al., 2012; Krause, 1993; Nakayama et al., 2012; Öst \& Jaatinen, 2013). Adult individuals lead more 
often than subadults and in many species members of the philopatric sex lead group movements more often, presumably because they are more familiar with the habitat (Erhart \& Overdorff, 1999; Leca et al., 2003; Pyritz, Kappeler, et al., 2011; Van Belle et al., 2013). In general, knowledge can facilitate leadership because all group members profit from an individual with superior knowledge leading them to resources on the shortest or safest path (Conradt \& Roper, 2003; Foley, Pettorelli, \& Foley, 2008; Lewis, Wartzok, \& Heithaus, 2013). In line with this notion, experiments have demonstrated that trained individuals can lead naïve group mates to food resources in fish (Köhler, 1976; Reebs, 2000), sheep (Ovis aries) (Pillot et al., 2010) and meerkats (Suricata suricatta) (Bousquet \& Manser, 2011). Furthermore, bottlenose dolphins (Tursiops truncatus) show consistent leadership of better-informed individuals (Lewis et al., 2013; Lusseau \& Conradt, 2009).

In addition, leadership can be associated with certain personality traits. The concept of animal personality refers to consistent individual differences in behavioural styles, which have been found to be widespread, fitness-relevant and linked to many aspects of ecology and behaviour (Bergmüller \& Taborsky, 2010; Réale et al., 2007; Sih et al., 2004; Wolf \& Krause, 2014; Wolf \& Weissing, 2012). Personality traits found in many species are boldness, exploration, activity, aggressiveness and sociability (Réale et al., 2007). We follow Réale et al. (2007) in our definitions of these traits. Thus, we define boldness as an individual's response to a risky situation, excluding reactions to novel situations and stimuli (Carter, Marshall, Heinsohn, \& Cowlishaw, 2012). The reaction to novelty is expressed in the trait exploration, whereas activity is the general activity in a familiar, non-risky context. Aggressiveness describes agonistic behaviour towards conspecifics and sociability describes socio-positive behaviour, in that sociable individuals seek contact to conspecifics.

The emerging picture is that proactive behavioural styles with high trait values in activity, exploration and boldness (Koolhaas et al., 1999; Sih \& Bell, 2008) are associated with leadership in fish, birds and mammals (Table 3.1). While boldness has received most attention (Briard et al., 2015; Harcourt et al., 2009; Leblond \& Reebs, 2006; Nakayama et al., 2012; Öst \& Jaatinen, 2013; Ward et al., 2004), the influence of exploration and activity on leadership remains less studied (Beauchamp, 2000; Kurvers et al., 2009; Ramseyer et al., 2009; Schuett \& Dall, 2009). Moreover, the effect of personality on leadership propensity has been studied mostly in captivity and often only within pairs of individuals. The latter is a critical shortcoming, as it has been shown in barnacle geese (Branta leucopsis) that the effect of personality on initiation likelihood can depend on group size (Kurvers, Adamczyk, van Wieren, \& Prins, 2011). The three studies on the effect of boldness on leadership in the wild used diverse measures and reveal no consistent picture, since boldness 
predicted leadership in feral horses (Equus caballus) but not in eider ducks (Somateria mollissima) nor in bighorn sheep (Ovis canadensis) (Berger, 1977; Öst \& Jaatinen, 2013; Réale \& FestaBianchet, 2003). Therefore, how these different personality traits affect the likelihood to lead merits additional investigation in larger, natural groups.

Sociability is also key in determining who initiates group movements (Byrne, Whiten, \& Henzi, 1990; King, Sueur, et al., 2011; Lusseau \& Conradt, 2009; Ramseyer, Petit, et al., 2009b; Reinhardt \& Reinhardt, 1981; Tokuyama \& Furuichi, 2017). For example, in black howler monkeys (Alouatta pigra) individuals with a central position in the social network initiate and lead movements more often (Van Belle et al., 2013). An individual with such social power can also decide the success of an initiation from behind, as a "key individual" joining the movement (Bourjade \& Sueur, 2010; Byrne et al., 1990; Sueur \& Petit, 2008b; Sueur, et al., 2009).

The opposite effect, in that less sociable individuals emerge as leaders, has also been theoretically argued (Conradt et al., 2009) and observed in three-spined sticklebacks, domestic sheep, cattle (Bos taurus) and barbary macaques (Arnold, 1977; Della-Rossa et al., 2013; Jolles et al., 2015; Ramseyer et al., 2009; Seltmann et al., 2013). Further studies would therefore seem indicated to determine which conditions promote these apparently opposing effects of social integration. Since affiliative relationships are often confounded with dominance rank (e.g. King, Sueur, et al., 2011) it would be especially valuable to assess the influence of affiliation without the confounding effect of rank.

In summary, although leadership is hardly ever equally distributed within a group, it remains unclear why some individuals take on leading roles in collective actions disproportionally more often than others. To contribute to discerning the traits that characterise leaders, we studied group movements in red-fronted lemurs (Eulemur rufifrons). Red-fronted lemurs are an excellent model species to investigate leader characteristics because they live in small, multi-male multi-female groups with female philopatry and no sexual size dimorphism. They exhibit a rather egalitarian social system with no dominant sex and no clear dominance relationships within the sexes (Pereira et al., 1990). Hence, leadership cannot be considered a by-product of high rank but rather ought to result from other individual traits. Since group living in lemurs stems from convergent evolution with other primates (Kappeler, 1999), studying lemurs also offers a valuable comparative perspective on group coordination processes in primates.

Earlier studies on collective movements in red-fronted lemurs revealed that they exhibit variable leadership with adult females leading most frequently (Erhart \& Overdorff, 1999; Pyritz, Kappeler, et al., 2011). Still, open questions remain about the characteristics of leaders, since leadership is not equally distributed between individuals of one sex (Erhart \& Overdorff, 1999). We, 
3 Initiators of collective movements

therefore, studied the effect of sociability, activity, boldness and exploration on the individual frequency of initiations of collective movements. 


\section{MATERIAL AND METHODS}

\section{Study site and Subjects}

The study was conducted in Kirindy Forest, a dry, semi-deciduous forest in Western Madagascar. The German Primate Center's 60 ha study site lies within a forestry concession operated by the Centre National de Formation, d'Etudes et de Recherche en Environnement et Foresterie (Kappeler \& Fichtel, 2012a). We studied four groups of red-fronted lemurs, with a total of 31 individuals (11 females, 10 males, 10 juveniles) and group sizes ranging between 6-11 individuals. As part of a long-term study group (Kappeler \& Fichtel, 2012b) the animals are individually marked with collars and pendants and are well habituated to observers. Furthermore, they have been trained to approach an experimenter in response to an auditory signal to participate in experiments (Huebner \& Fichtel, 2015; Schnoell \& Fichtel, 2012). This unique training allows studying individual behavioural traits systematically in a natural setting, which is exceptional for wild primates.

\section{Data collection}

Data were collected from April to September 2014. Observations were conducted mainly between 8:00 - 11:00 and 14:00 - 17:00 h, since groups usually rest during midday (Kappeler \& Erkert, 2003). We observed one focal group per half-day, and morning and afternoon observation sessions were balanced among groups. Observations were recorded using a handheld computer (Psion Workabout Pro 3).

\section{Movement initiations}

Initiations were recorded with all-occurrences sampling, following the definitions of Pyritz et al. (2011). Thus, an initiator was defined as an individual who after being "stationary for $\geq 4 \mathrm{~min}$ moved $\geq 15 \mathrm{~m}$ away from [the other] group members in a directed manner without pausing" (Pyritz, Kappeler, et al., 2011, p. 1332). An initiation attempt was considered successful if at least one follower (apart from dependent offspring) was recruited. A follower was defined as an individual who left $\leq 10 \mathrm{~min}$ after the initiator and whose "movement diverged $\leq 45^{\circ}$ from the trajectory of the movement of the initiator" (Pyritz, Kappeler, et al., 2011, p. 1332). We disregarded group movements caused by predator attacks or intergroup conflicts. We treated all group movements as independent events for statistical analyses ( $n=167$ successful group movements, group $A: n=49$, group $B: n=37$, group $F: n=35$, group $J: n=46$ ). Failed initiations, in which no followers 
were recruited and the initiator returned to the group within $10 \mathrm{~min}$, were excluded from the analysis as they were extremely rare $(n=2)$. Our procedures and definitions correspond to those used by Sperber, Kappeler \& Fichtel (2019).

\section{Personality from focal observations}

We conducted focal observations for 60 min periods, recording the individual's behaviours and social interactions (group A: 10.47 - $14.53 \mathrm{~h}$ per individual, group B: $9.12-13.33 \mathrm{~h}$ per individual, group F: $11.06-15.13 \mathrm{~h}$ per individual, group J: $8.92-13.13 \mathrm{~h}$ per individual). All recorded behaviours are listed in Table S3.1 in the Supplementary Material. For the analyses, values for each behaviour were calculated as the amount of time the individual performed the behaviour (in minutes) per time the individual was observed (in hours).

\section{Affiliation}

Affiliation was measured through grooming and huddling interactions. Grooming was defined as one individual being groomed by or grooming another individual (repeated strokes over the partner's pelage with the toothcomb and/or tongue) or both individuals grooming each other simultaneously. Huddling was defined as two or more individuals being in contact with their torsos or head to torso in a resting context. As an index of an individual's affiliative behaviour we calculated a composite sociability index (CSI, Eq. 1) following Silk, Cheney, \& Seyfarth (2013) and Sapolsky, Alberts, \& Altmann (1997).

$C S I_{x}=\frac{\left(\frac{\text { grooming }_{x}}{\text { groominggroup mean }}+\frac{\text { huddling }_{x}}{\text { huddling group mean }}\right)}{2}$

Activity

As a measure of activity, we took the sum of the values for walking (locomotion on the ground) and climbing (locomotion in the trees).

\section{Personality from opportunistic observations}

Drinking events - Behaviour in a natural, risky context

During the dry season, the Kirindy river falls dry, leaving only a few areas holding water that are visited regularly by the red-fronted lemur groups. In the dry river bed, the animals are exposed out in the open, increasing their risk to be attacked by terrestrial or aerial predators. The behaviour in this situation thus reflects an individual's risk-taking behaviour. Drinking is a group activity, in that no individual was ever observed drinking outside a group drinking event. Drinking events 
were recorded opportunistically using a handheld video camera. Five events per group were selected (no outside disturbance, completeness of record) and analysed using BORIS (Friard \& Gamba, 2016). We used three measures that we believe represent an individual's risk-taking behaviour. First was the order in which the animals left the forest and were exposed in the river bed. Second was the time spent drinking as a proportion of the total time spent exposed in the river bed. Third was the number of vigilance events while drinking, i.e. how often did an individual stop drinking to lift its head and look around. All measures were standardised by dividing the individual values by the group mean for the event.

\section{Personality from experiments}

\section{Testing personality in the wild}

Contrary to most other studies, we assessed personality traits in a natural group context instead of in isolation. This may be seen as a disadvantage, since the confounding factors presented by other group members cannot be controlled. However, previous research has not only shown that behaviour may generally differ between social and asocial contexts (Webster \& Ward, 2011), as for example in three-spine sticklebacks (Gasterosteus aculeatus) that became bolder and more active in groups (Webster, Ward, \& Hart, 2007). Pertinently, it has also shown that individual differences in behaviour may change as well. For example, the readiness of ravens (Corvus corax) to approach a novel object when alone did not correspond to their approach behaviour when tested in a group (Stöwe, Bugnyar, Heinrich, \& Kotrschal, 2006). Furthermore, individuals may be affected differently by the presence of others. Great tits (Parus major) with low scores for exploration became bolder in reaction to a startle test when in the presence of a conspecific, while for fast explorers the effect depended on sex (van Oers, Klunder, \& Drent, 2005). Since the behaviour and personality in the social context is the one that is naturally expressed, it is most relevant for the study of group coordination and for understanding the evolutionary processes behind it.

\section{Novel object test-Reaction to novelty}

To measure individual differences in the reaction to novelty (exploration) we used a novel object test in which we confronted the animals with novelty in a familiar feeding context. This is an established paradigm for measuring exploration (Bergman \& Kitchen, 2009; Carter, Marshall, et

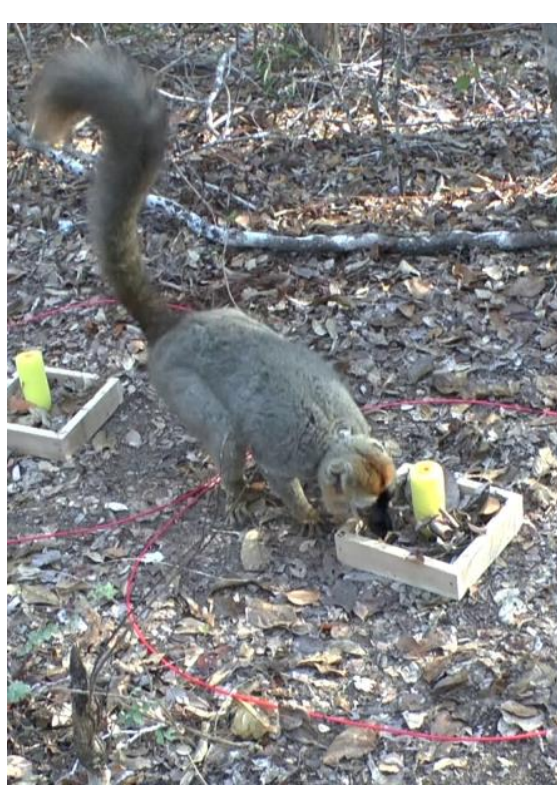

Figure. 3.1: Novel object test. 
al., 2012; Dammhahn, 2012; Dammhahn \& Almeling, 2012; Joubert \& Vauclair, 1986; Verdolin \& Harper, 2013). Unfamiliar items trial 1: a plastic egg, trial 2: a small paint roller) were placed in familiar food bowls at the centre of an area demarcated by a plastic ring (Fig. 3.1). The ring had a diameter of $60 \mathrm{~cm}$ and functioned as a reference for distance to the novel object. To avoid monopolisation of clumped food resources we provided one food bowl/object combination per group member. The experiment was set up near to, but out of sight of the group. The animals were then attracted to the setup using a familiar auditory signal (Schnoell \& Fichtel, 2012). Trials were recorded on video and analysed using Solomon Coder (Péter, 2017).

Exploration was measured as the sum of two kinds of interaction with the object, manipulating and sniffing. When an individual touched an object with its front paws, this action was counted as manipulating. This definition included pushing the object out of the way while eating. Sniffing was defined as the animal's nose remaining still near the object (head within the radius of the feeding bowl) for at least one second. Both measures were calculated as the proportion of the time spent in the demarcated area. The exploration measure was standardised by dividing the individual value by the group mean for the trial.

\section{Flight initiation distance - Reaction to approach}

Flight initiation distance (FID), the distance at which an approaching human elicits an escape response, provides an estimate of an individual's risk-taking behaviour when facing a potential threat. Human disturbance likely produces a response similar to that of an approaching predator (Frid \& Dill, 2002). FID has been shown to be repeatable in birds and reptiles, and it is commonly used as a measure of boldness (Boogert, Monceau, \& Lefebvre, 2010; Carrete \& Tella, 2010; Carter, Goldizen, \& Heinsohn, 2012; Carter, Goldizen, \& Tromp, 2010; Evans, Boudreau, \& Hyman, 2010; Seltmann et al., 2012).

We only tested an individual when certain prerequisites were fulfilled. To ensure that no other animal than the test subject was exposed to the experiment, we only tested individuals when there was no other animal present within a $5 \mathrm{~m}$ radius. Furthermore, to ensure that eye contact with the animal could be maintained without the experimenter tripping, we only tested individuals sitting within $1 \mathrm{~m}$ of a footpath and not higher than the experimenter's eye level (approximately $1.5 \mathrm{~m})$.

Since starting distance can influence FID (Blumstein, 2003), the experimenter always started from a $5 \mathrm{~m}$ distance. Individuals were approached in a straight line while maintaining direct eye contact. As approach speed can influence FID (Cooper, 2003), it was kept constant using a fabric sling restricting step length to $50 \mathrm{~cm}$ and an auditory cue given via headphones regulating step rate to 
one step per second. For visual consistency, the experimenter wore a pink, full-length apron the animals were not previously familiar with. Following the animal's departure, FID was measured from the midpoint between the experimenter's feet to the animal's former resting spot using a measuring tape. FIDs were standardised by dividing individual values by the group mean for the trial. Test were conducted over an eight-week period. Each individual was tested 1-5 times, with a minimum of $48 \mathrm{~h}$ between trials.

\section{Statistical analyses}

Analyses were conducted in R version 3.0.2 (R Core Team, 2014) and models were fit using the package ImerTest (Bates, Maechler, Bolker, \& Walker, 2015; Kuznetsova et al., 2015). Models were chosen in accordance with the Akaike information criterion (AIC) (Akaike, 1973) (see Supplementary Material Table S3.2) and tested against null models using a Chi ${ }^{2}$-test. The significance level was set at 0.05 .

\section{Repeatability of personality traits}

To be used as a measure for personality traits, the obtained measures have to be repeatable. We calculated the adjusted repeatability $r$ following Nakagawa \& Schielzeth (2010), controlling for trial and group in the experiments and only for group in the drinking measures. We considered a measure repeatable when $r \geq 0.35$ (Bell, Hankison, \& Laskowski, 2009). For FID, there was a steep decrease in the sample size after the third trial. Therefore, only the first three trials were used for determining repeatability.

\section{Effect of age class on initiation frequency}

To test for differences in initiation frequency between age classes, we fitted a generalised linear mixed model (GLMM) for a binomial distribution. We treated the individuals' number of initiations as successes and the difference to the total number of initiations in each group as failures. We fitted age-sex class (levels subadult, adult female, adult male) as a fixed factor and group as random factor.

\section{Differences in initiation frequency}

To test whether individual differences in leadership persist in our population, we tested for an equal distribution of initiations within a group using a $\mathrm{Chi}^{2}$-test. 


\section{Individual traits determining initiation frequency}

To test the effects of individual traits on initiation frequency we fitted a generalised linear mixed model (GLMM) for a binomial distribution. We treated the individuals' number of initiations as successes and the difference to the total number of initiations in each group as failures. We fitted group as a random factor and sex, CSI and the interaction of sex and CSI as fixed factors. Sample size for this analysis was 21 individuals.

Since not all animals participated in the novel object experiment, data for exploration time was not available for all individuals. We, therefore, did not include exploration time in the first model but rather fitted a second model for a subset of animals. The model was fitted as for the whole set, but had sex and exploration time (from the first trial) as fixed factors. The sample size was reduced to 15 individuals (10 females, 5 males). The subset is not a random sample of the study population as the availability of data depended on participation in the experiments and thus it is mainly immigrant males who were excluded from the dataset.

\section{Individual traits determining first follower frequency}

To elucidate the role of the first follower as a potential key individual, we also tested the effects of individual traits on the frequency of being the first follower. As for the initiation frequency model, we fitted a binomial model for the complete data set, with the number of times as the first follower as an individual's successes. We fitted group as a random factor and sex and activity as fixed factors.

As for the initiator model, we also fitted a first follower subset model for the exploration data. However, exploration time was not part of the best model. As for the complete first follower model, the best fit was achieved with group as a random factor and sex and activity as fixed factors. 


\section{RESULTS}

\section{Personality measures are repeatable}

In the novel object test, the time spent exploring the object was repeatable $(r=0.55, n=25$ individuals). FID was also repeatable ( $r=0.37, n=31$ individuals). In the drinking observations ( $n=31$ individuals), drinking time per time exposed in the open was repeatable $(r=0.36)$, whereas the order leaving the forest $(r=0.29)$ and the number of vigilance events while drinking $(r=0.16)$ were not. We thus considered exploration time as a measure for exploration and FID as well as drinking time ratio as measures of boldness. FID and drinking exposed were not correlated, however $(r=0.13, t=0.58, d f=19, p=0.57)$.

\section{Subadults initiate less than adults}

Both adult females and males initiated movements significantly more often than subadults (females: estimate: $2.30, \mathrm{SE}: 0.31, z=7.34, p<0.001$, males: estimate: 1.50 , SE: $0.33, z=4.56$, $p<0.001$; model better than the null model: $\chi^{2}=83.92, d f=2, p<0.001$; Fig. 3.2). Subadults initiated 12 of 167 movements (7.2\%), despite constituting $32.3 \%$ of the study population. They initiated 0 to 2 movements per individual whereas values for adults ranged from 0 to 21 initiations. As including subadult individuals would thus lead to an unbalanced dataset, we restricted further analyses to adult animals $(n=21)$.

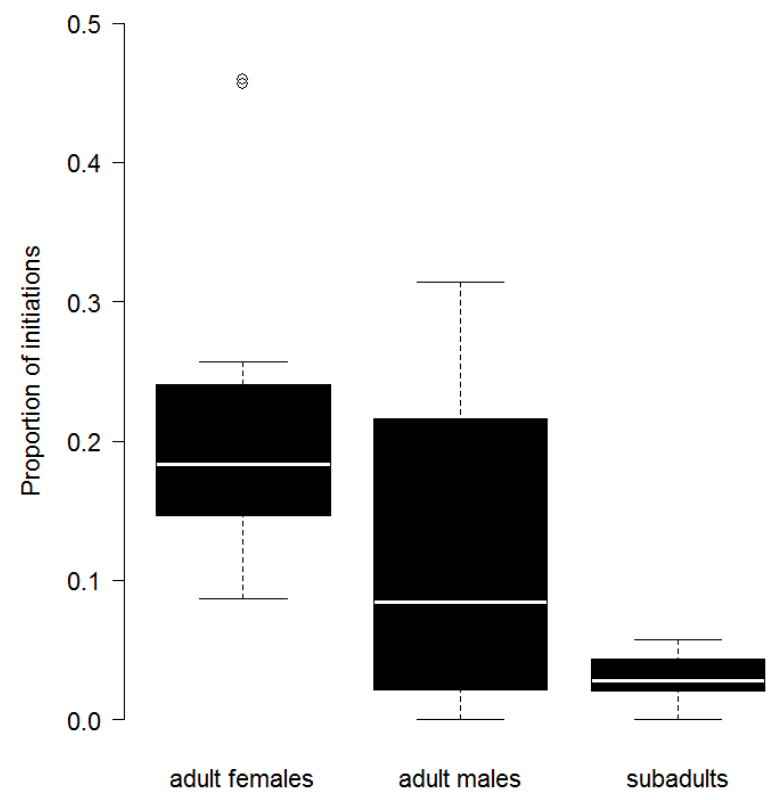

Figure 3.2: Proportion of initiations by individuals of different age classes and sexes. Proportions are the number of movements an individual initiated divided by the overall number of movements in their respective group (Sample $=167$ successful initiations for 11 females, 10 males, 10 subadults in four groups). 


\section{Individuals differ in initiation frequency}

In three out of four groups, adult individuals significantly differed in how often they initiated movements (group $\mathrm{A}: \chi^{2}=16.96, \mathrm{df}=5, p<0.01$, group $\mathrm{B}: \chi^{2}=12.82, \mathrm{df}=3, p<0.01$, group $\mathrm{F}: \chi^{2}$ $=2.25, \mathrm{df}=3, \mathrm{p}=0.52$, group $\mathrm{J}: \chi^{2}=47.33, \mathrm{df}=6, \mathrm{p}<0.001 ;$ Fig. 3.3).
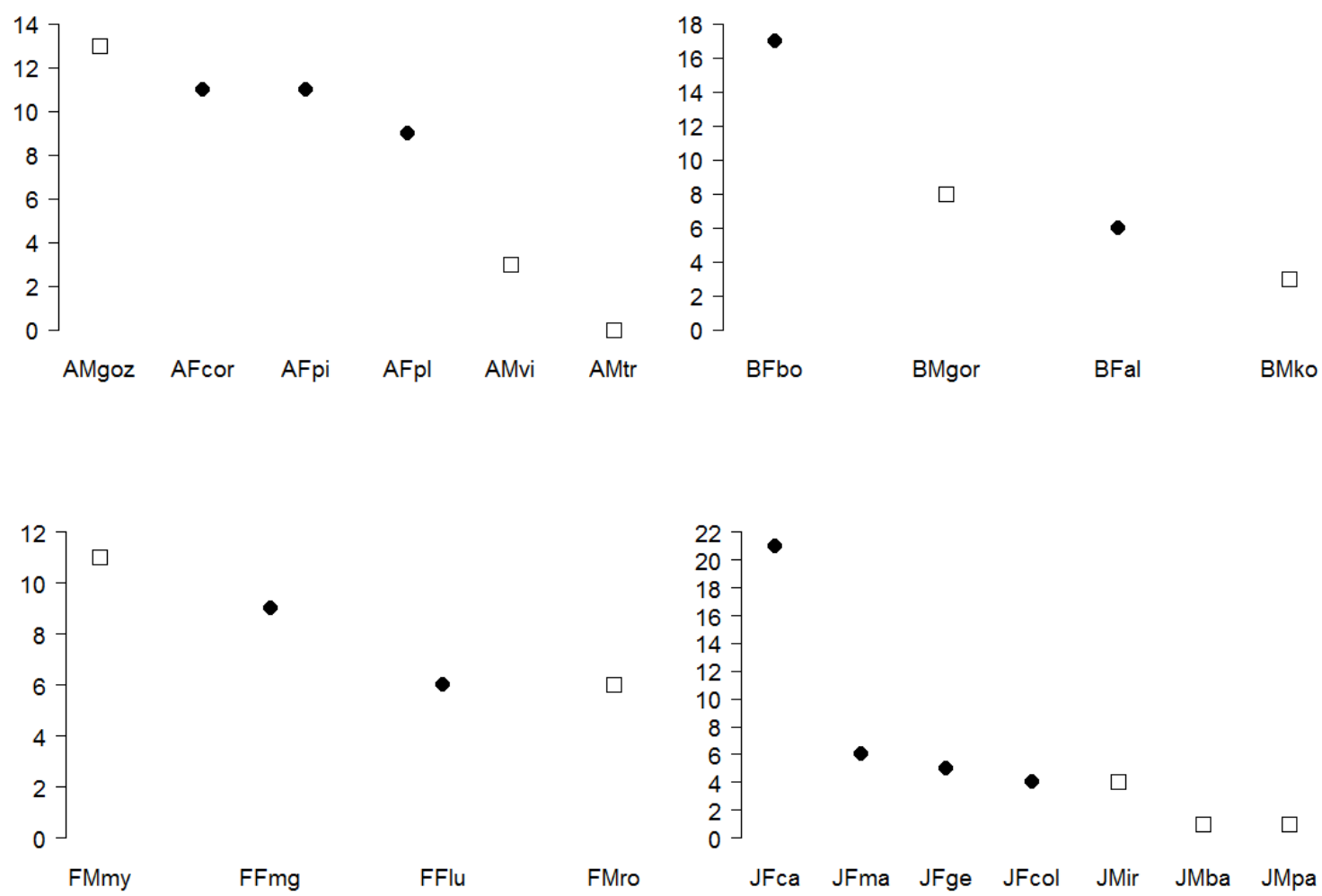

Figure 3.3: Number of successful initiations per adult individual in each group (clockwise for group A, B, J, F). Females $=\bullet$, males $=\square$. Sample $=155$ successful initiations, group A: $n=47$, group $B: n=34$, group $F: n=32$, group $\mathrm{J}: \mathrm{n}=42$

Sex, sociability and exploration affect initiation frequency

Initiation frequency:

\section{Complete dataset}

Sex determined the effect of sociability on initiation frequency. Females with a higher CSI initiated movements more often, while the reverse was true for males, where individuals with a lower CSI initiated movements more often (Table 3.2, Fig. 3.4).

\section{Exploration subset}

More explorative individuals initiated group movements more often (Table 3.2, Fig. 3.5). 


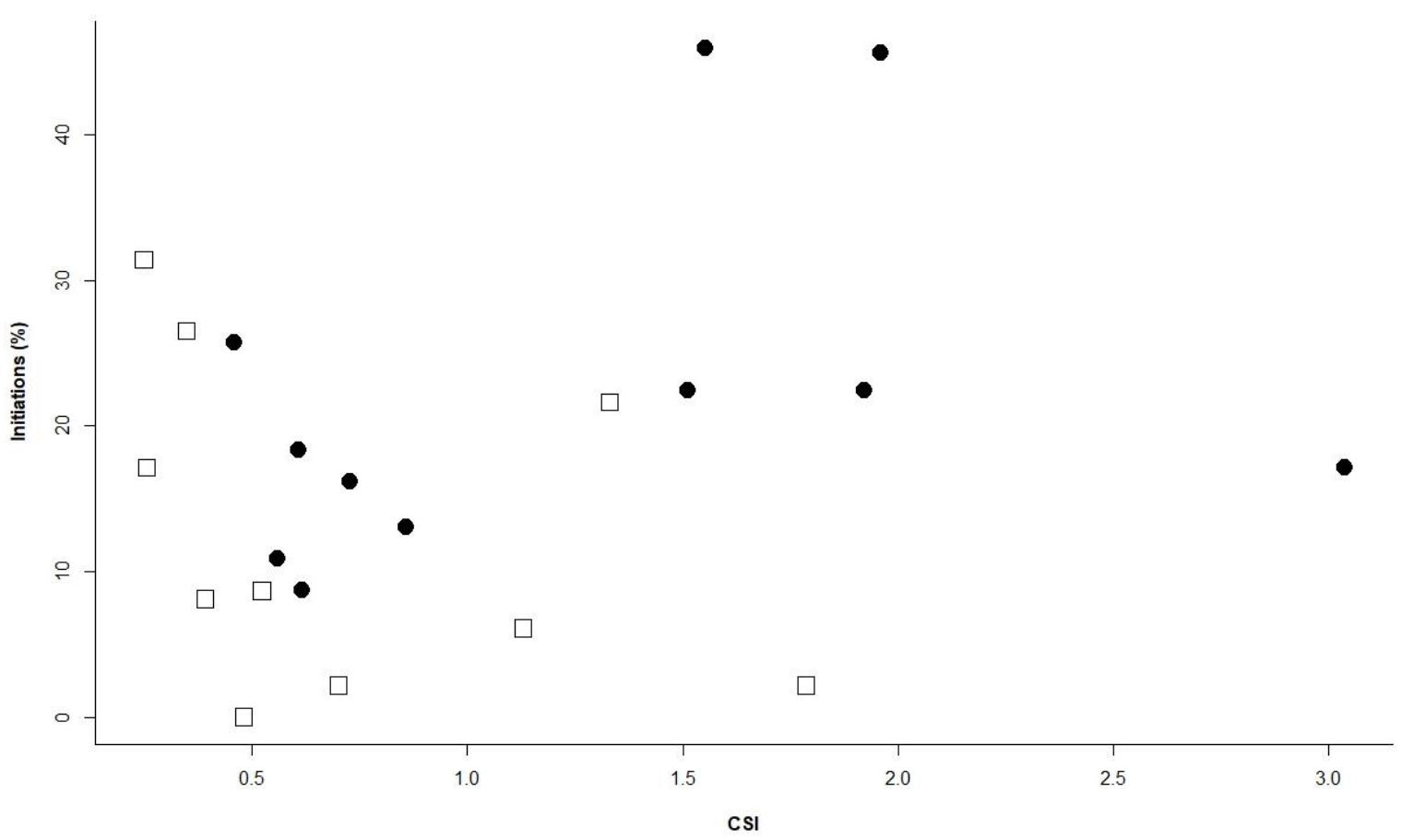

Figure 3.4: Initiation frequency as a function of CSI (huddling \& grooming in focal observations). Females $=\bullet$, males $=\square .155$ initiations, 21 individuals.

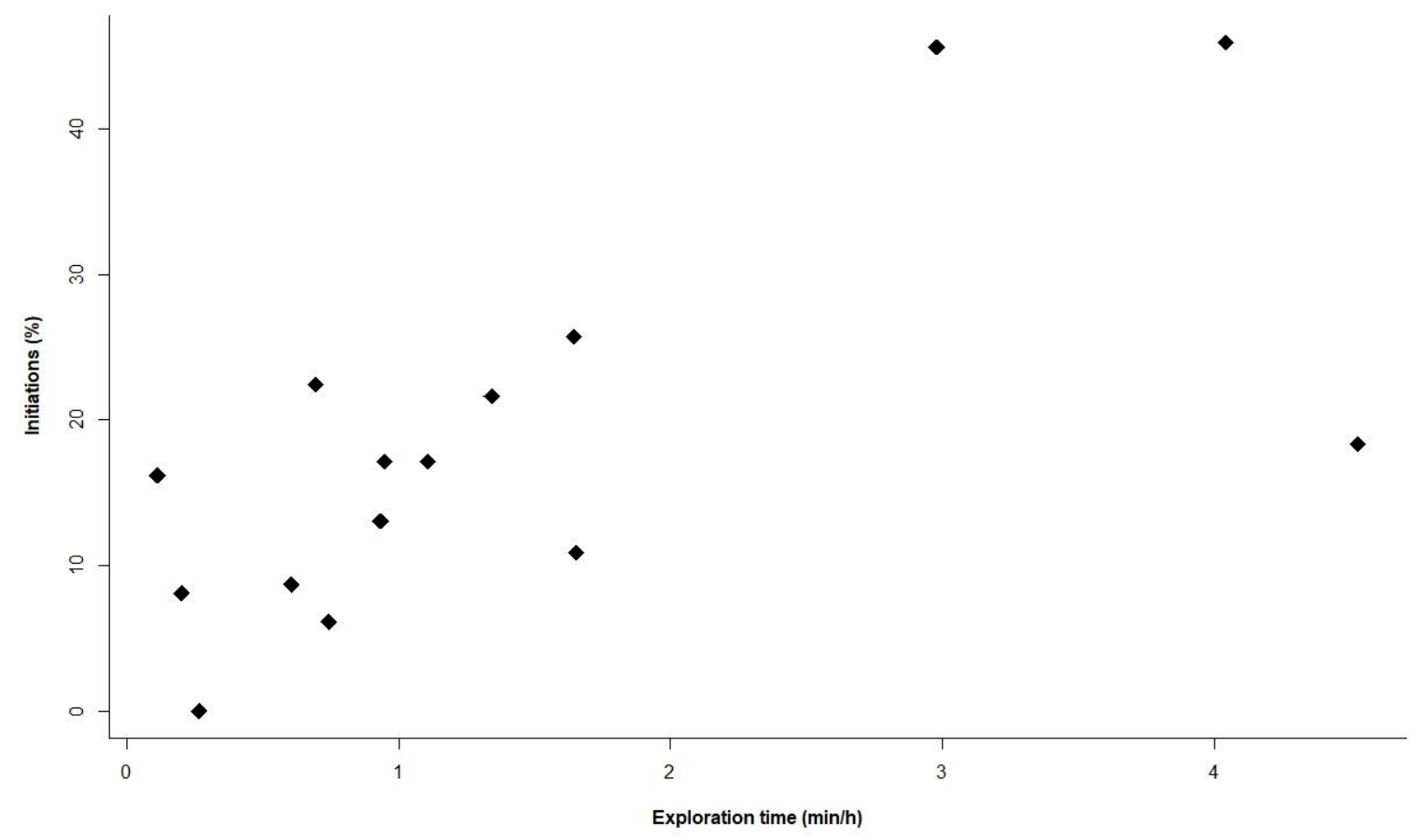

Figure 3.5: Initiation frequency as a function of time spent exploring in a novel object test. 155 initiations, 15 individuals. 
Table 3.2: Results for the GLMMs for initiation frequency

$\begin{array}{lllll}\text { Complete dataset }(\mathbf{n = 2 1}) & \text { Estimate } & \text { Std. Error } & \text { z value } & \text { p value } \\ \text { (Intercept) } & -1.68 & 0.25 & -6.68 & <0.001 \\ \text { Sex (male) } & 0.26 & 0.37 & 0.72 & 0.47 \\ \text { CSI (huddling \& grooming) } & 0.35 & 0.15 & 2.41 & 0.02 \\ \text { Sex (male) : CSI } & -1.25 & 0.42 & -2.94 & <0.01\end{array}$

Test against null model: $\chi^{2}=29.89, \mathrm{df}=3, \mathrm{p}<0.001$

$\begin{array}{lllll}\text { Exploration subset }(\mathbf{n}=\mathbf{1 5}) & \text { Estimate } & \text { Std. Error } & \mathbf{z} \text { value } & \mathbf{p} \text { value } \\ \text { (Intercept) } & -1.43 & 0.21 & -6.97 & <0.001 \\ \text { Sex (male) } & -0.57 & 0.31 & -1.85 & 0.06 \\ \text { Exploration time } & 0.45 & 0.11 & 3.99 & <0.001\end{array}$

Test against null model: $\chi^{2}=32.57, \mathrm{df}=2, \mathrm{p}<0.001$

\section{First follower frequency:}

\section{Complete dataset}

Males were first followers less often than females, whereas more active individuals were more often the first group member to follow the initiator (Table 3.3).

\section{Exploration subset}

The best model did not explain the data better than the null model (test against null model: $\chi^{2}=$ $5.15, d f=2, p=0.08)$.

Table 3.3: Results for the GLMM for first follower frequency (complete dataset, $n=21$ individuals)

$\begin{array}{lllll} & \text { Estimate } & \text { Std. Error } & \text { z value } & \text { p value } \\ \text { (Intercept) } & -1.65 & 0.13 & -12.65 & <0.001 \\ \text { Sex (male) } & -0.45 & 0.20 & -2.20 & 0.03 \\ \text { Activity (walking and climbing) } & 0.24 & 0.10 & 2.47 & 0.01\end{array}$

Test against null model: $\chi^{2}=11.83, \mathrm{df}=2, \mathrm{p}<0.01$ 


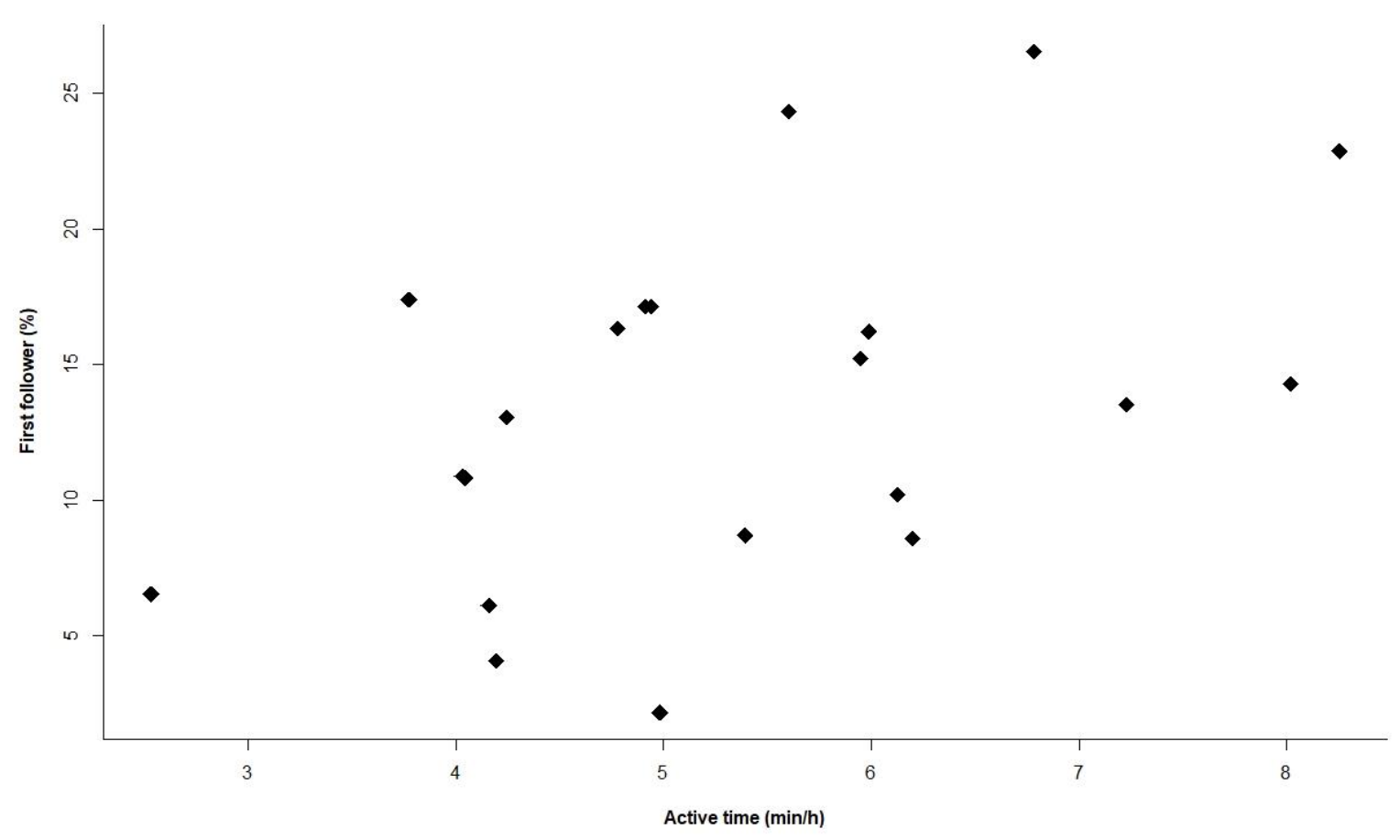

Figure 3.6: First follower frequency as a function of time spent active (walking or climbing) in focal observations. 155 initiations, 21 individuals. 


\section{DISCUSSION}

We set out to characterise leaders of group movements in wild red-fronted lemurs. To this end, we measured the individuals' scores for different personality traits using focal observations and experiments in the wild and related them to their initiation frequencies. Individuals differed in the number of movements they initiated, and we found that a higher initiation frequency was associated with higher levels of exploration. This result agrees with findings in other species; a proactive personality is often linked to leadership. We furthermore found that sociability affected initiation frequency, however inversely for the sexes. Female initiators were more sociable, while male initiators were less sociable. A positive effect of sociability on leadership has been reported for many species, whereas a negative effect is rarer, though not without precedent, even in other primates. Despite their independent evolution of group living, red-fronted lemurs show leader characteristics similar to those found in anthropoid primates and species from other taxa.

\section{Leadership is variable with habitual leaders}

Leadership varied between events, with almost all individuals initiating group movements. This result is consistent with the red-fronted lemurs high level of social tolerance (Fichtel, Schnoell, \& Kappeler, 2018; Pereira et al., 1990) and has been reported for other socially tolerant species, such as white-faced capuchins (Cebus capucinus), Tonkean macaques (Macaca tonkeana) and Tibetan macaques (Macaca thibetana) (Leca et al., 2003; Sueur \& Petit, 2008b; Wang et al., 2016). We found different degrees of the distribution of initiations across group members in our four groups, so much so that while in one group half of all initiations were made by a single individual, in another group there was no significant difference in initiation frequency between individuals at all. This variability in the distribution of initiations could depend on the number of individuals in a group that share traits or a combination of traits predisposing them for initiating (Smith, Estrada, et al., 2015). It would, therefore, be interesting for future studies to investigate whether the degree to which group members differ in characteristics such as personality or physical traits translates into the degree to which leadership is distributed. In our study population, leadership was at least partially distributed in all groups, and in three out of the four groups adult individuals differed significantly in initiation frequency, making some individuals habitual leaders.

\section{Adults almost exclusively initiate}

Although subadults were able to initiate movements, they did so significantly less often than adults, confirming results of earlier studies (Pyritz et al., 2013; Pyritz, Kappeler, et al., 2011). This pattern is common across species and often subadults do not initiate group movements at all 
(Boinski, 1991; Fernández et al., 2013; Sueur \& Petit, 2008b; Van Belle et al., 2013). This age effect is likely due to a higher risk of predation for individuals in the van, which commonly leads to a protective travel order with the vulnerable subadults in the centre of the group (Fichtel, 2012; Holekamp et al., 2000; Prins, 1989; Sperber et al., 2019; Wright, 1998). Although subadults' poorer knowledge of the resource distribution within their home range could affect movement initiations, this explanation seems less likely, as some recently immigrated adult males were frequent initiators.

\section{Activity determines first follower frequency}

We did not find an effect of sociability on the frequency of being the first follower. Rather, individuals with a higher general activity level were more often the first to follow the initiator. These findings speak against the first follower being a key individual determining the initiation's success (Bourjade \& Sueur, 2010; Byrne et al., 1990; Sueur \& Petit, 2008b; Sueur et al., 2009).

\section{Sex-specific effect of sociability on initiation frequency}

We found opposing effects of sociability for male and female initiators: While more sociable females initiated more movements, the reverse was true for males. Finding a negative effect of sociability on leadership is noteworthy, since it is more rarely reported than a positive effect. We reviewed nineteen studies investigating the influence of sociability on leadership (Table 3.1). Only one study found no effect of sociability; it was measuring recruitment success in a trained choice task (Meunier, Leca, Deneubourg, \& Petit, 2006). Thirteen studies found a positive effect, which was due to higher recruitment success in seven studies and due to more frequent initiating or leading in six. However, theoretical models have suggested that individuals with less affinity to others will more easily move away from the group, resulting in movement initiations (Conradt et al., 2009) This prediction was supported in three studies which reported a negative effect in sheep, cattle and three-spined sticklebacks, always due to less sociable individuals initiating or leading more movements (Arnold, 1977; Della-Rossa et al., 2013; Jolles et al., 2015).

In addition to the sex-specific effect of sociability on initiation frequency reported in our study, affiliation has a positive effect on following in red-fronted lemurs, as individuals with stronger affiliative relationships follow each other in quicker succession (Sperber et al., 2019). Of particular interest are, thus, the two studies that reported both a positive and a negative effect in the same species. Groups of heifers and ewe-lambs showed a negative effect of social integration on initiation frequency and a positive effect on following order (Ramseyer et al., 2009). The crux of the matter can be seen in barbary macaques (Macaca sylvanus), where less sociable individuals 
make more initiation attempts, but do not lead movements more frequently, as they are less successful in recruiting the group (Seltmann et al., 2016, 2013). We thus posit that when recruitment is guaranteed by high group cohesion or a shared decision on departure time, high social "power" may not be necessary for leadership and the readiness to move away from the group becomes a decisive factor.

\section{Proactive personality encourages leadership}

We found that more exploratory individuals initiated group movements more often. The observed positive effect of exploration on initiation frequency is in accordance with the findings in other species, as we will show in a short review on the effect of personality on leadership.

We reviewed fifteen studies that investigated the effects of the proactive traits exploration, boldness and activity on leadership in eleven species (Table 3.1). The species tested were all birds, fish and ungulates, so there is a need for more diverse study species. Most studies tested more than one trait, thus we report the number of times a trait was tested rather than the number of studies. Exploration, boldness and activity affected leadership at least half of the times they were tested, and always positively, with more active, more exploratory and bolder individuals initiating and leading more group movements.

Reviewing studies on exploration and boldness is complicated by a lack of consensus on the definition of these traits (Carter, Feeney, Marshall, Cowlishaw, \& Heinsohn, 2013). Many authors label a reaction to novelty, e.g. in a novel object test, boldness, even though it has been shown that the behaviour in this context is not equal to the reaction to risk as from a predator (Carter, Marshall, et al., 2012). We, therefore, referred to the definition of Réale et al. (2007), and considered tests to be measuring exploration if they included novelty.

Thus, we found that the effect of exploratory behaviour on leadership has been tested seven times, having an effect four times. Most often, exploration was assessed using a novel object test, measuring the latency to approach and the minimal distance, as in barnacle geese, where this measure positively affected initiation and leadership (Kurvers et al., 2009, 2011). The number of contacts with the novel objects were used as the measure in cattle and domestic geese, which did not affect their probability to initiate movement or to be at the front of the moving group (Ramseyer et al., 2009). Another measure for exploration are the locations investigated in a novel environment, which positively affected leadership in zebra finches (Beauchamp, 2000; Schuett \& Dall, 2009).

Boldness as risk-taking behaviour has been studied most often (fourteen times, having an effect eight times) and using diverse measures. For example, the tendency to leave cover and the 
time spent outside cover predicted leadership in three-spined sticklebacks (Harcourt et al., 2009; Nakayama et al., 2012). The latency to emerge into an open space did not predict leadership in golden shiners (Notemigonus crysoleucas), but did in homing pigeons (Columbia livia) (Leblond \& Reebs, 2006; Sasaki et al., 2018). Another commonly used measure is a startle response, which was linked to leadership in three-spined sticklebacks (Ward et al., 2004) and domestic geese (Ramseyer, Petit, et al., 2009b), but not in cattle and domestic sheep (Ramseyer et al., 2009). Boldness, to our knowledge, is the only personality trait that has been studied in the wild. Flight initiation distance was measured in female eider ducks (Öst \& Jaatinen, 2013) and trappability, as the willingness to accept the risk of being captured in exchange for the bait, in bighorn sheep ewes (Réale \& Festa-Bianchet, 2003). Neither of these studies found an effect on leadership. A study on feral horses, however, reported that more nervous individuals showing more vigilance behaviours lead fewer movements (Berger, 1977).

The effect of activity on leadership had thus far only been investigated twice, in two bird species, zebra finches (Taenopygia guttata) and barnacle geese. Activity was measured as the time spent moving and the number of locations visited in a familiar environment within a defined time span. It was associated with leadership in zebra finches, but not in barnacle geese (Beauchamp, 2000; Kurvers et al., 2009).

Our study is among the first to investigate an effect of boldness on leadership in the wild, and the first for activity and exploration. Further studies are necessary to elucidate why in some species exploration, boldness and activity do not seem to affect leadership probability at all, as in cattle and domestic sheep (Ramseyer et al., 2009), while in others they do. Before we are able to identify underlying causes, however, we may have to deal with interfering factors. In this context, a question that needs to be addressed is whether a test measures the same trait across species (Carter et al., 2013). Furthermore, the difference in effects could be connected to how animals perceive the environment in which their groups are moving, particularly in regard to threat level. This point calls for more studies on group movements in the natural context in the field.

\section{Conclusions}

This study demonstrates that the frequency of initiating group movements in wild red-fronted lemurs not only depends on an individual's sex and age, but also on its personality. Leaders were characterised by higher levels of exploration. This finding backs the results from studies in captivity that link leadership to proactive personality. Leadership was also affected by sociability, though inversely for the sexes, with more sociable female and less sociable male leaders. This finding lends support to the hypothesis that lower social attraction can result in leadership when moving 
away from the group is sufficient to elicit following behaviour. Individuals who are not well integrated in the group can thus initiate movements and determine the group's activity. Further research is needed to identify the social or ecological circumstances causing the ambivalent effects of sociability on leadership. This study describes how individual personality affects the propensity to lead in a primate species with an egalitarian social system. It contributes important new aspects to our knowledge of what characterises leaders of collective movements and thus furthers our understanding of the general principles underlying group coordination and decision making. 

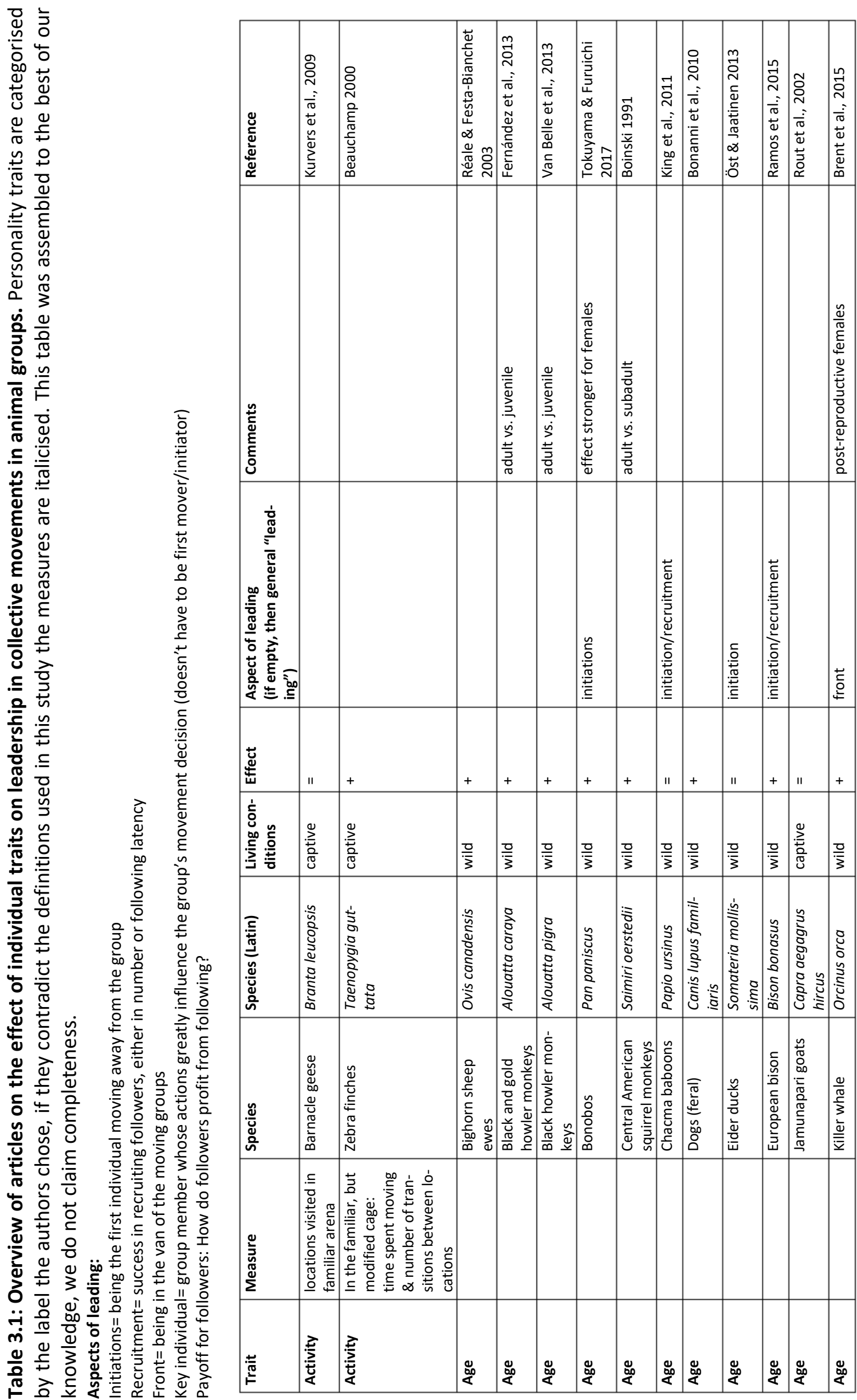


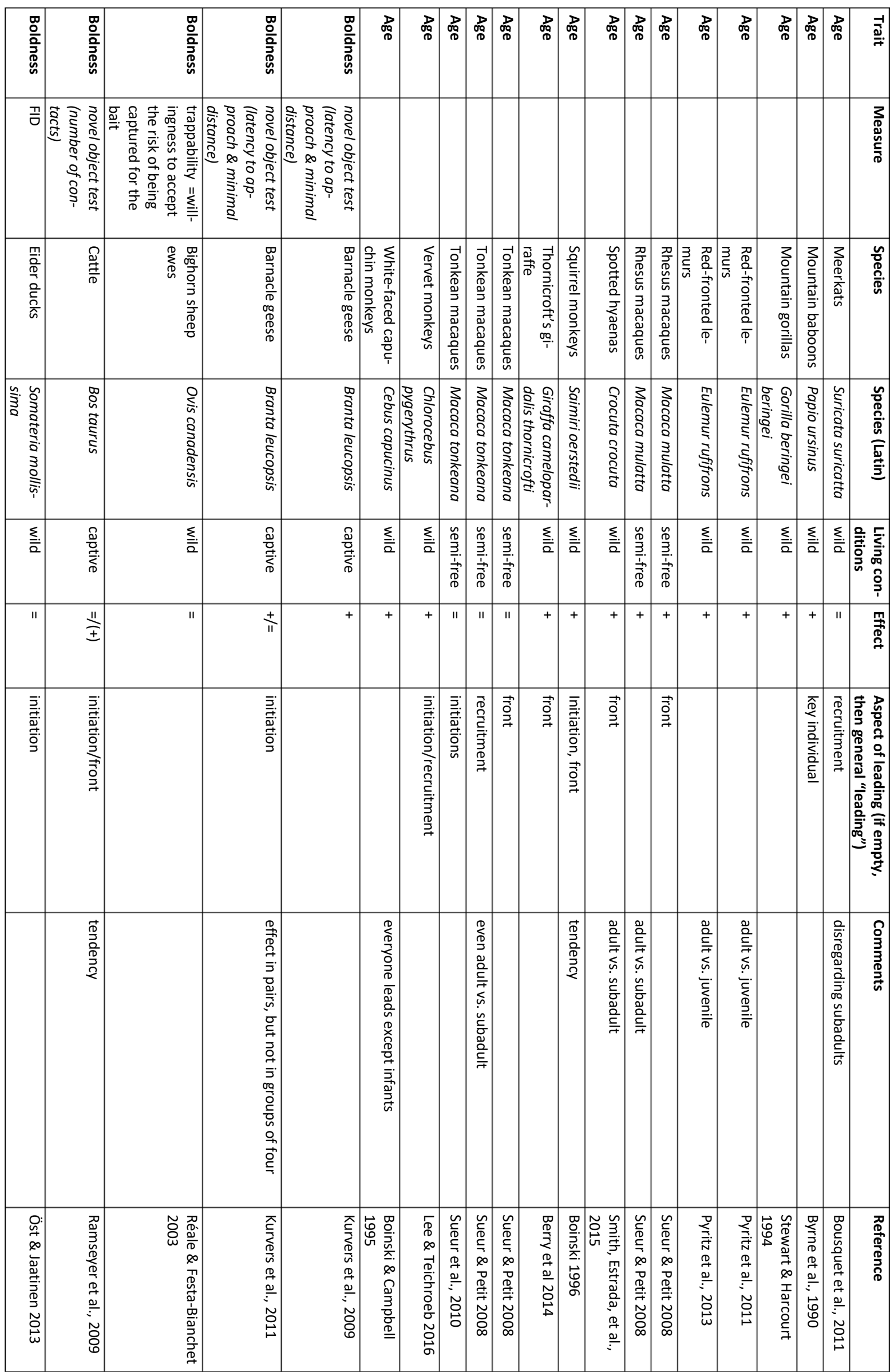


Initiators of collective movements 3

\begin{tabular}{|c|c|c|c|c|c|c|c|c|c|c|c|c|c|}
\hline 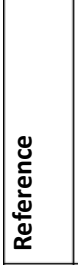 & 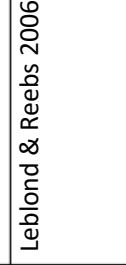 & & 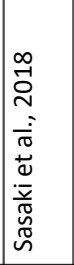 & 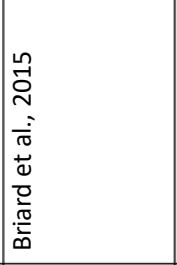 & 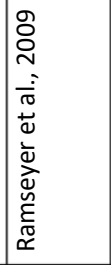 & 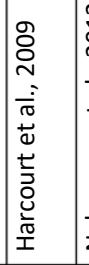 & 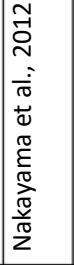 & 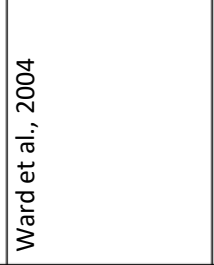 & 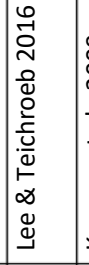 & 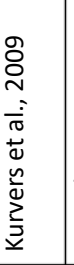 & 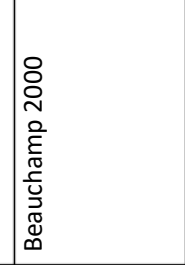 & 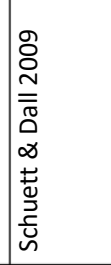 & 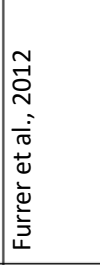 \\
\hline 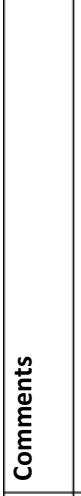 & 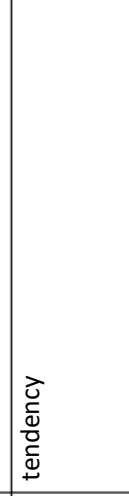 & & & 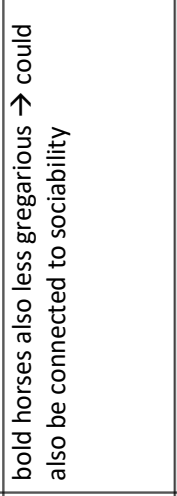 & & & & 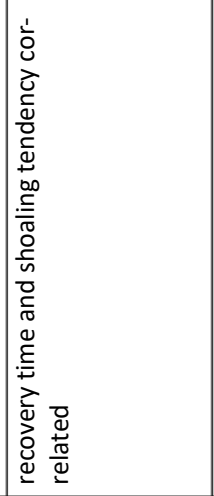 & 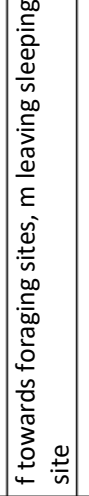 & & & & \\
\hline 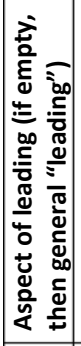 & 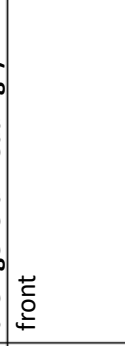 & 䓂 & & 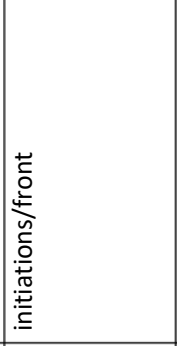 & 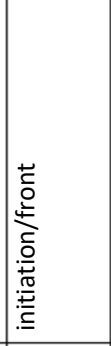 & & & 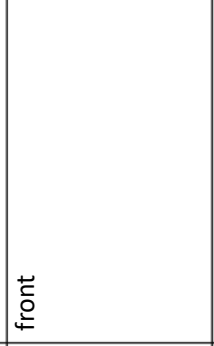 & 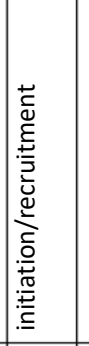 & & & & 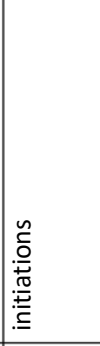 \\
\hline $\begin{array}{l}\overrightarrow{\mathbf{u}} \\
\text { 密 } \\
\end{array}$ & $\mp$ & $"$ & + & + & ${ }^{111}$ & + & + & + & & " & + & + & + \\
\hline 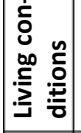 & 总 & & $\begin{array}{l}\frac{y}{2} \\
\frac{\partial}{0} \\
\tilde{c}\end{array}$ & 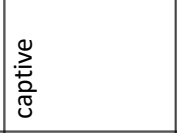 & 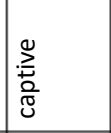 & 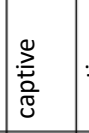 & $\begin{array}{l}\frac{y}{2} \\
\frac{\partial}{0} \\
\tilde{c}\end{array}$ & 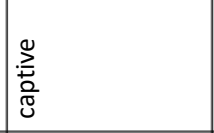 & $\frac{\pi}{3}$ & 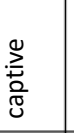 & 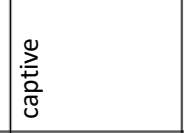 & 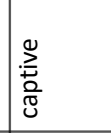 & $\frac{\pi}{3}$ \\
\hline 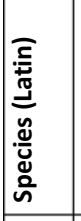 & 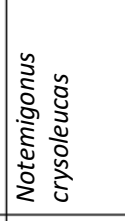 & & 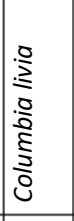 & 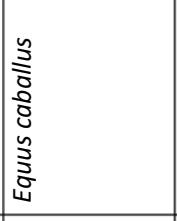 & 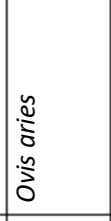 & 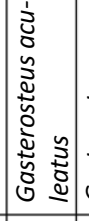 & 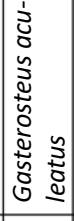 & 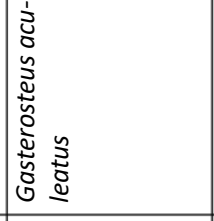 & 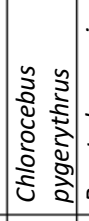 & 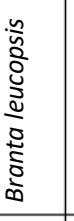 & 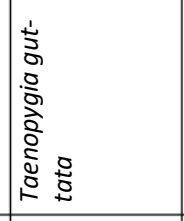 & 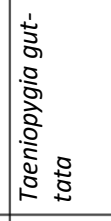 & 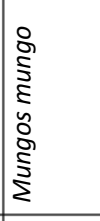 \\
\hline 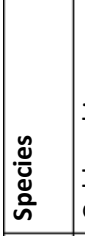 & 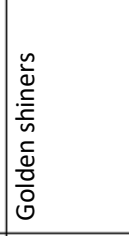 & & 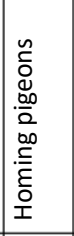 & 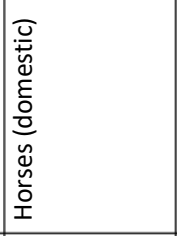 & 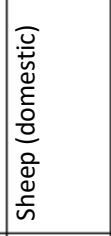 & 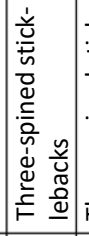 & 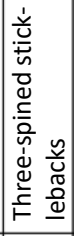 & 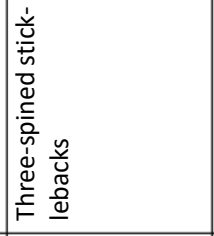 & 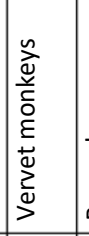 & 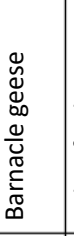 & 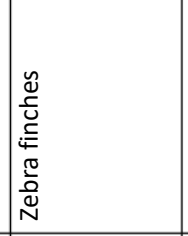 & 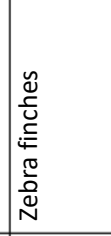 & 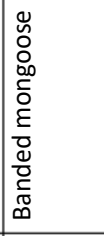 \\
\hline 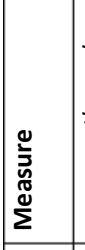 & 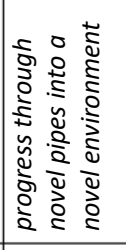 & 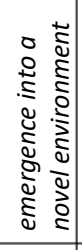 & 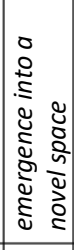 & 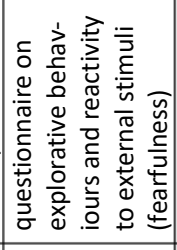 & 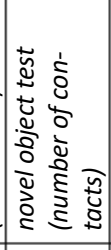 & 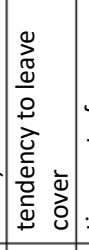 & 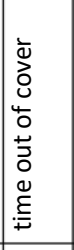 & 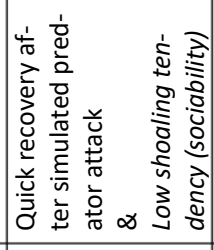 & & 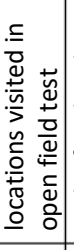 & 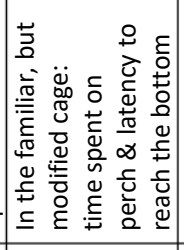 & 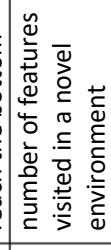 & 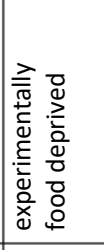 \\
\hline 范 & 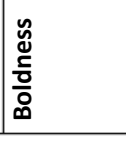 & & 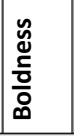 & 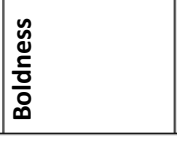 & 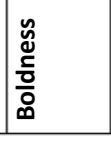 & 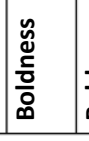 & 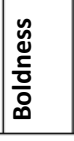 & 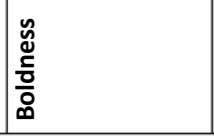 & 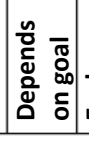 & 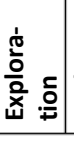 & 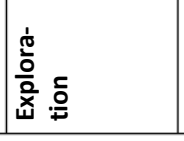 & 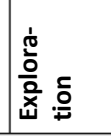 & 辛 \\
\hline
\end{tabular}




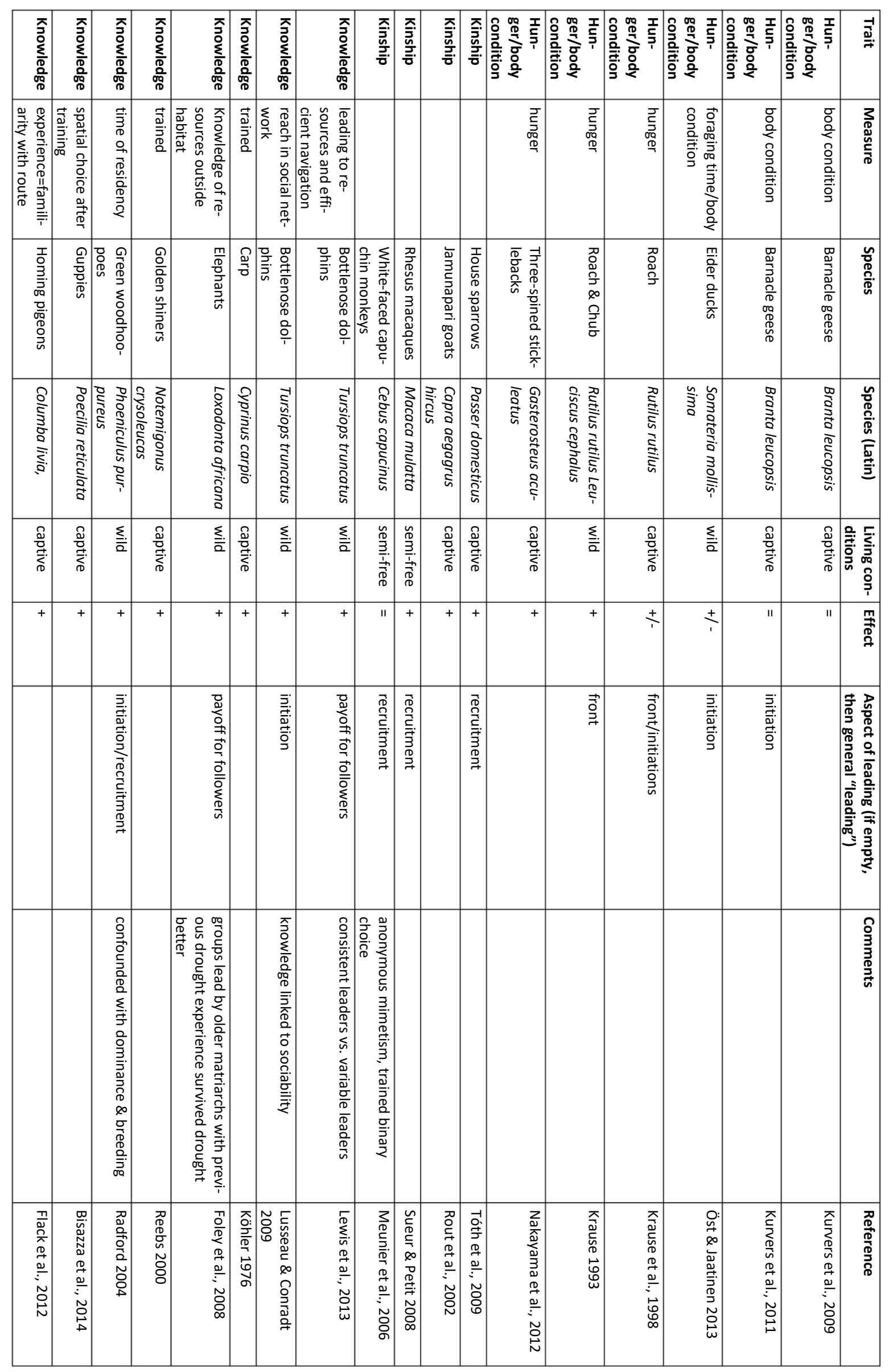




\begin{tabular}{|c|c|c|c|c|c|c|c|c|c|c|c|c|c|c|c|c|c|}
\hline 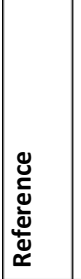 & 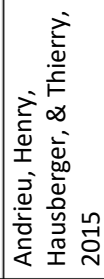 & 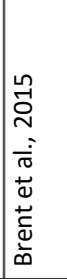 & 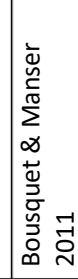 & 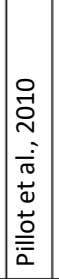 & 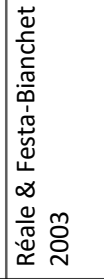 & 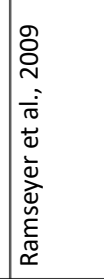 & 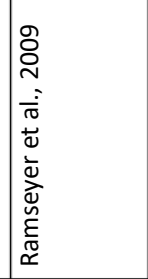 & 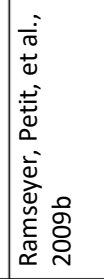 & 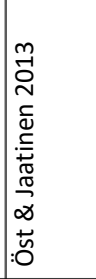 & 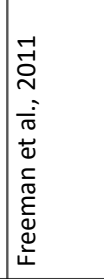 & 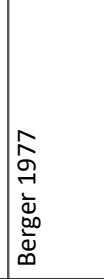 & 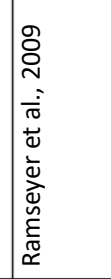 & 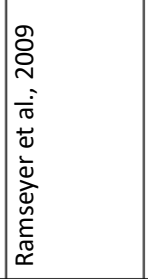 & 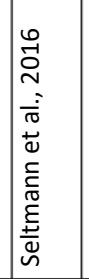 & 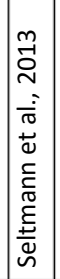 & & 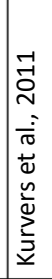 \\
\hline 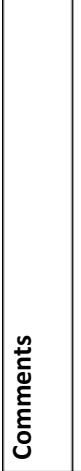 & & 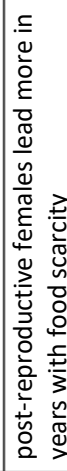 & & & & & & & & & & & & & 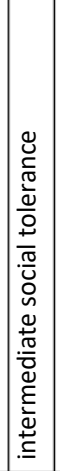 & & \\
\hline 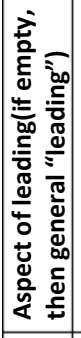 & 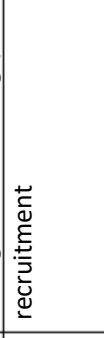 & 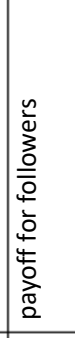 & 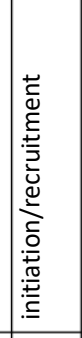 & & & 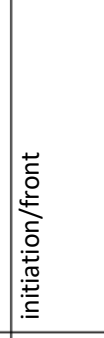 & 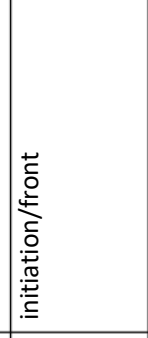 & 䓂 & 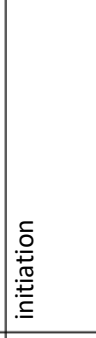 & & & 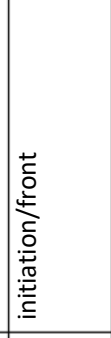 & 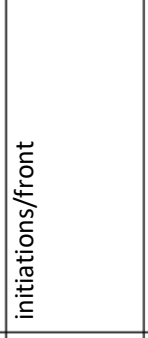 & & 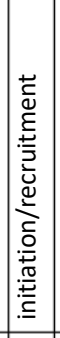 & & 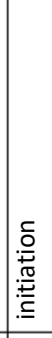 \\
\hline $\begin{array}{l}\overrightarrow{\mathrm{d}} \\
\text { 离 }\end{array}$ & + & + & + & + & " & $\frac{11}{11}$ & ${ }^{11}$ & + & + & + & : & ${ }^{\prime \prime}$ & $\frac{11}{11}$ & 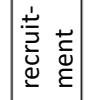 & + & " & " \\
\hline 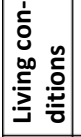 & 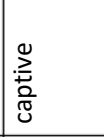 & $\frac{0}{3}$ & $\frac{0}{3}$ & 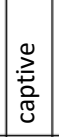 & $\frac{0}{3}$ & 总 & 总 & 总 & $\frac{7}{3}$ & 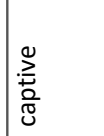 & $\frac{\pi}{3}$ & $\begin{array}{l}: \frac{0}{2} \\
\frac{\partial}{0} \\
0 \\
0\end{array}$ & 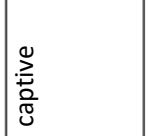 & $\frac{0}{3}$ & $\frac{0}{3}$ & 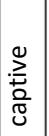 & 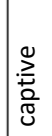 \\
\hline 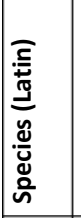 & 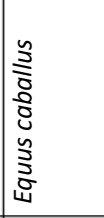 & 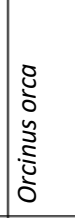 & 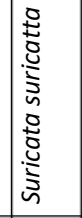 & 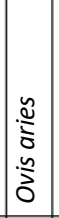 & 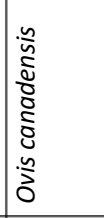 & 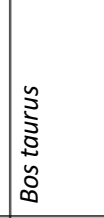 & 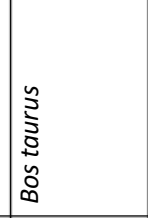 & 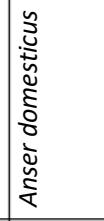 & 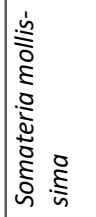 & 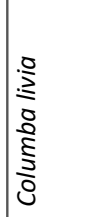 & 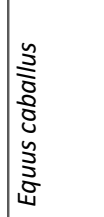 & 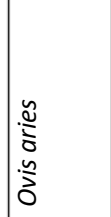 & 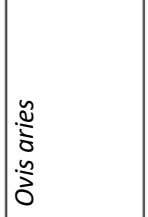 & 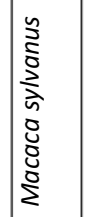 & 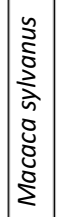 & 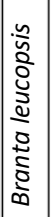 & 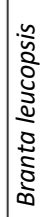 \\
\hline 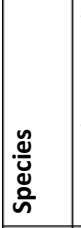 & 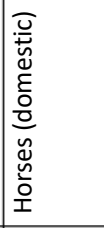 & 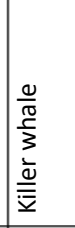 & 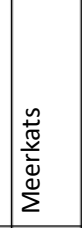 & 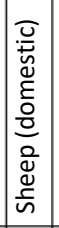 & 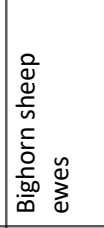 & 畩 & 惌 & 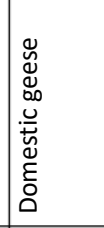 & 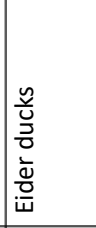 & 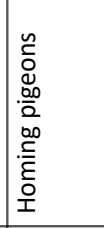 & 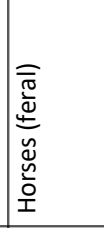 & 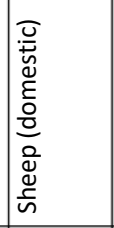 & 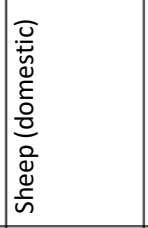 & 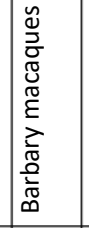 & 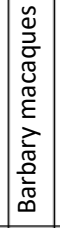 & 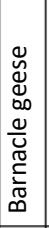 & 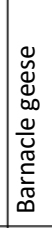 \\
\hline 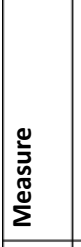 & 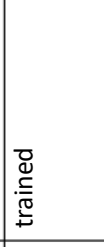 & 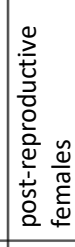 & 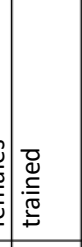 & 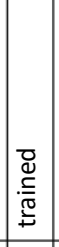 & 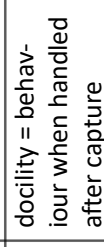 & 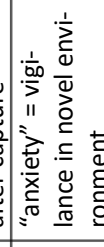 & 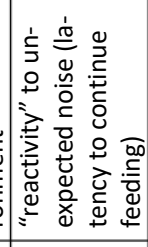 & 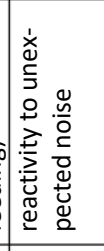 & 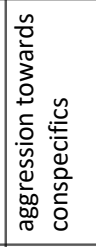 & 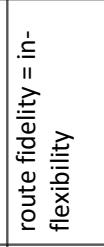 & 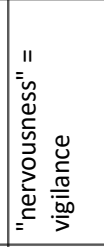 & 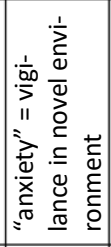 & 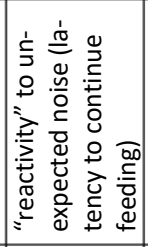 & & & & \\
\hline 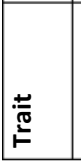 & 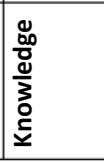 & 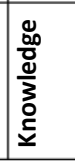 & 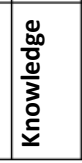 & 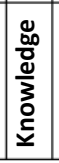 & 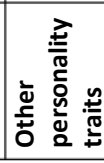 & 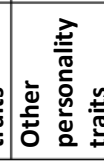 & 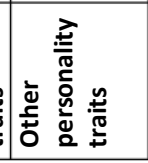 & 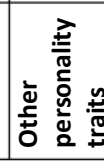 & 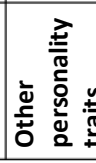 & 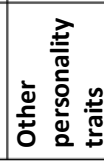 & 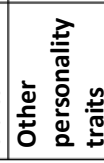 & 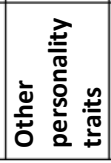 & 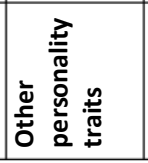 & 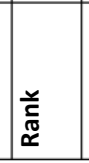 & 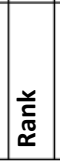 & & 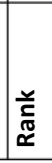 \\
\hline
\end{tabular}




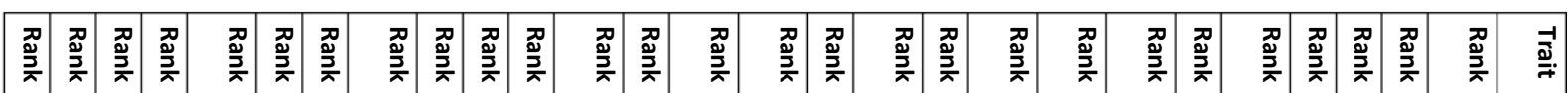

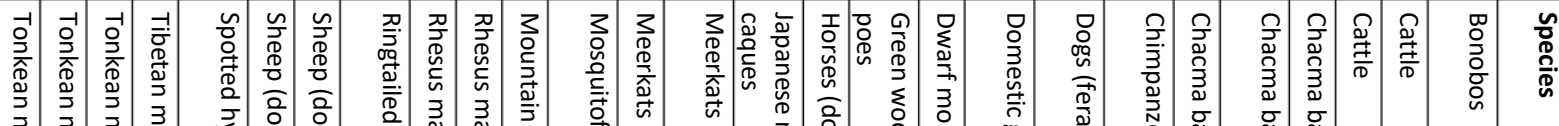

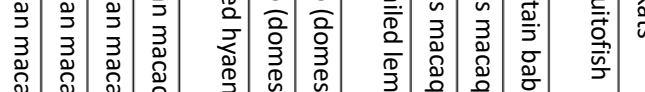

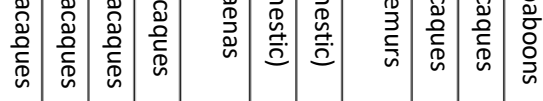

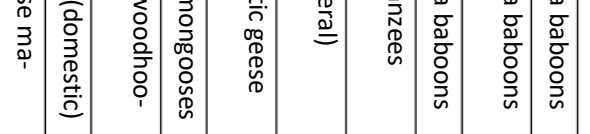

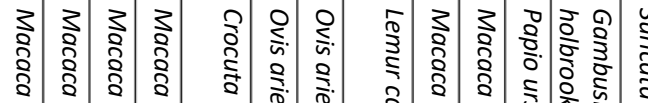

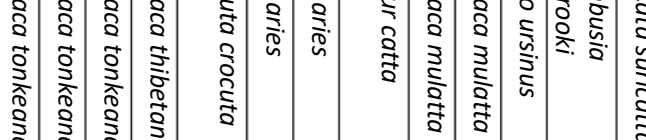

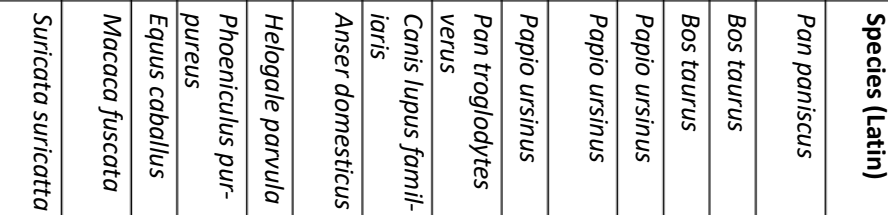

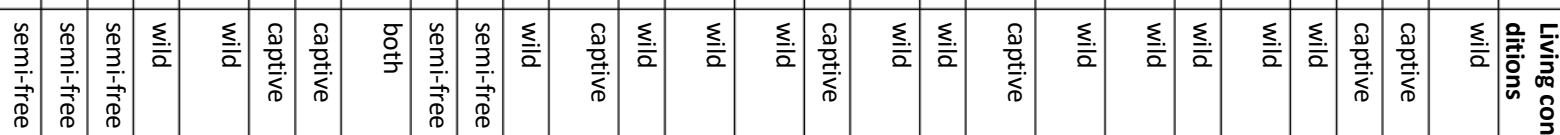

"

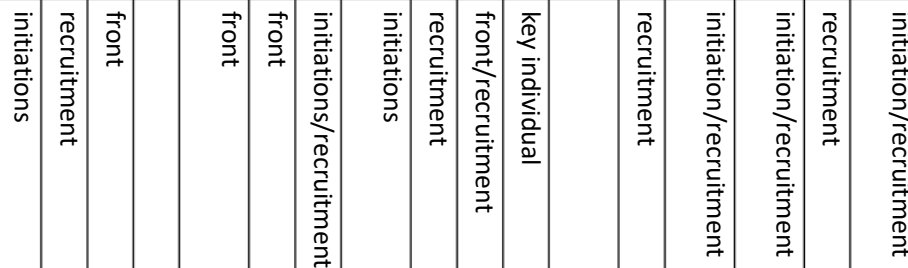

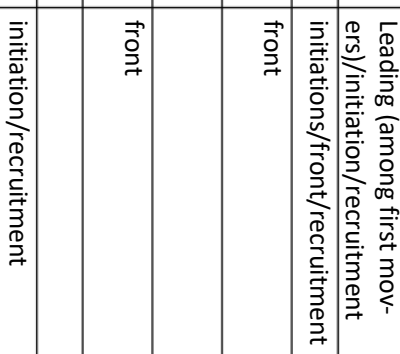

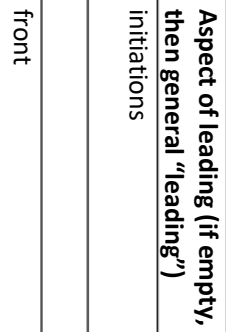

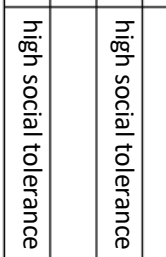

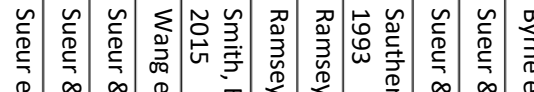

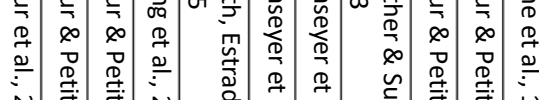

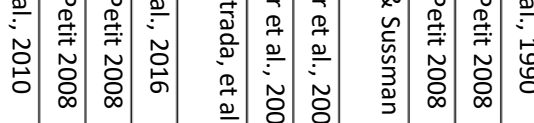

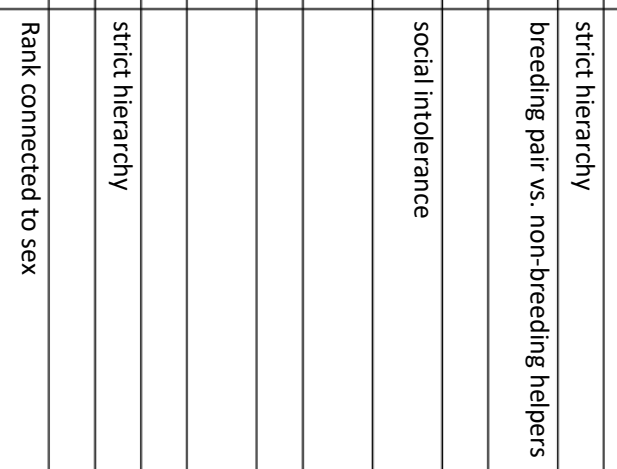

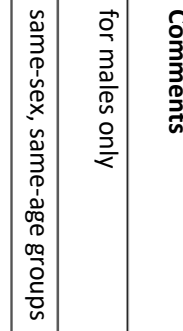




\begin{tabular}{|c|c|c|c|c|c|c|c|c|c|c|c|c|c|c|c|c|c|c|c|c|c|}
\hline 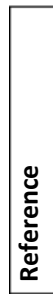 & 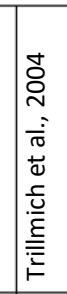 & 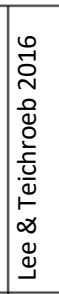 & 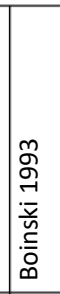 & 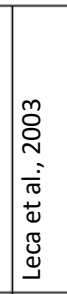 & 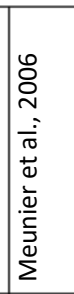 & 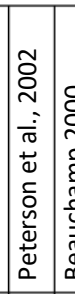 & 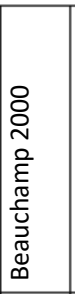 & 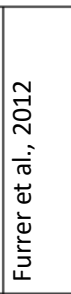 & 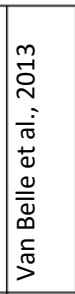 & 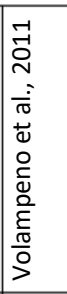 & 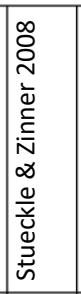 & 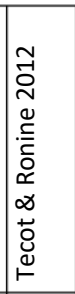 & 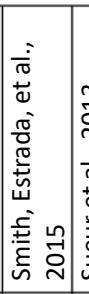 & 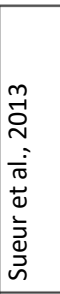 & 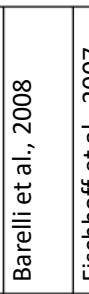 & 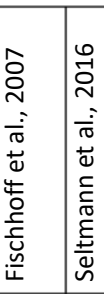 & 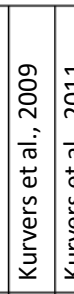 & 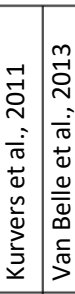 & 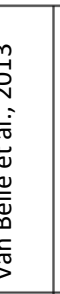 & 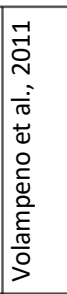 & 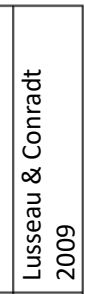 \\
\hline 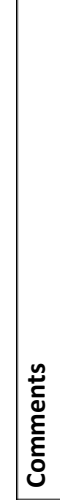 & & & & 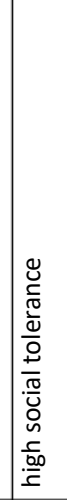 & 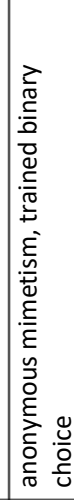 & 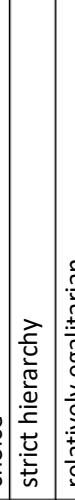 & 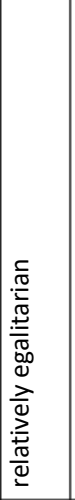 & & & & 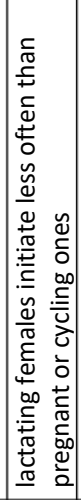 & & & & 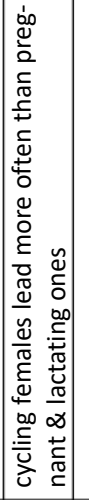 & & & 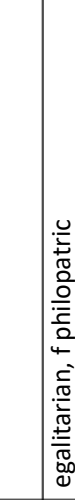 & 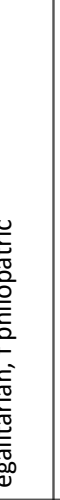 & $\bar{\sigma} \bar{z}$ & \\
\hline
\end{tabular}

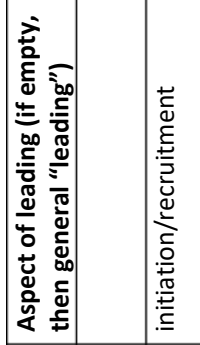

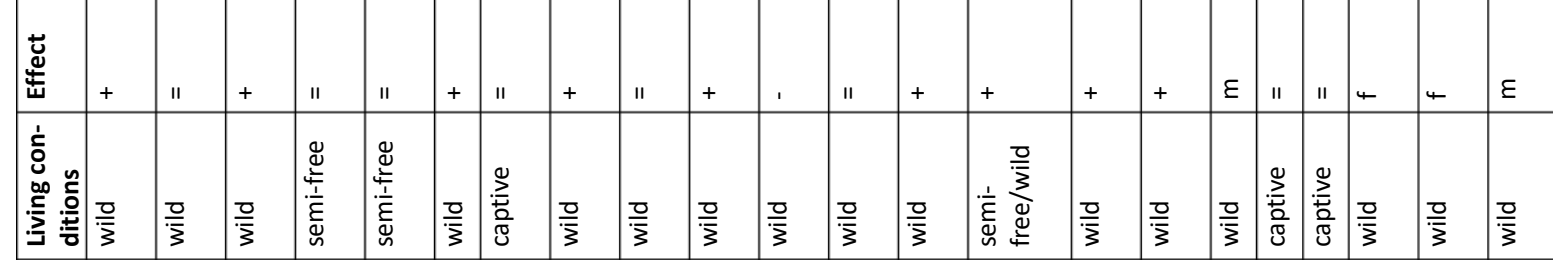

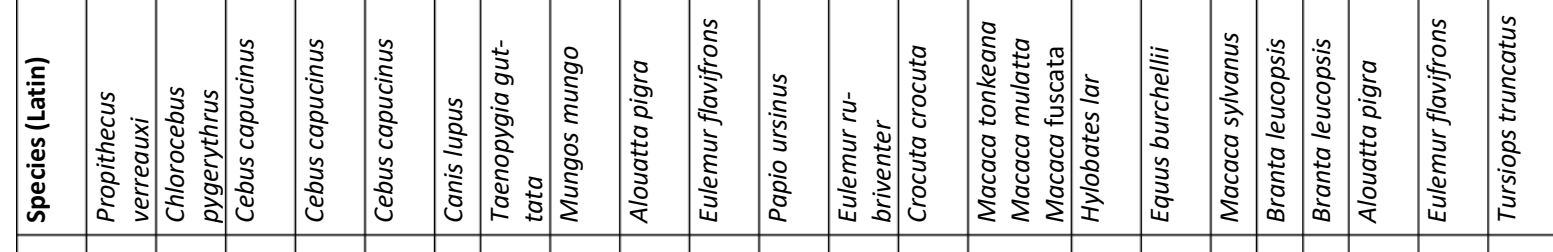

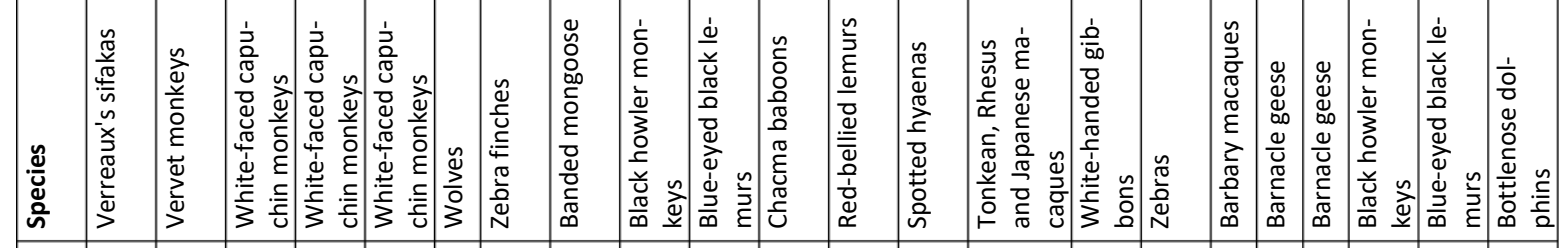

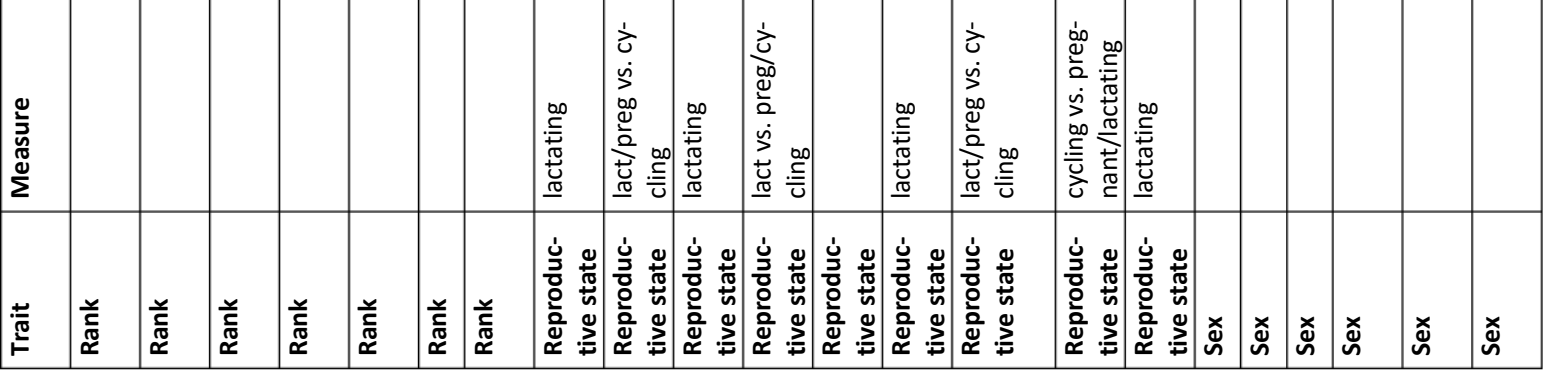




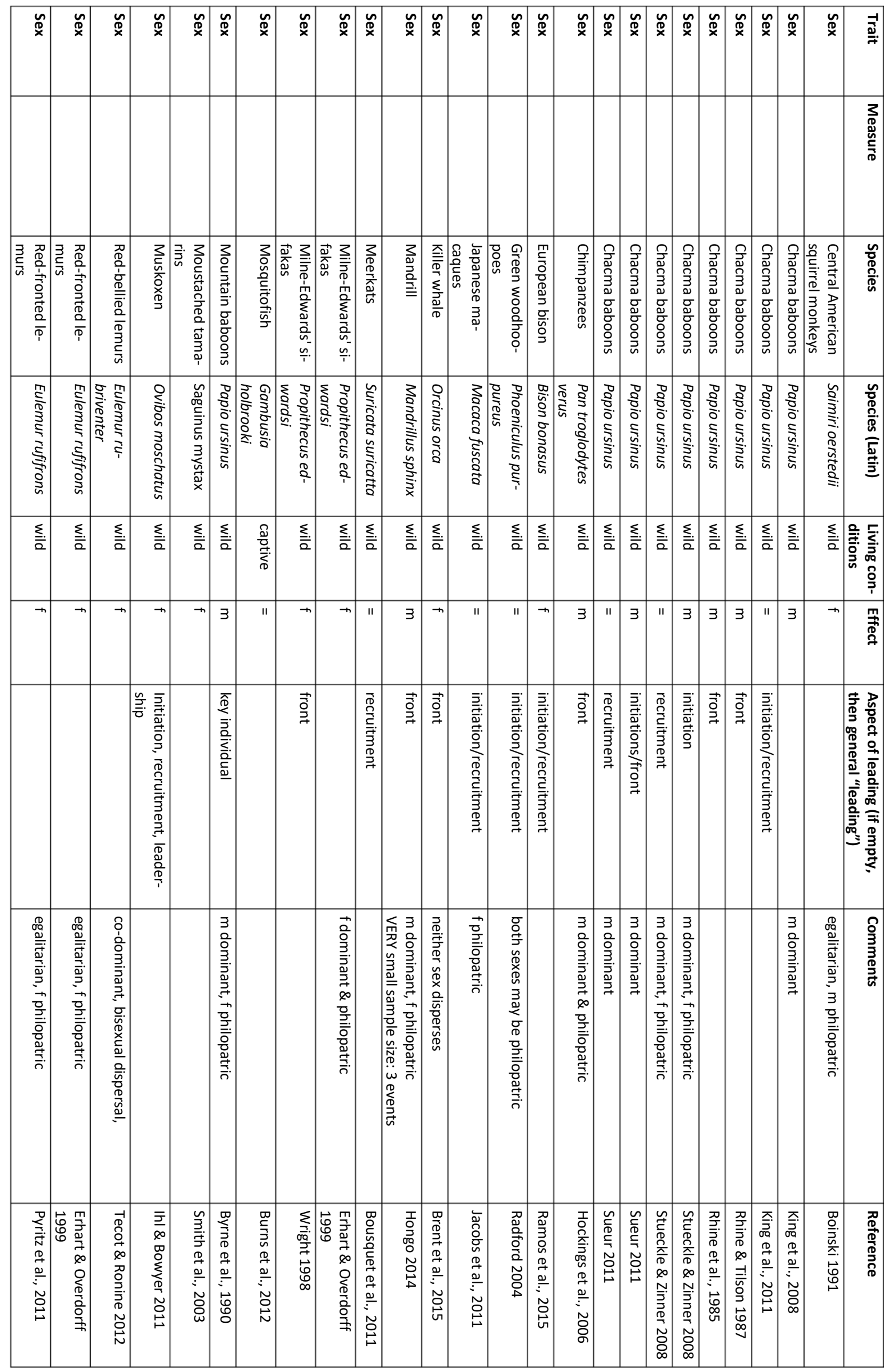




\begin{tabular}{|c|c|c|c|c|c|c|c|c|c|c|c|c|c|c|c|c|c|c|c|c|c|}
\hline 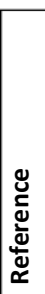 & 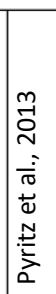 & 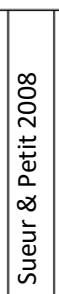 & 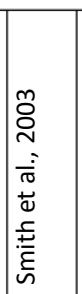 & 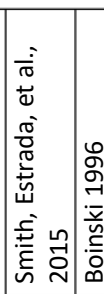 & 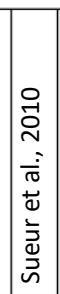 & 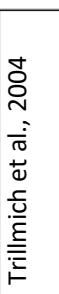 & 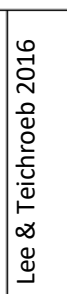 & 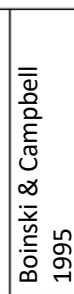 & 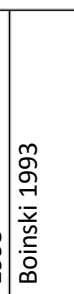 & 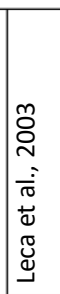 & 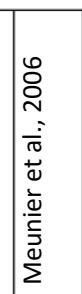 & 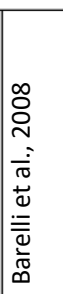 & 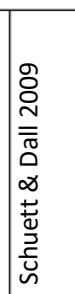 & 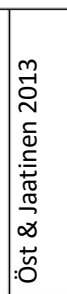 & 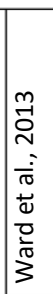 & 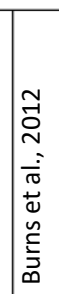 & 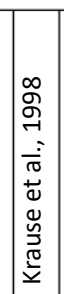 & 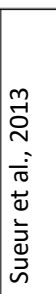 & 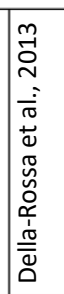 & 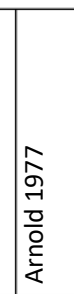 & 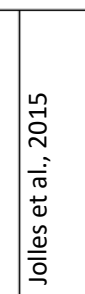 \\
\hline 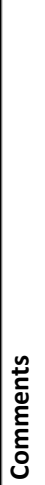 & 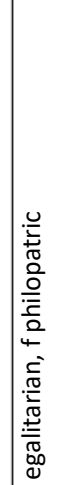 & 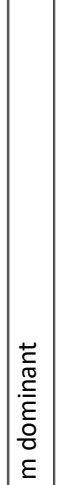 & 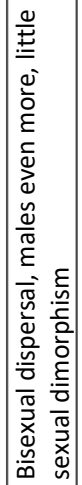 & 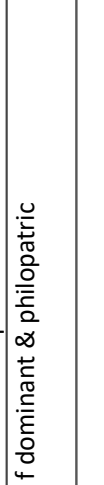 & & 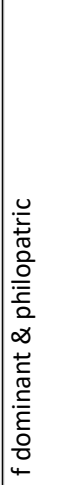 & 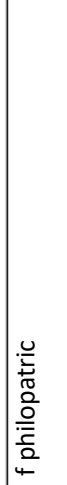 & 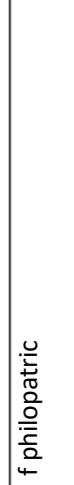 & 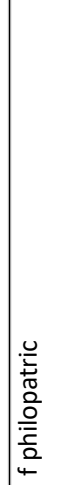 & 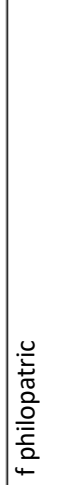 & 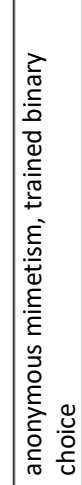 & 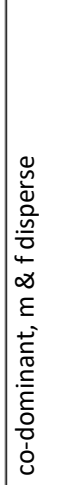 & & & 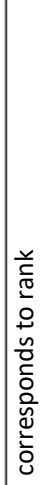 & & & & 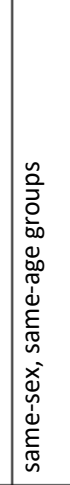 & & 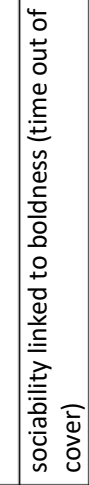 \\
\hline
\end{tabular}

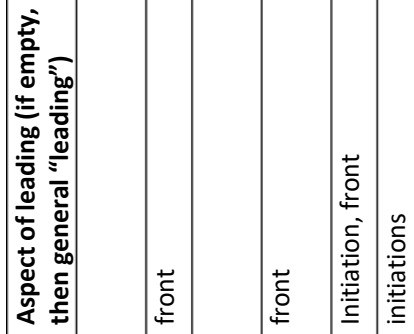

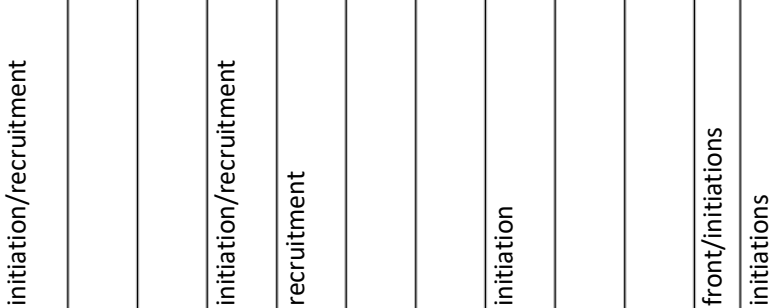

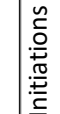

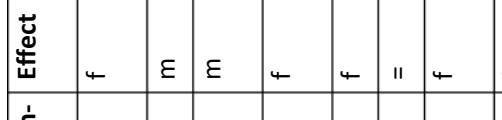

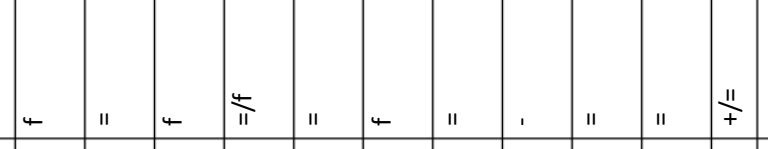

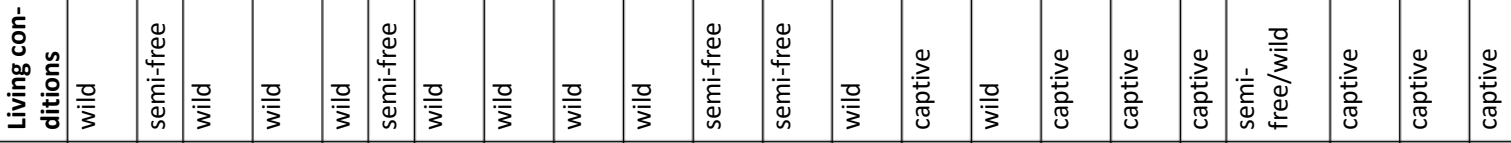

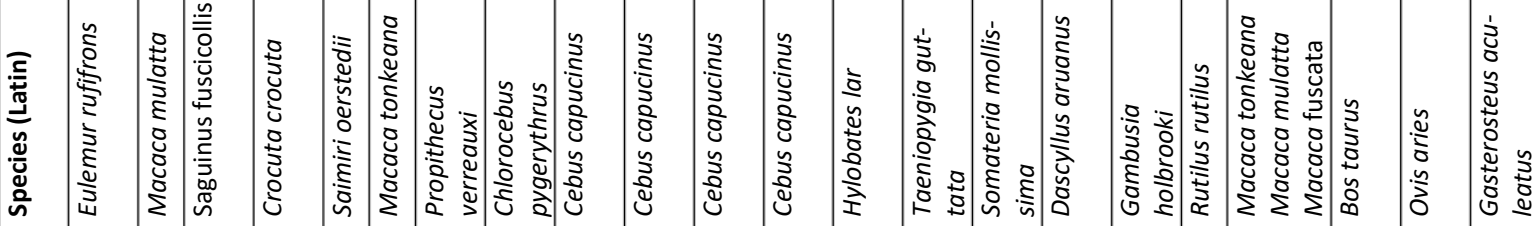

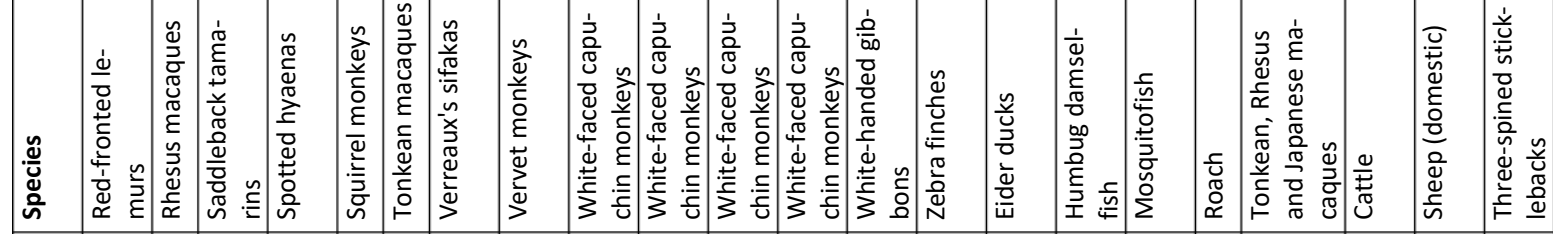

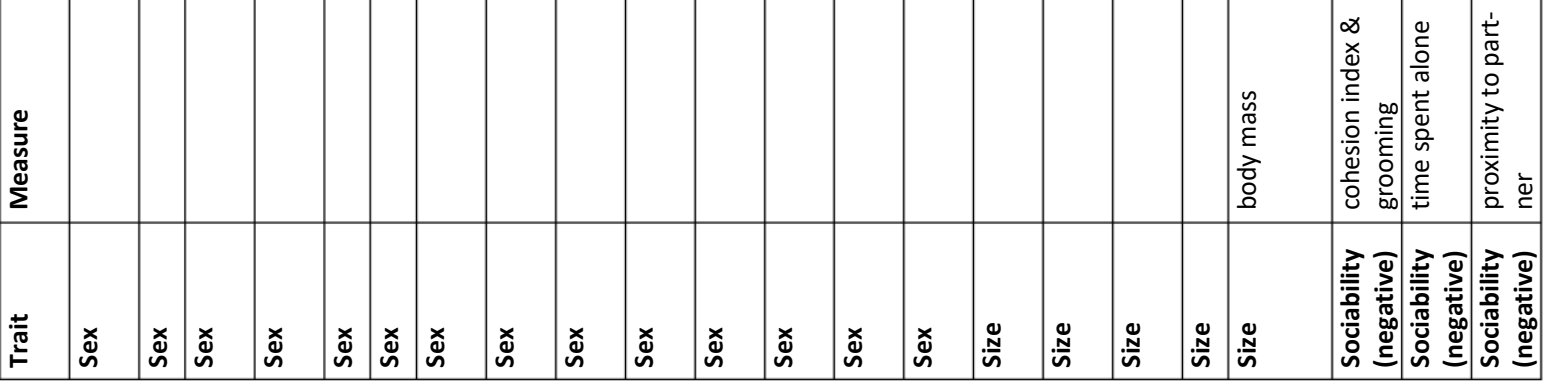




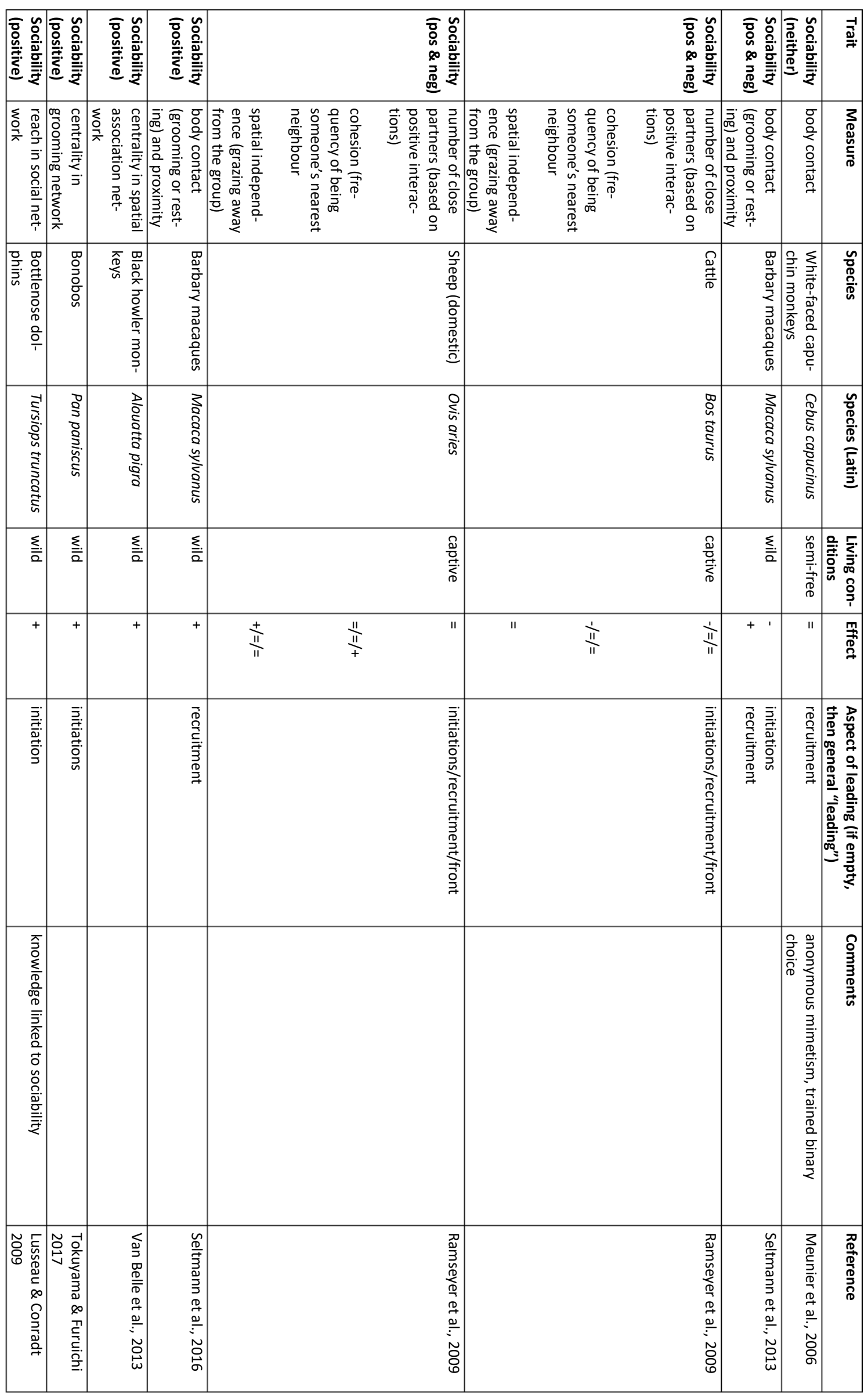




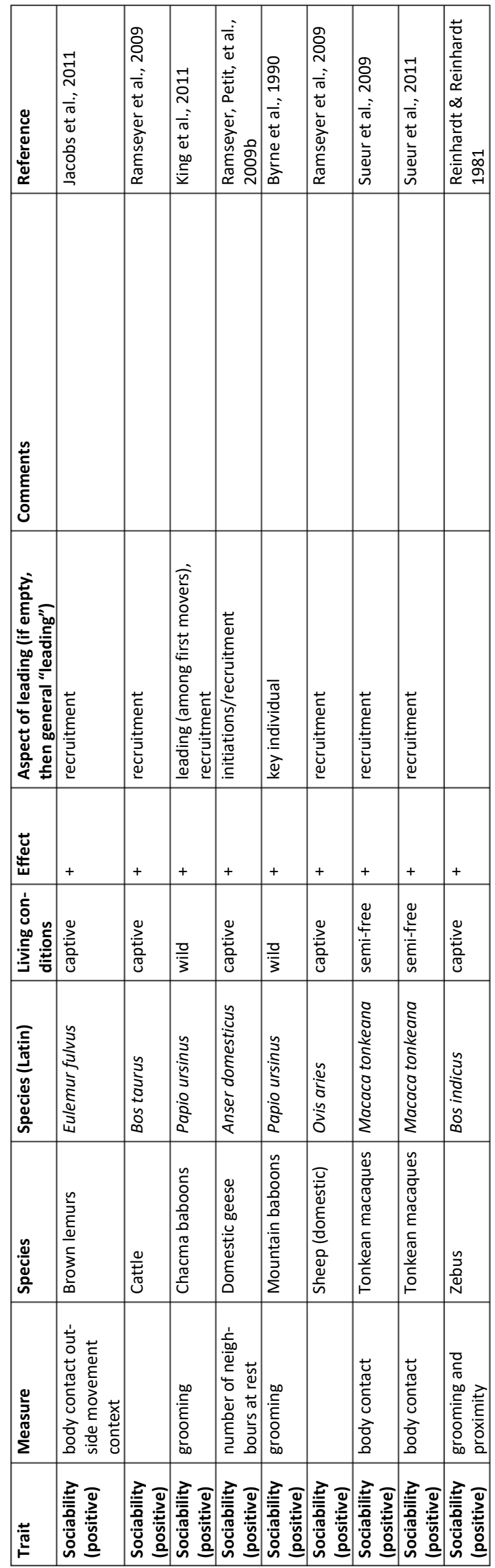




\section{ACKNOWLEDGMENTS}

We thank the Malagasy Ministère de l'Environnement et des Eaux et Forêts, the Departement de Biologie, Ecologie et Conservation Animale de l'Université d'Antananarivo, and the Centre National de Formation, d'Etudes et de Recherche en Environnement et Foresterie de Morondava for supporting our research in Kirindy Forest. We are particularly thankful to Heather Sanders for collecting the data on flight initiation distance. We would also like to thank Sophie Kirberg and Hannah Kleine-Weber for their vital support in data collection.

\section{SUPPLEMENTARY MATERIAL}

Table S3.1: Ethogram used for behavioural observations. Behaviours that require a partner are marked with an asterisk.

\begin{tabular}{|l|l|}
\hline Behaviour & Definition \\
\hline climb & move in trees \\
\hline walk & move on the ground \\
\hline forage & Searching for food or feeding \\
\hline drinking & Add source in comment (river, snail shell, tree hole...) \\
\hline rest & Being stationary, without any activities mentioned here \\
\hline huddle* & $\begin{array}{l}\text { sitting in close physical contact (torsos touching/head touching } \\
\text { torso) with } \geq 1 \text { partner }\end{array}$ \\
\hline body contact* & $\begin{array}{l}\text { while resting, body part touching another animal. Add in comment } \\
\text { which part }\end{array}$ \\
\hline groom* & grooming another animals fur \\
\hline be groomed* & being groomed by another animal \\
\hline $\begin{array}{l}\text { reciprocal/mutual } \\
\text { grooming* }\end{array}$ & $\begin{array}{l}\text { taking turns grooming with another animal (if grooming is simulta- } \\
\text { neous or turns are too short to protocol separately) }\end{array}$ \\
\hline autogrooming & grooming self \\
\hline self-scratching & $\begin{array}{l}\text { animal scratches itself at least twice in quick succession with its } \\
\text { hands or feet } \\
1 \text { sec interruption => new bout }\end{array}$ \\
\hline armover* & arm laid over other animal \\
\hline touch animal* & touch another animal with the hands \\
\hline $\begin{array}{l}\text { approach, can't hear } \\
\text { whether grunting } \\
\text { grunting approach/silent } \\
\text { approach* }\end{array}$ & $\begin{array}{l}\text { coming into a radius of } 2 x \text { body length ( 1m) of another individual, } \\
\text { add whether approach is accompanied with a grunt or not }\end{array}$ \\
\hline $\begin{array}{l}\text { be approached, can't } \\
\text { hear whether grunting } \\
\text { be grunting ap- } \\
\text { proached/silent ap- } \\
\text { proached* }\end{array}$ & $\begin{array}{l}\text { another individual approaches focal } \\
\text { add if the one approaching is grunting or not }\end{array}$ \\
\hline
\end{tabular}




\begin{tabular}{|c|c|}
\hline depart* & $\begin{array}{l}\text { leaving the 1-m radius, possible reaction to be approached=be dis- } \\
\text { placed (bdis) }\end{array}$ \\
\hline be departed* & $\begin{array}{l}\text { another individual leaves the } 1 \mathrm{~m} \text { radius around the focal, possible } \\
\text { reaction to approach =displace(dis) }\end{array}$ \\
\hline mate* & (attempt of) mounting, copulation \\
\hline fight* & $\begin{array}{l}\geq 2 \text { animals chasing, hitting, biting each other aggressively } \\
\text { Add in the comments what exactly happens, to be able to compare } \\
\text { the aggression level (chasing, biting, hitting) }\end{array}$ \\
\hline chase* & chasing another animal \\
\hline hit* & hitting another animal \\
\hline bite* & biting another animal \\
\hline flee* & $\begin{array}{l}\text { moving away rapidly from another animal, possible reaction to } \\
\text { chase, hit, bite }\end{array}$ \\
\hline scent-mark anogenital( $\left.{ }^{*}\right)$ & rubbing anogenital region on substrate or another individual \\
\hline scent-mark forehead $(*)$ & rubbing forehead on substrate or another individual \\
\hline overmark(*) & $\begin{array}{l}\text { rubbing anogenital region or forehead on substrate or individual } \\
\text { that was previously marked by another individual }\end{array}$ \\
\hline chewing on branch & excessive, non-foraging chewing on a branch \\
\hline mark with saliva & smearing saliva on substrate (rubbing snout on substrate) \\
\hline mark with arms & rubbing arms on substrate \\
\hline sniff(*) & investigating substrate/animal with the nose, inhaling \\
\hline licking & investigating substrate by licking \\
\hline licking water & licking water from leaves, branches etc. \\
\hline licking sap & licking tree sap \\
\hline licking face* & licking face to face or mouth to mouth with another animal \\
\hline play* & play with another animal \\
\hline yawn* & yawn into the direction of another animal \\
\hline tongue flicking $\left({ }^{*}\right)$ & flicking tongue, add comment who is in $2 \mathrm{~m}$ radius (also observer) \\
\hline duck* & sudden ducking, turning body away from another individual \\
\hline approach human & $\begin{array}{l}\text { coming into a radius of } 2 \mathrm{~m} \text { of a human, stay there for at least } 10 \\
\text { sec }\end{array}$ \\
\hline touch non-food objects & $\begin{array}{l}\text { touching objects like snail shells/backpack with hands (add details } \\
\text { in comment) }\end{array}$ \\
\hline Intergroup encounters & $\begin{array}{l}\text { individuals of the focal group in physical contact with other group } \\
\text { Duration, Group identity (if possible), Location, Details in comment } \\
\text { (fight, etc) }\end{array}$ \\
\hline tail pendulum & swinging the tail while sitting/with croaking \\
\hline defecate & defecate \\
\hline urinate & urinate \\
\hline out of sight & can't see the individual \\
\hline
\end{tabular}


Table S3.2: Model selection

\begin{tabular}{|c|c|c|c|}
\hline & & df & AIC \\
\hline Initiation frequenc & & & \\
\hline Complete dataset & m0: (1 |group) & 2 & 173.24 \\
\hline & sex $+\mathrm{CSI}+$ active & 5 & 155.70 \\
\hline & sex + CSI + drink.exposed & 5 & 157.35 \\
\hline & sex + CSI + FID & 5 & 159.09 \\
\hline & sex + active + FID & 5 & 157.48 \\
\hline & sex + active + drink.exposed & 5 & 156.23 \\
\hline & $\operatorname{sex} *$ CSI & 5 & 149.35 \\
\hline & sex $*$ active & 5 & 155.93 \\
\hline & sex * drink.exposed & 5 & 157.09 \\
\hline & sex * FID & 5 & 158.66 \\
\hline Exploration subset & m0: (1|group) & 2 & 122.54 \\
\hline & sex + exploration & 4 & 93.98 \\
\hline & $\operatorname{sex}+\mathrm{CSI}$ & 4 & 102.82 \\
\hline & sex + active & 4 & 104.11 \\
\hline & sex + drink.exposed & 4 & 110.53 \\
\hline & sex + FID & 4 & 109.64 \\
\hline First follower frequ & & & \\
\hline Complete dataset & m0: (1|group) & 2 & 104.18 \\
\hline & sex $+\mathrm{CSI}+$ active & 5 & 98.07 \\
\hline & sex + CSI + drink.exposed & 5 & 104.07 \\
\hline & $\operatorname{sex}+\mathrm{CSI}+\mathrm{FID}$ & 5 & 103.15 \\
\hline & sex + active + FID & 5 & 98.21 \\
\hline & sex + active + drink.exposed & 5 & 98.34 \\
\hline & $\operatorname{sex} * \mathrm{CSI}$ & 5 & 103.97 \\
\hline & sex $*$ active & 5 & 96.82 \\
\hline & sex $*$ drink.exposed & 5 & 104.08 \\
\hline & sex * FID & 5 & 103.12 \\
\hline & sex + active & 4 & 96.35 \\
\hline & $\begin{array}{l}\text { Interaction sex*active not sig., interaction model not sig. } \\
\text { better }\left(\chi^{2}=1.53, d f=1, p=0.22\right)\end{array}$ & & \\
\hline Exploration subset & m0: (1|group) & 2 & 71.94 \\
\hline & sex + exploration & 4 & 75.13 \\
\hline & $\operatorname{sex}+\mathrm{CSI}$ & 4 & 74.80 \\
\hline & sex + active & 4 & 70.79 \\
\hline & sex + drink.exposed & 4 & 75.44 \\
\hline & sex + FID & 4 & 73.34 \\
\hline
\end{tabular}




\section{ChAPTER 4}

\section{Should I stay or should I go? Individual movement decisions during group departures in red-fronted lemurs}

Anna Lucia Sperber, Peter M. Kappeler, Claudia Fichtel

Royal Society Open Science, 2019, Volume 6, Issue 3, 180991

http://dx.doi.org/10.1098/rsos.180991

Authors' contributions

ALS, PMK \& CF designed the study, ALS collected and analysed the data and drafted the manuscript, CF and PMK participated in writing the manuscript 


\section{ABSTRACT}

Collective movements are essential for maintaining group cohesion. However, group members can have different optimal departure times, depending on individual, social and contextual factors whose relative importance remains poorly known. We, therefore, studied collective departures in four groups of red-fronted lemurs (Eulemur rufifrons) in Kirindy Forest, Madagascar, to investigate the influence of an individual's age, sex, their affiliative relationships and their proximity to other group members at the time of departure on their individual departure decision. We recorded behavioural and spatial data on individual departures during 167 group movements and conducted group scans (181-279 per group) to assess affiliative relationships. All factors influenced individual departures. Both affiliation and proximity determined a mimetic joining process in which dyads with stronger affiliative bonds departed in closer succession, and individuals followed the initiator and predecessors more quickly when they were in closer proximity at departure. While the influence of affiliation is common, the effect of inter-individual distance has rarely been considered in groups with heterogeneous social relationships. Although local rules influenced joining, the overall movement pattern was mainly determined by individual traits: Juveniles took protected central positions, while females made up the van and males brought up the rear. Individual needs, expressed in the departure order, to an extent overruled the effect of affiliation. These results highlight the importance of considering individual, social and contextual factors collectively in the study of collective movements.

Key words: group coordination, collective movements, mimetism, primates, Eulemur 


\section{INTRODUCTION}

Living in a group provides benefits (Alexander, 1974; Silk, 2007; Terborgh, 1983; van Schaik, 1983; Wrangham, 1980), such as a reduced individual predation risk (Hass \& Valenzuela, 2002; Landeau \& Terborgh, 1986; Pulliam, 1973), reduced time spent on vigilance (Fairbanks \& Dobson, 2007) and more efficient foraging, e.g. through information transmission (Krebs, MacRoberts, \& Cullen, 1972; Schnoell \& Fichtel, 2012; Thornton \& Malapert, 2009). To maintain group cohesion, animals normally do not decide independently on activity changes, but rather base their choice on the actions of their group mates. This form of positive feedback, when one individual taking an action makes it more likely for others to do so as well, is called mimetism (Deneubourg \& Goss, 1989). Mimetism has been suggested in several species to determine the joining process of collective departures (King \& Sueur, 2011; Petit \& Bon, 2010). Mimetism can be anonymous, where joining solely depends on the number of individuals who have already left (Petit et al., 2009), or it can be selective. Joining can be shaped by affiliation in that the strength of the social bond between individuals determines how much one's actions are influenced by other's. Affiliative mimetism has been shown to determine following in primates (Jacobs, Sueur, et al., 2011; King et al., 2008; King, Sueur, et al., 2011; Seltmann et al., 2013; Sueur et al., 2011, 2009), ungulates (Briard et al., 2015; Ramseyer et al., 2009, 2009, 2009) and birds (Ramseyer, Petit, et al., 2009b). Joining can also be based on distance, so that individuals are more likely to join a group movement when those in closest proximity to themselves do so. This mechanism has been demonstrated in fish (Ward et al., 2013), domestic geese (Anser domesticus) (Ramseyer, Petit, et al., 2009a), domestic sheep (Ovis aries) (Ramseyer et al., 2009) and anonymous human groups (Faria et al., 2010). It has been termed "local mimetism" by Ward et al. (Ward et al., 2013). However, since anonymous and affiliative mimetism are also considered local rules (King, Sueur, et al., 2011; Sueur et al., 2009), we feel that the word 'local' is ambiguous here. We prefer the term "spatial mimetism" to refer to mimetism based on physical proximity, to emphasize the spatial effect and to clarify that all kinds of mimetism, not only spatial mimetism, can be considered a local rule.

In groups where individuals exhibit heterogeneous social relationships, the effects of affiliation and proximity on joining are hard to discern, as proximity is generally necessary for most affiliative behaviours (for an exception see Kulahci, Rubenstein, \& Ghazanfar, 2015). In Chacma baboons (Papio ursinus), for example, affiliation and spatial association determined the likelihood of individuals following each other (King, Sueur, et al., 2011). The spatial association considered in this study on baboons was, however, the proportion of time individuals spent in proximity as nearest neighbours throughout the observation period, making it difficult to distinguish the 
effects of social affiliation and spatial association. Although most of these studies examined the occurrence of mimetism on a dyadic level, this does not mean that individuals base their decision solely on individuals closest to them or with whom they have stronger social bonds. As highlighted in olive baboons (Papio anubis) through high-resolution GPS tracking data, individuals indeed base their movement decisions on several neighbouring individuals (Farine et al., 2016).

In general, an individual's departure time relative to the other group members' determines their position in the movement order. Since different positions have different advantages and disadvantages, the decision on when to leave is also influenced by individual, nonmutually independent factors, such as vulnerability and nutritional needs (Morrell \& Romey, 2008), which largely depend on the individual's age and sex. Moving groups often display a "protective travel order" (Wright, 1998), with the most vulnerable group members in the centre. Since the van and rear of a group are exposed to a higher average predation risk, less vulnerable individuals may serve as a van- and rearguard (e.g. Barelli et al., 2008). The van is a high-risk but also a high-payoff position. Due to the "finder's advantage"(Vickery et al., 1991), specific or high nutritional needs (Boinski, 1988; Rothman et al., 2008; Sauther, 1994) can be met more easily in this position (DeBlois \& Rose, 1996; Di Bitetti \& Janson, 2001; Fischhoff et al., 2007; Krause, 1993; Krause, Reeves, et al., 1998).

Since individual, social and contextual factors can all affect the choice of departure time, they have to be considered together to understand departure decisions in collective movements. However, only a few studies of collective departures have considered contextual factors, such as the spatial positions of group members, at all (for an overview of those studies that have included a spatial factor, see Table 4.1 at the end of the chapter). It is even rarer that studies investigated the effects of both proximity and affiliative relationships on following, and when they did, the measures were often conflated. Furthermore, these local rules are usually considered separately from the global effect of ecological factors, as expressed in an individual's position in the departure order.

Thus, to investigate the interacting effects of individual, social and contextual factors on individual departure decisions, we studied group departures in wild red-fronted lemurs (Eulemur rufifrons). Red-fronted lemurs live in small multi-male multi-female groups and are relatively egalitarian and socially tolerant Malagasy primates (Pereira et al., 1990). They are cathemeral and arboreal but travel and forage regularly on the ground. Adult females lead group movements most frequently, but leadership is variable (Erhart \& Overdorff, 1999; Pyritz, Kappeler, et al., 2011). As group living in lemurs is the result of convergent evolution with other primate taxa (Kappeler, 1999), studying lemur group coordination processes provides a valuable comparative perspective 
to begin identifying general principles in this context, at least for primates. We, therefore, examined the influence of age, sex, proximity at departure and affiliative relationships on individual departure decisions in collective movements. If red-fronted lemurs exhibit affiliative mimetism in group departures, we predicted individuals would preferentially follow those group members they were more strongly affiliated with. By contrast, we predicted individuals would preferentially follow those in closer spatial proximity if following is guided by spatial mimetism. If differences in needs affect individual departure decisions, we predicted red-fronted lemurs of different ages and sex to take up different positions in the departure order corresponding to the positions' advantages and disadvantages. 


\section{MATERIAL AND METHODS}

\section{Study site and Subjects}

The study was conducted at the field site of the German Primate Center in Kirindy Forest, Western Madagascar. The 60 ha study site is situated in a dry, semi-deciduous forest within a forestry concession operated by the Centre National de Formation, d'Etudes et de Recherche en Environnement et Foresterie (Kappeler \& Fichtel, 2012a). Several natural predators of red-fronted lemurs are present at this site, and the animals are not supplemented with food or water. We studied four groups of red-fronted lemurs, with a total of 31 individuals ((group A: 3 females, 3 males, 2 juveniles; group B: 2 f, 2 m, 2 j; group F: 2 f, 2 m, 2 j; group J: 4 f, $3 \mathrm{~m}, 4$ j). Study animals are individually marked and are well habituated to observers, as they are part of a long-term study (Kappeler \& Fichtel, 2012b).

\section{Data Collection}

Data were collected from April to September 2014. Observations were conducted mainly between 8:00 - 11:00 and 14:00 - 17:00h, since groups usually rest during midday (Kappeler \& Erkert, 2003). We observed one focal group per half-day, and morning and afternoon observation sessions were balanced among groups. Observations were recorded with a handheld computer (Psion Workabout Pro 3).

\section{Group departures}

Group departures were recorded with all-occurrences sampling, following the definitions of Pyritz et al. (2011). An initiator was defined as an individual who after being "stationary for $\geq 4 \mathrm{~min}$ moved $\geq 15 \mathrm{~m}$ away from [the other] group members in a directed manner without pausing" (Pyritz, Kappeler, et al., 2011, p. 1332). An initiation attempt was considered successful if at least one follower (apart from dependent offspring) was recruited. A follower was defined as an individual who left $\leq 10 \mathrm{~min}$ after the initiator and whose "movement diverged $\leq 45^{\circ}$ from the trajectory of the movement of the initiator" (Pyritz, Kappeler, et al., 2011, p. 1332).

We disregarded group movements caused by mating or intergroup conflicts. We treated all group movements as independent events for statistical analyses ( $n=167$ successful group movements, group $\mathrm{A}: \mathrm{N}=49$, group $\mathrm{B}: \mathrm{N}=37$, group $\mathrm{F}: \mathrm{N}=35$, group $\mathrm{J}: \mathrm{N}=46$ ). Failed initiations, where no followers were recruited and the initiator returned to the group within $10 \mathrm{~min}$, were extremely rare $(n=2)$ and excluded from the analysis. During group departures, we noted the identities of initiators and followers and the timing of individual departures. Whenever possible, 
we also recorded the distances between the initiator and the other group members at the time of initiation and the distances between followers succeeding each other. Distance was estimated in five categories: $0-1 \mathrm{~m}, 1-3 \mathrm{~m}, 3-5 \mathrm{~m}, 5-10 \mathrm{~m}$ and greater than $10 \mathrm{~m}$.

To quantify the travel association of each dyad, we calculated their inter-departure interval (IDI) as their average difference in departure time across all movements, adjusted for the mean difference in departure time per movement (Eq. 1). A dyad often following each other in close succession would therefore have a short IDI.

$I D I_{x y}=\frac{\sum_{i=1}^{n} \frac{\mid \text { departure time }_{x i}-\text { departure time }_{y i} \mid}{\text { mean departure time difference } i}}{n}$

\section{Affiliation}

To characterise affiliative relationships, we conducted group scans every $15 \mathrm{~min}$ when the group was stationary and recorded the activity and social interactions of all visible animals. Grooming and huddling were used as measures of affiliation. Grooming was defined as at least one individual grooming another (repeated strokes over the partner's pelage with the toothcomb and/or tongue) or both individuals grooming each other simultaneously. Huddling was defined as the individuals being in contact with their torsos or head to torso in a resting context. For each dyad, we calculated the proportion of scans in which they were grooming or huddling, corrected for the number of scans in which both individuals were observed (number of scans: group A: total 199 scans (ranging from 130 - 172 per dyad), group B: total 200 scans (ranging from160 - 187 per dyad), group F: total 181 scans (ranging from 134 - 167 per dyad), group J: total 279 scans (ranging from 166 206 per dyad). As an index of a dyad's affiliation we calculated the dyadic composite sociability index (DSI, Eq. 2) following Silk et al. (2013).

$D S I_{x y}=\frac{\left(\frac{\text { grooming }_{x y}}{\text { grooming group mean }}+\frac{\text { huddling }_{x y}}{\text { huddling group mean }_{\text {mea }}}\right)}{2}$

\section{Statistical analyses}

All analyses were conducted in R Version 3.0.2 (R Core Team, 2014). Frequentist linear models were fit using the package ImerTest (Bates, Mächler, et al., 2015; Kuznetsova et al., 2015) and were chosen according to lowest Akaike information criterion (AIC) (Akaike, 1973). Bayesian linear models were fit using the package MCMCgImm (Hadfield, 2010) and chosen according to lowest deviance information criterion (DIC) (Spiegelhalter, Best, Carlin, \& Van Der Linde, 2002). The significance level was set at 0.05 , and results from the linear models were corrected for multiple 
testing using the Holm correction (Holm, 1979), unless they were compared using a multiple comparison procedure.

\section{Group cohesion}

To characterise the degree of group cohesion, we calculated the median latency to join the movement. Furthermore, we analysed the distribution of the number of departures according to the number of followers (how often how many individuals followed the initiator) within groups, using a Chi²-test. A heterogenous distribution of the frequency of number of followers would indicate an all-or-nothing process and a cohesive group, whereas a homogenous distribution would be caused by clustering into sub-groups (Sueur, 2011). We also estimated the effect of group size on the time until the last follower joined the movement, considering only departures in which the entire group followed $(n=106)$. We fit a LMM with the last follower latency as the response, group size as a fixed factor and initiator and last follower ID as random factors.

\section{Individual factors}

To assess the influence of individual factors on departure order, we tested the distribution of agesex classes (juveniles ( $<2.5$ years), adult males and adult females) across the departure order. To be able to combine the data from differently sized groups, we grouped departure ranks into the position categories "van", "centre" and "rear". Van and rear were defined as the two first and two last movers, respectively, whereas the size of the centre category differed between groups (range 2-7 individuals, Fig. S4.1 \& S4.2). We furthermore included the option "not joined" as a position category for the departures in which an individual did not participate in the movement. We fit a linear model for the number of times an individual had been observed in each position category divided by the individual's total number of departures. We excluded the intercept to allow for an easier comparison of the effects (Bretz et al., 2010; Hothorn, 2016) and included group and a factor combining age-sex class and position category as fixed factors. We then used multiple comparisons (package multcomp (Hothorn et al., 2008)) to test for differences between juveniles, adult males and adult females within position categories.

\section{Interactions between individual, social and contextual factors}

If individuals of the same age class or sex travel together, this assortativity could be due to similar requirements regarding nutrition or safety from predation. However, it could also be caused by affiliative or spatial mimetism, if affiliative bonds and proximity to the initiator are not random 
with regard to the age class and sex of an individual. To discern these effects, we tested for interactions between these factors.

To determine the effects of individual traits on affiliative bonds, we calculated the weighted assortativity coefficient for age-sex classes (juveniles, adult males and females) in the affiliation network of each group using the package assortnet (Farine, 2014). To examine the effect of an animal's age-sex class on its proximity to the initiator at initiation we fit a LM with an individual's number of observations in a distance category divided by their overall number of observations as the response ( $n=237$ observations). We included group and a factor combining age-sex class and distance category as fixed factors and excluded the intercept to allow for an easier comparison of the effects. We used multiple comparisons (package multcomp (Hothorn et al., 2008)) to test for differences between age-sex classes in their occurrence in the distance categories 0 $1 \mathrm{~m}$ and $>10 \mathrm{~m}$, since differences in occurrence in these extremes of the recorded range would have the biggest effect.

\section{Variation in affiliation strength}

We assessed how evenly distributed affiliative contacts were across group members by inspecting the distribution of the DSI across dyads $(n=113)$. The variation in relationship strength between dyads is expressed in the skewness of the distribution curve, which can be gauged by comparing the curve's mean and median (Haunhorst, Schülke, \& Ostner, 2016; Kalbitz, Ostner, \& Schülke, 2016; Silk, Altmann, \& Alberts, 2006).

\section{Social and contextual factors}

Our aim was to assess the influence of affiliation and proximity on following behaviour. To control for a potential covariation between the two factors, and to determine other influences on proximity, we fit a Bayesian GLMM, regressing a dyad's proximity at departure on their DSI and the age-sex class of the individuals (juvenile-juvenile, female-female, female-male, female-juvenile, male-male, male-juvenile). We included group as a fixed factor, event ID as a random factor and dyad ID as a multiple membership random factor. The multiple membership approach was chosen to acknowledge the fact that each individual was part of several dyads. The model contained both the distance to the initiator and to the predecessor ( $n=347$ observations).

Since affiliation and proximity at departure were not independent, we assessed the effects of affiliation and proximity separately. This allowed us to make use of the much bigger sample size for affiliation and to choose a measure which likely better represents the way a factor would affect following. One problem in testing for an influence on followership is that the animal an individual 
is closest to in departure time may not actually be the one it is following. For affiliation, we addressed this problem by inspecting the IDIs for all group members. This was possible since data on affiliation were available for all dyads and were naturally the same for all departures. A similar approach could not be used for proximity, however, since recording the distances between all group members was not always possible due to the quick succession of followers. We therefore restricted our data collection and analyses to the distance of followers to the initiator and to the direct predecessor.

The effect of affiliation on following was tested as the influence of the DSI of a dyad on their IDI. We fit a Bayesian GLMM on data from all four groups ( $n=113$ dyads), regressing dyad IDI on dyad DSI. We included group as a fixed factor and dyad as a multiple membership random factor. The age-sex classes of a dyad were also included as a random factor.

To assess the influence of spatial proximity on following, we fit two LMMs regressing the latency in following an individual on the proximity to it. The response was the following latency, divided by the mean of the following latencies of the departure event (square-root transformed in the first model and log-transformed in the second model). In the first model, the latency considered was the latency in following the predecessor (including the initiator). We included the distance to the predecessor and the age-sex class (juvenile, adult female, adult male) of the follower as fixed factors and predecessor ID, follower ID, event ID as well as number of predecessors nested in group size as random factors. In the second model, the latency considered was the latency in following the initiator. We included the distance to the initiator and the age-sex class of the follower as fixed factors and initiator ID, follower ID, event ID as well as group size as random factors.

To avoid a biased sample, we only included departures in the distance analysis for which the distance data for all followers had been recorded. Due to the difficult observation conditions with agile animals in a forest setting, applying this criterion greatly reduced our dataset. For the distance to the predecessor we retained 234 following events in 46 departures and for distance to the initiator we retained 159 following events in 33 departures. 


\section{RESULTS}

\section{Strong group cohesion}

The median latency in joining the initiator was 96s (IQR 33s - 217s). The latency from initiation to the last follower increased with group size (estimate $+\mathrm{SE}: 22.86+7.50, \mathrm{df}=18.66, \mathrm{t}=3.05, \mathrm{p}=$ 0.007, test against null model: $\chi^{2}=7.57, d f=1, p=0.006$, Fig. 4.1).

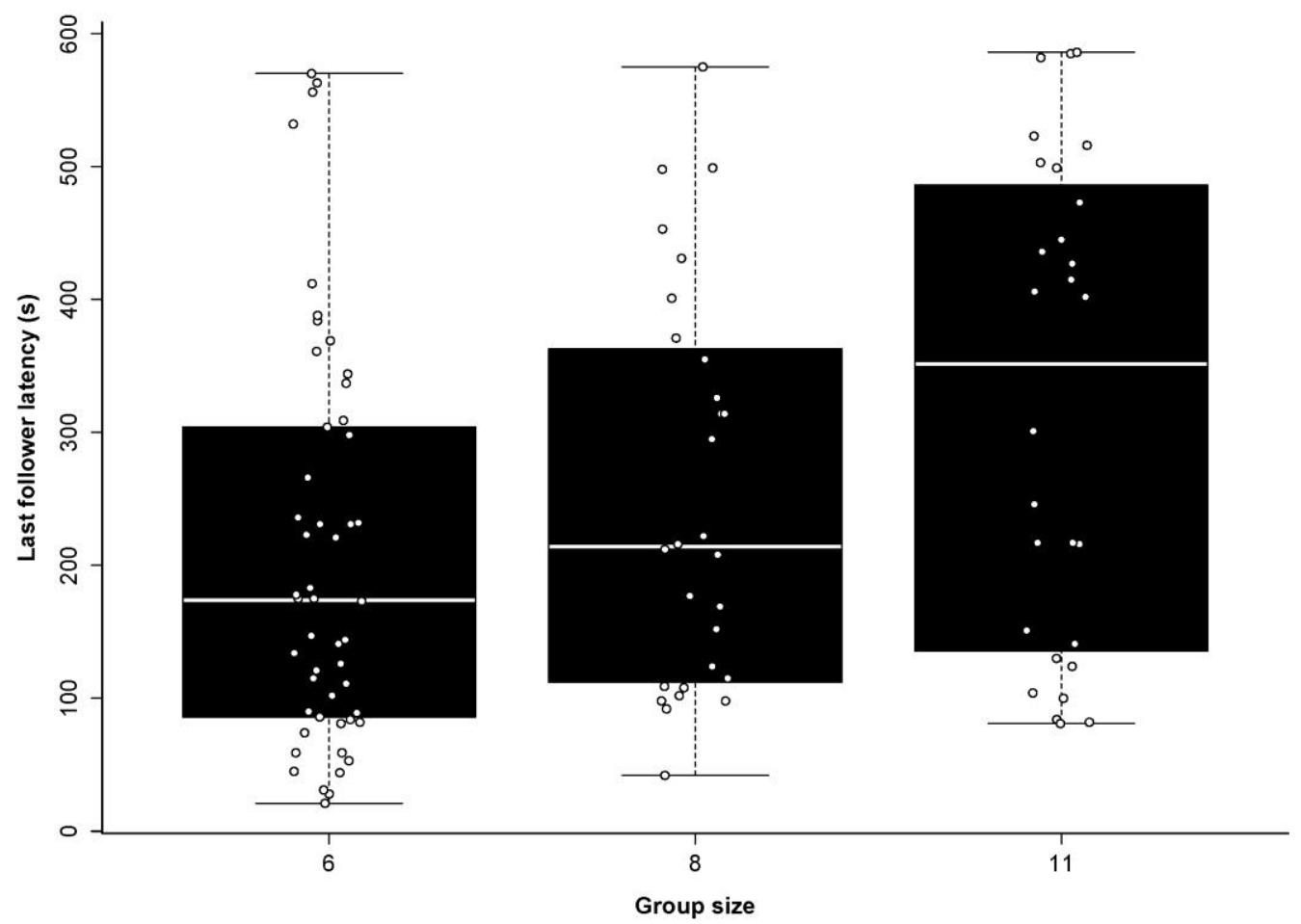

Figure 4.1: Boxplots with datapoints of joining latencies of the last followers as a function of group size. Group size 6 includes groups B \& F. Only movements in which the whole group followed were considered ( $n=106$ movements; group $A=28, B=25, F=25, J=28$ ).

The number of followers recruited per movement was not homogeneously distributed (Group A: $\chi^{2}=82, d f=6$, Group B: $\chi^{2}=42.46, d f=3$, Group F: $\chi^{2}=72.29, \mathrm{df}=4$, Group J: $\chi^{2}=116.39$, $d f=8, p<0.0001$ for all groups), but left-skewed (Fig. 4.2). Hence, most of the successful initiations of group movements (64.67\%) recruited the entire group. Failed initiations, where no followers were recruited and the initiator returned to the group within $10 \mathrm{~min}$, were extremely rare (on average less than $1 \%$ of all observed initiations). 

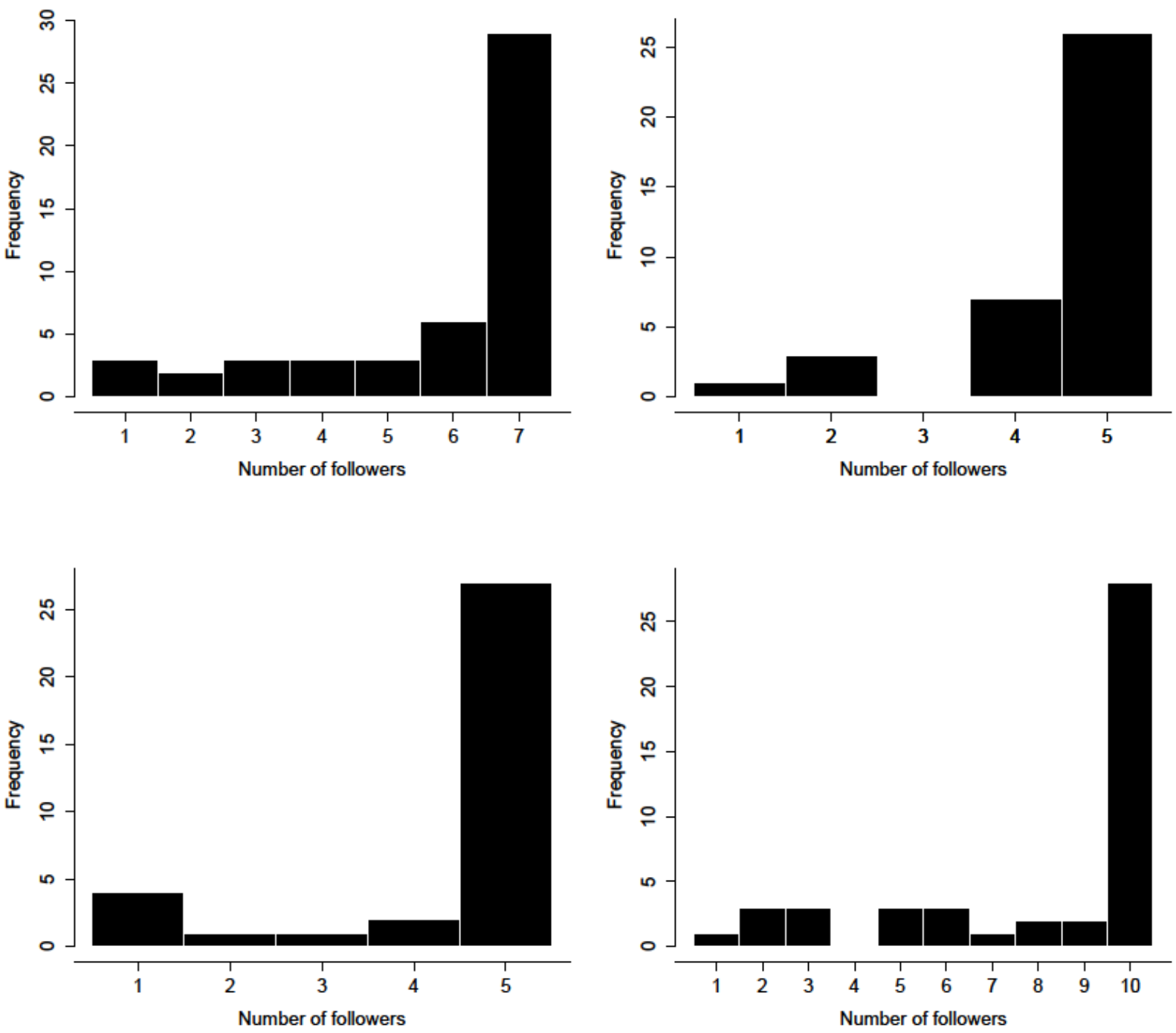

Figure 4.2: Frequency of follower numbers in group departures in groups A (top left), B (top right), F (bottom left) \& J (bottom right). Most successful initiations recruited the entire group.

\section{Age class and sex affect departure position}

Juveniles, adult males and adult females differed significantly in their departure positions. Females were observed significantly more often in the van of the departing group than juveniles and males. The females' distribution on departure ranks (Fig. S4.2) shows that females are not only more often in the van because they initiate group movements most frequently, but that they generally cluster on the lower ranks and thus make up the whole vanguard of a movement. In the centre, juveniles were observed more often than both adult males and females. Males were observed significantly more often in the rear than females, but not more often than juveniles (Fig. 4.3 \& Table S4.2). 


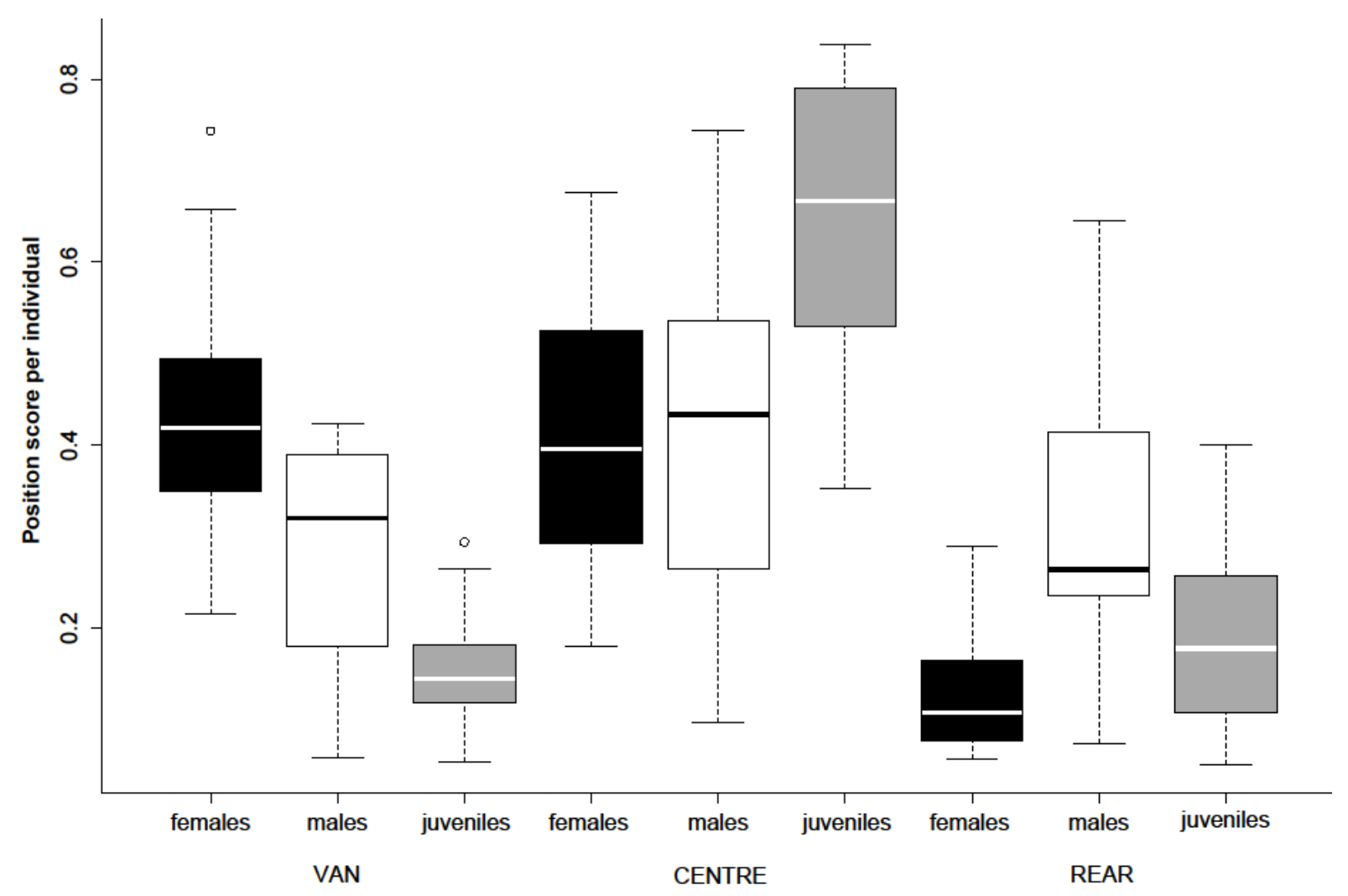

Figure 4.3: Boxplots of departure positions based on age and sex. Position scores were calculated as the observations of an individual in a position divided by the total number of times the individual was observed in a movement. Females are depicted in black, males in white and juveniles in grey.

The assortativity by age class and sex in the departure order cannot result solely from affiliation or proximity. The affiliation networks were not assorted by age-sex classes; instead they tended towards disassortativity (Table S4.3). Regarding proximity, age classes and sexes did not differ in their occurrence in the $0-1 \mathrm{~m}$ distance category from the initiator, nor age classes in the $>10 \mathrm{~m}$ distance category. However, adult males were observed proportionally more often than adult females in the $>10 \mathrm{~m}$ distance category from the initiator (Table S4.4).

\section{Affiliative and spatial mimetism influence joining}

The distribution of the DSI across dyads was strongly right-skewed (Fig. S4.4), as demonstrated by the large difference between the mean of 1 (by definition of the DSI) and the median of 0.38 . Furthermore, only $32 \%$ (36) of the dyads had DSI values larger than the mean. These results indicate that dyads differed strongly in the strength of affiliative bonds. Dyads with a higher DSI were observed at closer proximity at departure (post. mean: $-0.61, \mathrm{Cl}:-1.10$ to -0.20 , ESS: 45.5 , pMCMC: 0.002 ), whereas the age-sex class combination of the dyad had no effect on the proximity (Figure S 4.3 \& Table S 4.1). 
The affiliation of a dyad had a significant effect on their IDI. A higher DSI was associated with a shorter IDI (post. mean: -0.02, Cl: -0.04- -0.01, ESS: 1000, pMCMC: 0.002, Table 4.2).

Table 4.2: Results for the MCMC GLMM regressing a dyad's inter-departure interval on its dyadic composite sociability index (DSI).

Post. mean $\mathrm{Cl}$ lower $\mathrm{Cl}$ upper Eff. sample size $\mathrm{p} \mathrm{MCMC}$

$\begin{array}{llllll}\text { (Intercept) } & 1.01 & 0.80 & 1.19 & 1292.00 & <0.001 \\ \text { DSI } & -0.02 & -0.04 & -0.01 & 1000.00 & 0.002 \\ \text { group B } & 0.01 & -0.25 & 0.29 & 1000.00 & 1.00 \\ \text { group F } & 0.01 & -0.28 & 0.26 & 1000.00 & 1.00 \\ \text { group J } & 0.01 & -0.25 & 0.21 & 1000.00 & 1.00\end{array}$

The reference level is group A.

Table 4.3: Results for the fixed effects from the predecessor and the initiator LMs (distance categories $0-1 \mathrm{~m}, 1-3 \mathrm{~m}, 3-5 \mathrm{~m}, 5-10 \mathrm{~m}$ and $>10 \mathrm{~m}$ ).

\begin{tabular}{|c|c|c|c|c|c|}
\hline & Estimate & Std. Error & df & $t$ value & $\operatorname{Pr}(>|t|)$ \\
\hline \multicolumn{6}{|l|}{ Latency to predecessor } \\
\hline (Intercept) & 0.64 & 0.09 & 71.28 & 7.46 & $<0.001$ \\
\hline distance predec 1-3m & 0.11 & 0.09 & 210.43 & 1.14 & 0.38 \\
\hline distance predec 3-5m & 0.13 & 0.10 & 215.48 & 1.32 & 0.38 \\
\hline distance predec $5-10 \mathrm{~m}$ & 0.16 & 0.10 & 213.81 & 1.54 & 0.38 \\
\hline distance predec $>10 \mathrm{~m}$ & 0.31 & 0.12 & 222.07 & 2.66 & 0.03 \\
\hline adult female & 0.20 & 0.08 & 21.81 & 2.53 & 0.04 \\
\hline adult male & 0.14 & 0.08 & 20.35 & 1.82 & 0.08 \\
\hline
\end{tabular}

Test against null model: $\chi^{2}=16.53, \mathrm{df}=6, \mathrm{p}=0.01$

The reference levels are distance predecessor 0-1m and age-sex category juvenile.

\section{Latency to initiator}

$\begin{array}{llllll}\text { (Intercept) } & 0.50 & 0.07 & 70.85 & 6.79 & <0.001 \\ \text { distance ini 1-3m } & 0.09 & 0.08 & 149.74 & 1.08 & 0.28 \\ \text { distance ini 3-5m } & 0.18 & 0.08 & 146.29 & 2.13 & 0.07 \\ \text { distance ini 5-10m } & 0.20 & 0.08 & 146.91 & 2.54 & 0.04 \\ \text { distance ini >10m } & 0.25 & 0.08 & 150.83 & 3.16 & <0.01 \\ \text { adult female } & -0.04 & 0.07 & 23.81 & -0.50 & 1.00 \\ \text { adult male } & 0.02 & 0.08 & 24.79 & 0.22 & 1.00\end{array}$

Test against null model: $\chi^{2}=13.36, \mathrm{df}=6, \mathrm{p}=0.04$

The reference levels are distance initiator $0-1 \mathrm{~m}$ and age-sex category juvenile.

Distance increased the following latency (Table 4.3). The latency to follow the predecessor was significantly higher at $>10 \mathrm{~m}$ distance than in $0-1 \mathrm{~m}$ distance to the predecessor (Fig. 4.5A). The latency to follow the initiator was significantly higher at 5-10 $\mathrm{m}$ and $>10 \mathrm{~m}$ distance than in $0-1 \mathrm{~m}$ distance to the initiator (Fig. 4.5B). Juveniles followed their predecessors significantly more quickly than adult females, whereas age and sex of the follower had no influence on the latency to follow the initiator. 

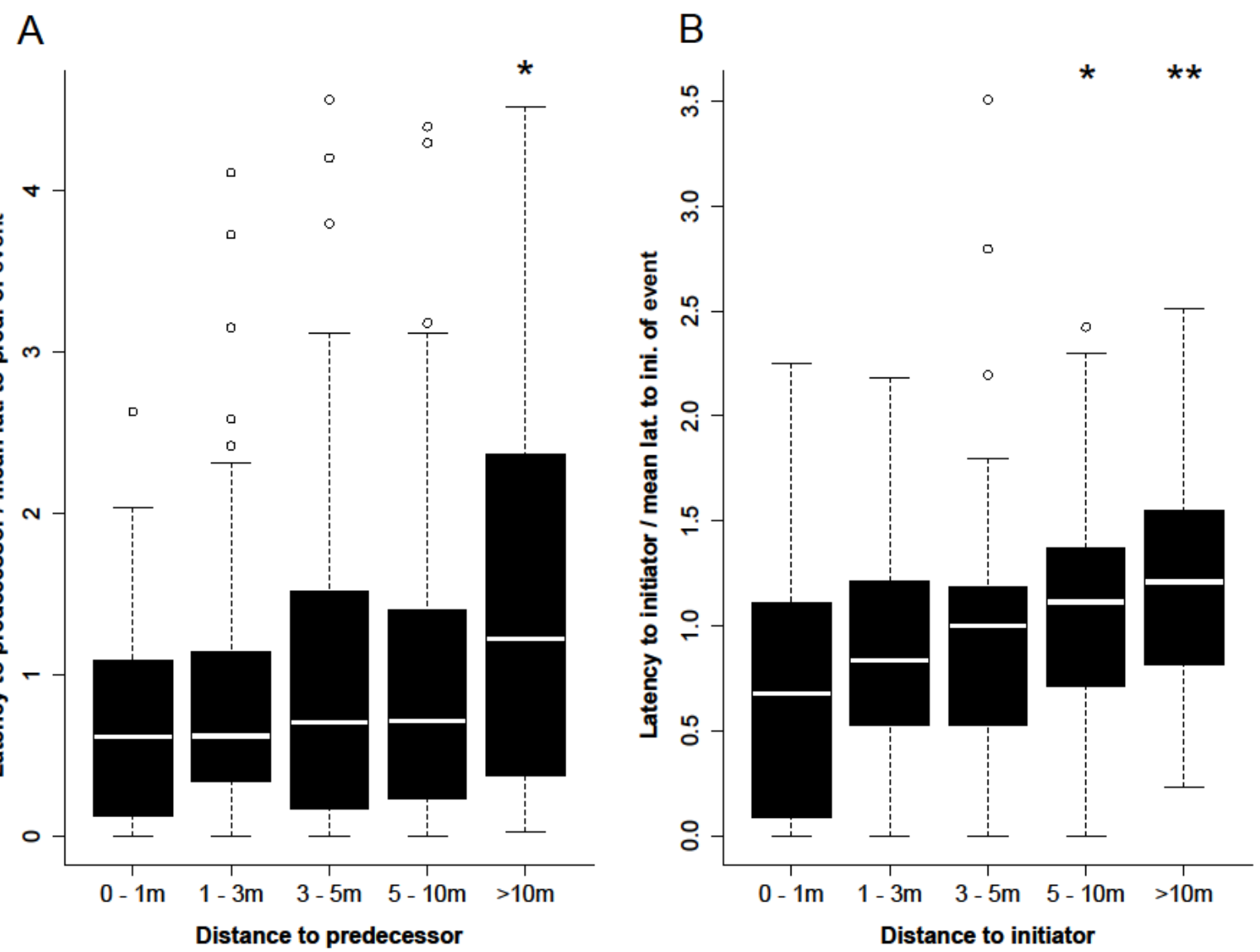

Figure 4.5: Latency in following the preceding animal (A) or the initiator (B) as a function of distance. The latency was calculated as the latency of an individual following its predecessor (A) or the initiator (B) divided by the mean latency of group members following their predecessor or the initiator of the movement event. Distance categories marked with asterisks differ significantly from the $0-1 \mathrm{~m}$ category $\left({ }^{*}=p<0.05,{ }^{* *}=p<0.01\right)$. 


\section{DISCUSSION}

We examined the effects of individual, social and contextual factors on the departure process of collective movements in red-fronted lemurs. To this end, we tested the influence of age, sex, proximity at departure and affiliative relationships on departure decisions. Sex and age determined the position in the departure order, with adult females departing more often in the van, juveniles in the centre and adult males in the rear of the group. Joining was a mimetic process guided by both affiliation and distance to the initiator and predecessor.

\section{Strong group cohesion}

Red-fronted lemurs followed initiators quickly; in most cases the whole group joined the movement and initiations rarely failed. Hence, red-fronted lemurs exhibit strong group cohesion. This effective group coordination may be facilitated by the vocal coordination of departure time. Group departures in red-fronted lemurs are preceded by a pre-departure period in which the rate of close calls ("grunts") of initiators and followers increases significantly, suggesting that these vocalisations may serve to determine departure time (Sperber et al., 2017). In addition, the latency from initiation to the last joiner increased with group size, suggesting that a longer duration of the recruitment process might be a cost of living in larger groups.

\section{Age class and sex determine departure order}

Age and sex affected the individual decision on departure, which underscores the importance of considering individual variation in the context of collective action (Farine, Strandburg-Peshkin, Couzin, Berger-Wolf, \& Crofoot, 2017). In comparison to adults, juveniles were less likely to be in the van of the departing group and more likely to be in the centre. This observation is in line with the "protection theory" (Rhine, 1975; Sueur \& Petit, 2008a): Since the van and rear of a moving group are positions of high predation risk, many species exhibit a "protective travel order" (Wright, 1998) in which juveniles or other vulnerable individuals are situated in the group's centre as shown in African buffalo (Syncerus caffer) (Prins, 1989), lions (Panthera leo) (Holekamp et al., 2000), and several primate species (reviewed in Fichtel, 2012).

Adult females were significantly more often in the van of the departing group than males and juveniles. The females' predominance in the van might be due to higher average nutritional needs, since this position may offer better feeding opportunities, as shown in fish schools (DeBlois \& Rose, 1996; Krause, 1993; Krause, Reeves, et al., 1998) and capuchin monkeys (Cebus capucinus) (Di Bitetti \& Janson, 2001). Adult males left more often in the rear than females, possibly 
functioning as a rear guard. However, given that there was no difference between adults and juveniles leaving in the rear, the rear guard explanation seems unlikely. Instead, spatial mimetism offers a more likely explanation as males were generally observed at a greater distance from the initiator than females and would consequently follow later. Thus, the adult individuals' distribution across departure positions could also be influenced by their spatial distribution. Affiliative mimetism, however, cannot explain the observed assortment by age class and sex in the departure order because affiliative bonds tended to be disassortative, for age classes as well as for sexes.

\section{Affiliative mimetism in joining}

Joining was a mimetic process and depended both on affiliative relationships and proximity between individuals. Affiliation had a significant effect on the inter-departure interval of dyads, with more strongly affiliated individuals having shorter IDIs and thus joining movements in faster succession. Affiliative mimetism in group departures has also been reported for the closely related brown lemurs (Eulemur fuvus) (Jacobs, Sueur, et al., 2011). It is a shared trait between lemurs and anthropoid primates (Tonkean macaques (Macaca tonkeana) (Sueur et al., 2011, 2009), Chacma baboons (King, Sueur, et al., 2011), Barbary macaques (Seltmann et al., 2013), Tibetan macaques (Macaca thibetana) (Wang et al., 2016)) and diverse other species, including domestic sheep (Ramseyer et al., 2009, 2009), domestic geese (Ramseyer, Petit, et al., 2009b), cattle (Bos taurus) (Ramseyer et al., 2009, 2009) as well as domestic horses (Equus caballus) (Briard et al., 2015).

\section{Spatial mimetism in joining}

The latency to join a movement was determined by spatial mimetism, as initiators and predecessors were followed more quickly by individuals in closer proximity. The influence of proximity was not purely an effect of movement information becoming available later to individuals farther away, since red-fronted lemur groups are highly cohesive and group members are usually in visual or acoustic contact with each other (Pyritz, Kappeler, et al., 2011) and coordinate departure times vocally (Sperber et al., 2017).

Proximity affecting movement coordination is a mechanism generally associated with large, anonymous groups, where individuals adjust their movements to their closest neighbours, leading to coordinated movements of the whole group (Couzin \& Krause, 2003). Similarly, spatial mimetism at departure has been show in anonymous human groups for pedestrian road crossing behaviour, where an individual's likelihood to cross the road increased when their next neighbour started crossing (Faria et al., 2010). Still, an effect of proximity on group movements can also be 
found in individualised groups. In cattle, for example, recruitment success increased when more individuals were in close proximity to the initiator (Ramseyer et al., 2009). Likewise, being in the core rather than on the edge of the group had a positive effect on initiation success in white-faced capuchins (Leca et al., 2003) as well as on recruitment success in Rhesus macaques (Macaca mulatta), but not in Tonkean macaques (Sueur \& Petit, 2008b). Moreover, spatial proximity can influence an individual's choice of travel direction during group movements. In olive baboons, nearest neighbours predict an individual's location in the short term, whereas over the long term it is determined by affiliative relationships. (Farine et al., 2016).

The influence of inter-individual distance at departure on the timing of departure decisions has rarely been studied (Table 4.1). Where it has been studied, results are in line with our study in red-fronted lemurs. Domestic geese and sheep show affiliative and spatial mimetism, with initiators being followed first by animals in close proximity, which are also their preferred partners (Ramseyer et al., 2009; Ramseyer, Petit, et al., 2009a).

Spatial mimetism is a simple and advantageous mechanism because mimicking animals close to oneself allows an individual to benefit from public information while saving on monitoring effort and processing power (Herbert-Read et al., 2011). Furthermore, it is adaptive, since the neighbours' situation is similar to an individual's own. The information a neighbour is acting upon is thus likely relevant for the individual as well, they could for example be aware of a better alternative foraging patch (Hewitson, Gordon, \& Dumont, 2007). In addition, if proximity is not circumstantial, but rather the result of preferential association, maintaining this proximity may be the goal itself.

\section{Interdependence of proximity and affiliation}

The effects of affiliation and proximity are generally difficult to discern. In our study we assessed affiliation independently from the group movement context. Still, dyads that were more closely affiliated were also closer to each other directly before departures. The interdependence of affiliation and proximity is rarely considered in studies on affiliative mimetism. In fact, it is possible that in many cases a measure of affiliation unwittingly acts as a proxy for the distance between individuals and the reported affiliative mimetism could be explained more parsimoniously as spatial mimetism. However, this has no strong implications for the essential role of affiliative relationships in group decisions: Either an individual is preferentially following those it has a strong affiliative relationship with, or the individual follows according to proximity, and proximity is the result of preferential association. In the end, affiliative relationships determine the individual's movement decision, whether directly or indirectly (King \& Fürtbauer, 2017). Either way, the cognitive 
skills necessary for affiliative mimetism, such as individual recognition and differentiated social relationships, would still be required (Jacobs, Sueur, et al., 2011). Despite their interdependence, it is possible to see nuances in the effects of affiliation and proximity on movement decisions. In Chacma baboons, group members "follow 'friends', but preferentially those friends that are in closest proximity." (King, Sueur, et al., 2011, p. 1342). Olive baboons, however, follow neighbours, but preferentially those who are their friends (Farine et al., 2016).

\section{Conclusions}

In red-fronted lemurs, individual decisions during departures in collective group movements depend on both contextual and social factors, as following is mimetic and influenced by spatial proximity as well as affiliative relationships. However, departure decisions are also influenced by individual traits. This effect is evident in the departure order, which reveals clear positional preferences by different ages and sexes. Working towards uncovering the mechanisms behind the process of group departures, it is thus important to consider individual, social and contextual factors together to understand why an individual chooses to leave at a certain time. 


\begin{tabular}{|c|c|c|c|c|c|c|}
\hline 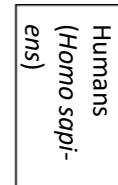 & & 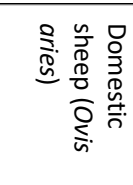 & 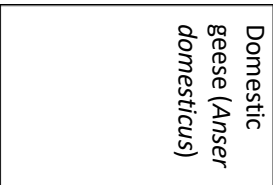 & 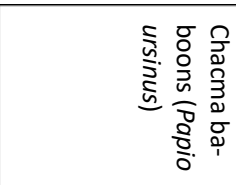 & 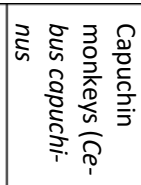 & $\begin{array}{l}\frac{n}{0} \\
\frac{0}{0} \\
\frac{0}{0} .\end{array}$ \\
\hline$\underline{\underline{a}}$ & & 疍 & 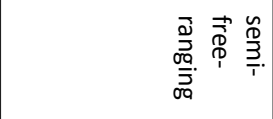 & $\underline{\underline{a}}$ & 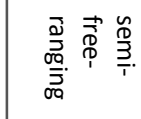 & $\begin{array}{l}\stackrel{0}{0} \\
\stackrel{ \pm}{ \pm} \\
\text { 今. }\end{array}$ \\
\hline 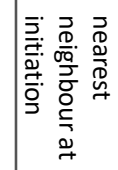 & 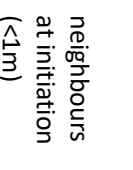 & 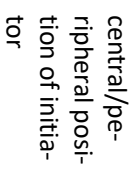 & 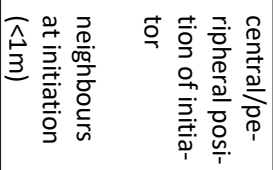 & 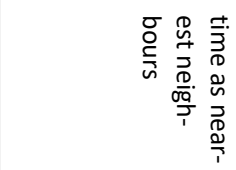 & 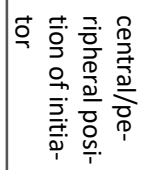 & 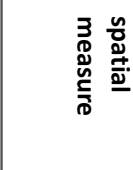 \\
\hline 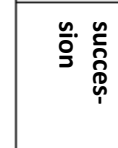 & 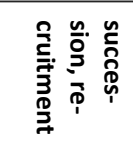 & 裉 & 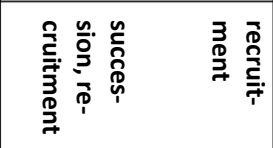 & 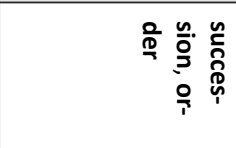 & 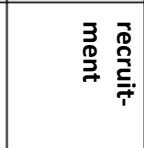 & 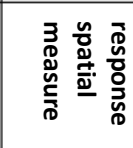 \\
\hline & & ' & & 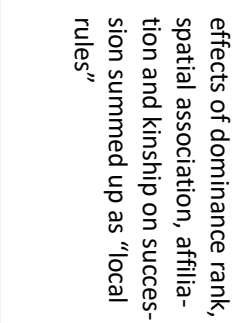 & & 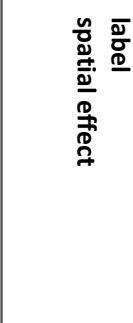 \\
\hline '* & & 总. & 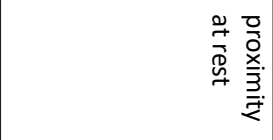 & 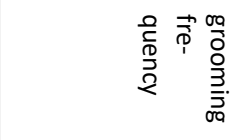 & & 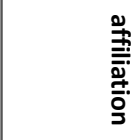 \\
\hline & & 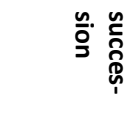 & 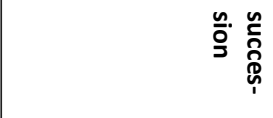 & 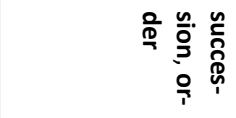 & & 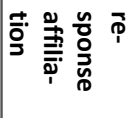 \\
\hline 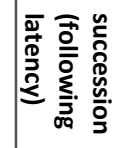 & & '* & '* & 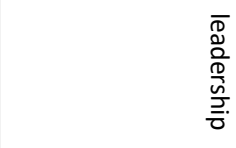 & 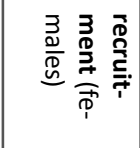 & $\tilde{\mathscr{x}}$ \\
\hline & & '* & '* & 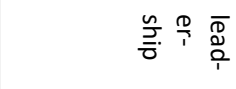 & & ฆั \\
\hline '* & & 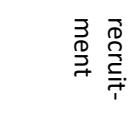 & & 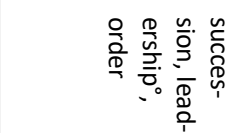 & 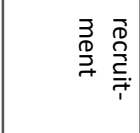 & 突 总 \\
\hline & & 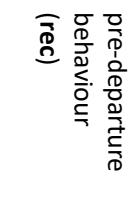 & 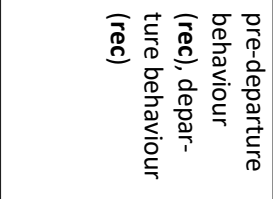 & 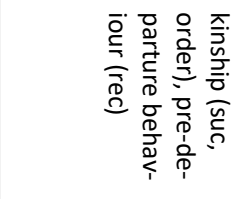 & 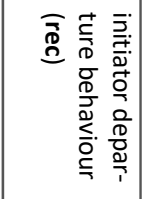 & 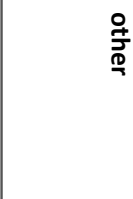 \\
\hline 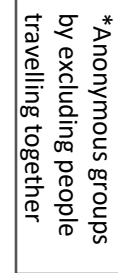 & & 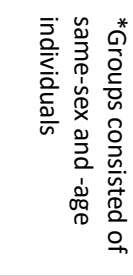 & 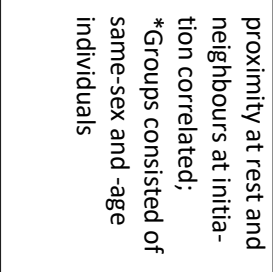 & 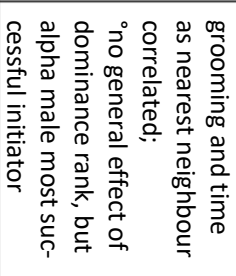 & & 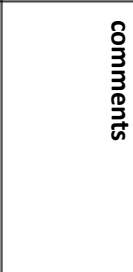 \\
\hline 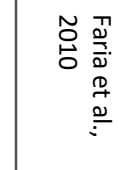 & & 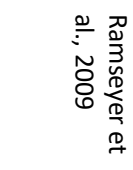 & 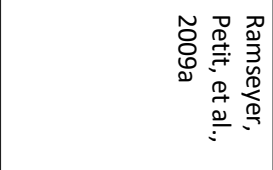 & 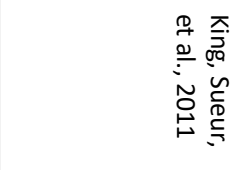 & 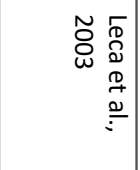 & 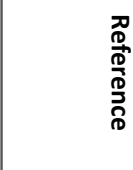 \\
\hline
\end{tabular}

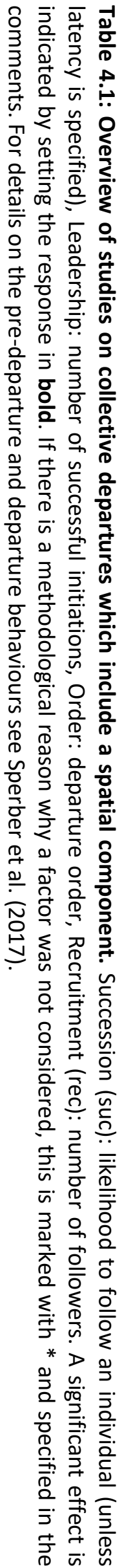




\begin{tabular}{|c|c|c|c|c|}
\hline 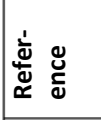 & 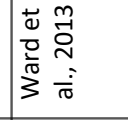 & 竞 & 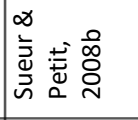 & 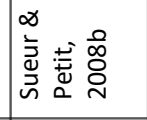 \\
\hline 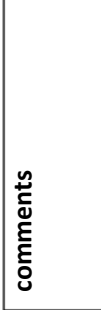 & & 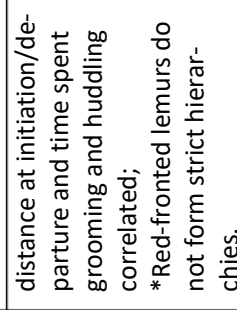 & & \\
\hline 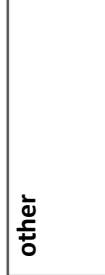 & 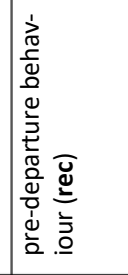 & 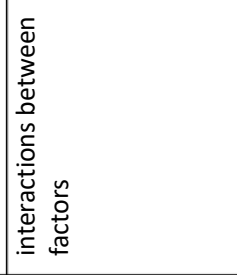 & 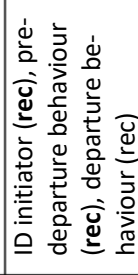 & 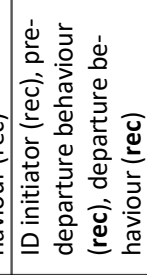 \\
\hline 它 & 訔 & ${ }_{1}$ & 言 & 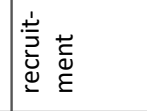 \\
\hline 㟧 & & 㖜 & ذ) & 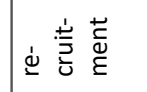 \\
\hline 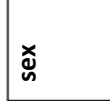 & & 耪 &. & 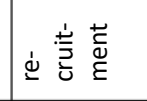 \\
\hline 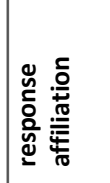 & & 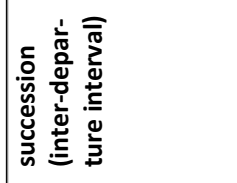 & & \\
\hline 童 & & 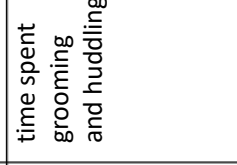 & . & \\
\hline 竞 & 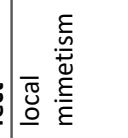 & 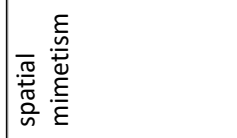 & & \\
\hline 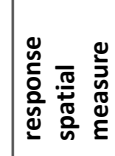 & 毫 & 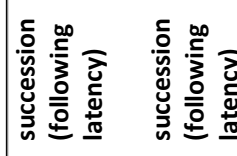 & 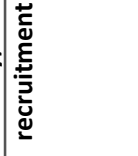 & 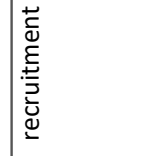 \\
\hline 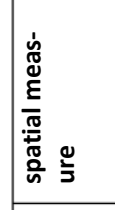 & 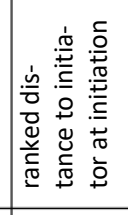 & 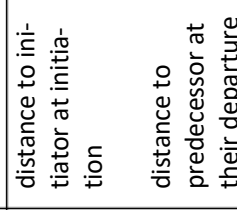 & 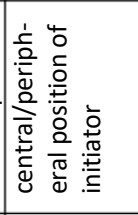 & 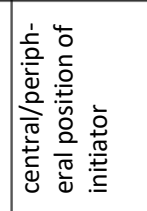 \\
\hline 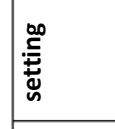 & 总 & $\frac{2}{3}$ & 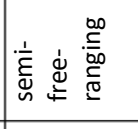 & 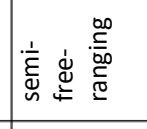 \\
\hline 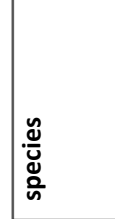 & 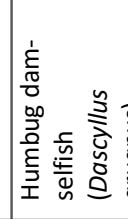 & 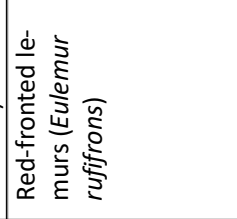 & 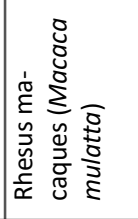 & 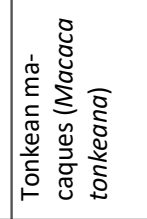 \\
\hline
\end{tabular}




\section{ACKNOWLEDGEMENTS}

We are grateful to the Malagasy Ministère de l'Environnement et des Eaux et Forêts, the Departement de Biologie, Ecologie et Conservation Animale de l'Université d'Antananarivo, and the Centre National de Formation, d'Etudes et de Recherche en Environnement et Foresterie de Morondava for supporting our research in Kirindy Forest. We also thank Holger Sennhenn-Reulen for his support with statistical analyses. We are grateful to Alecia Carter, Damien Farine, Danai Papageorgiou and an anonymous reviewer for constructive comments on the manuscript. 

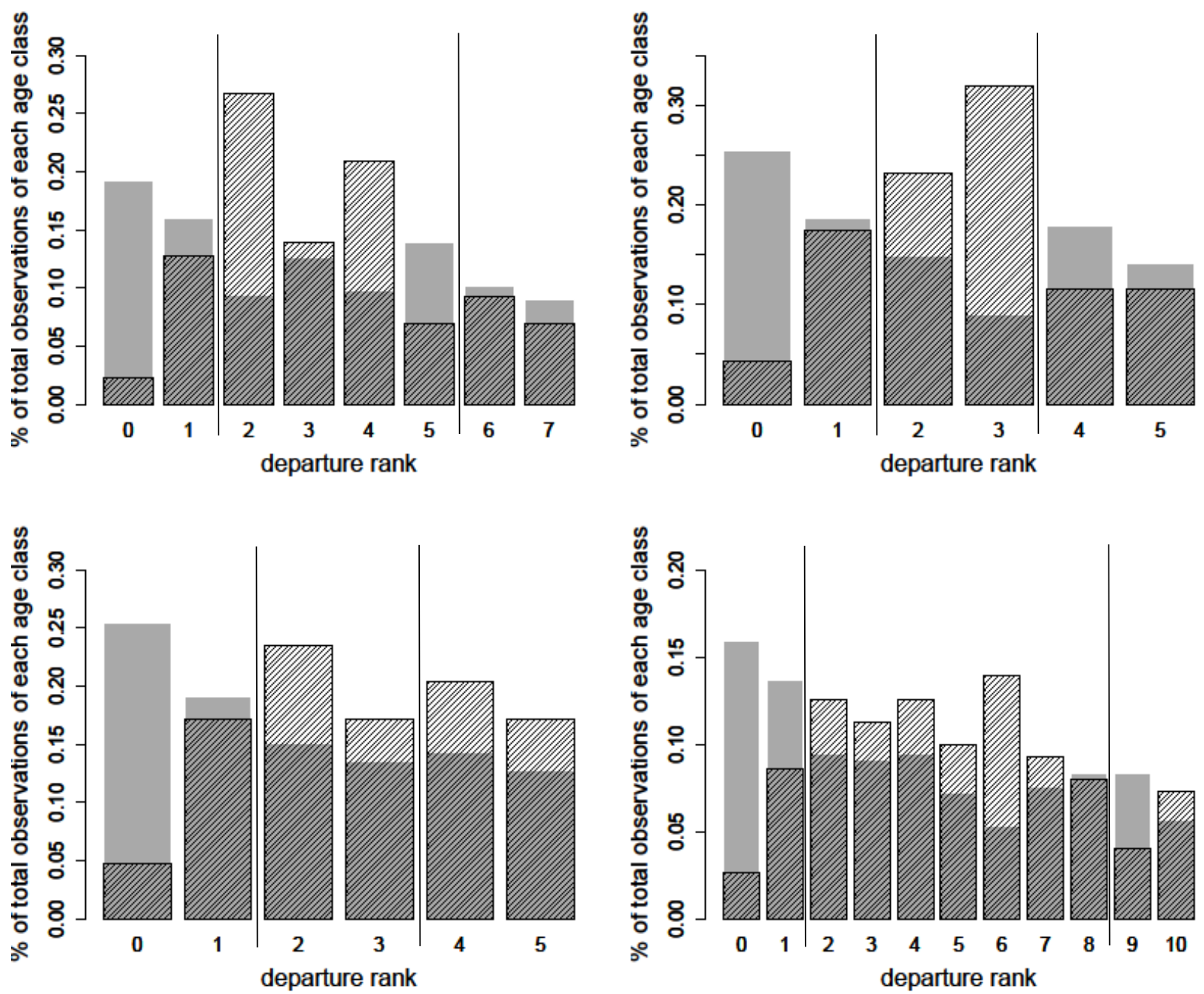

Figure S4.1: Distribution of age classes (juveniles and adults) on departure ranks in group A (2 juveniles $\& 6$ adults, top left), B ( 2 juveniles $\& 4$ adults, top right), F ( 2 juveniles and 4 adults, bottom left) and J ( 4 juveniles $\& 7$ adults, bottom right). Proportions were calculated as number of times an age class was observed per rank divided by the total number of observations of the age class. Solid grey bars show adult proportions, hatched black bars juveniles. Rank 0 is the initiator of the movement. Black lines indicate the division into position categories (van, centre \& rear) for modelling. 

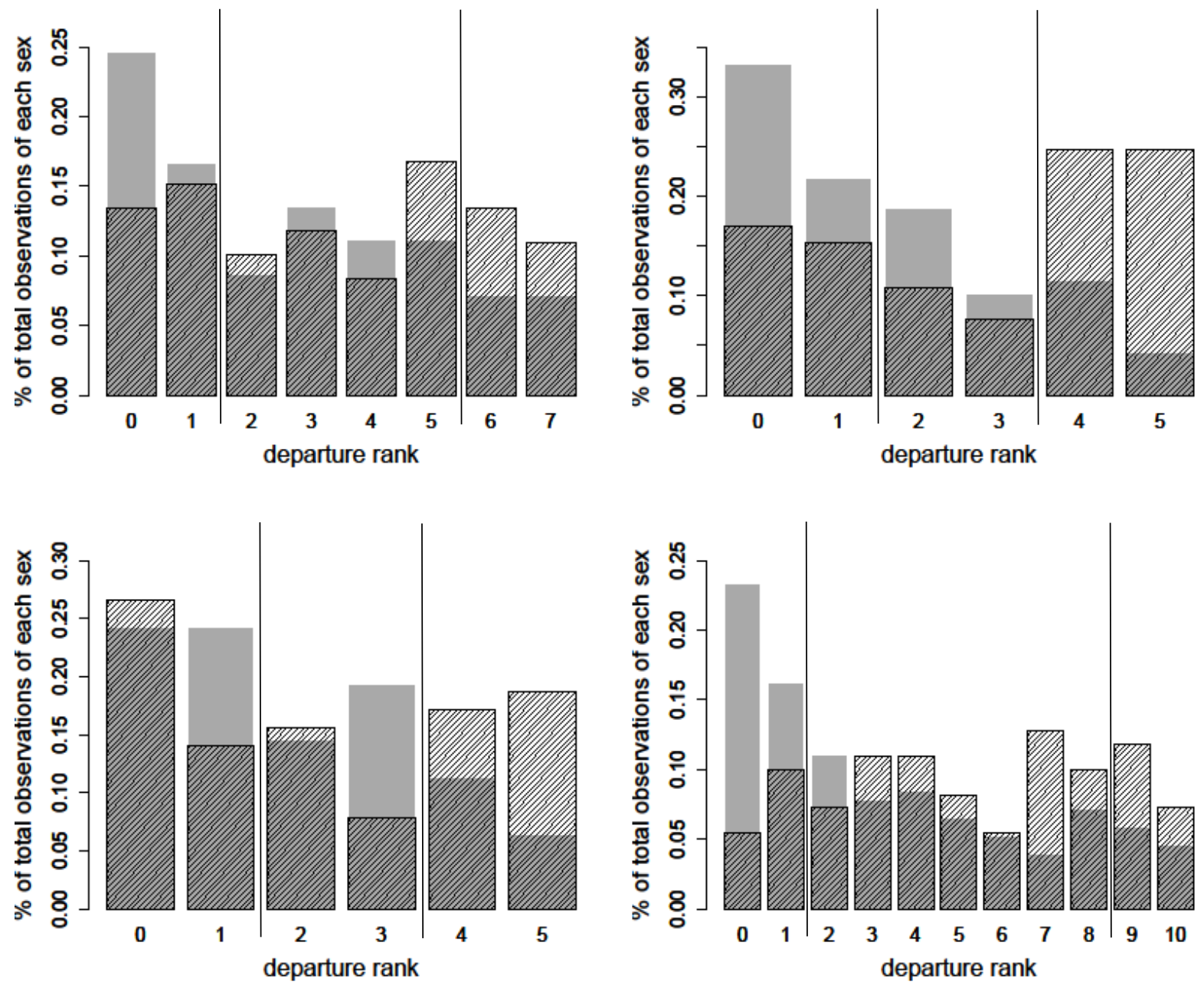

Figure S4.2: Distribution of sexes (adult individuals only) on departure ranks in group A (3 females \& 3 males, top left), B ( 2 females \& 2 males, top right), F ( 2 females \& 2 males, bottom left) and J (4 females $\& \mathbf{3}$ males, bottom right). Proportions were calculated as number of times each sex was observed per rank divided by the total number of observations of each sex. Solid grey bars show female proportions, hatched black bars males. Rank 0 is the initiator of the movement. Black lines indicate the division into position categories (van, centre \& rear) for modelling. 


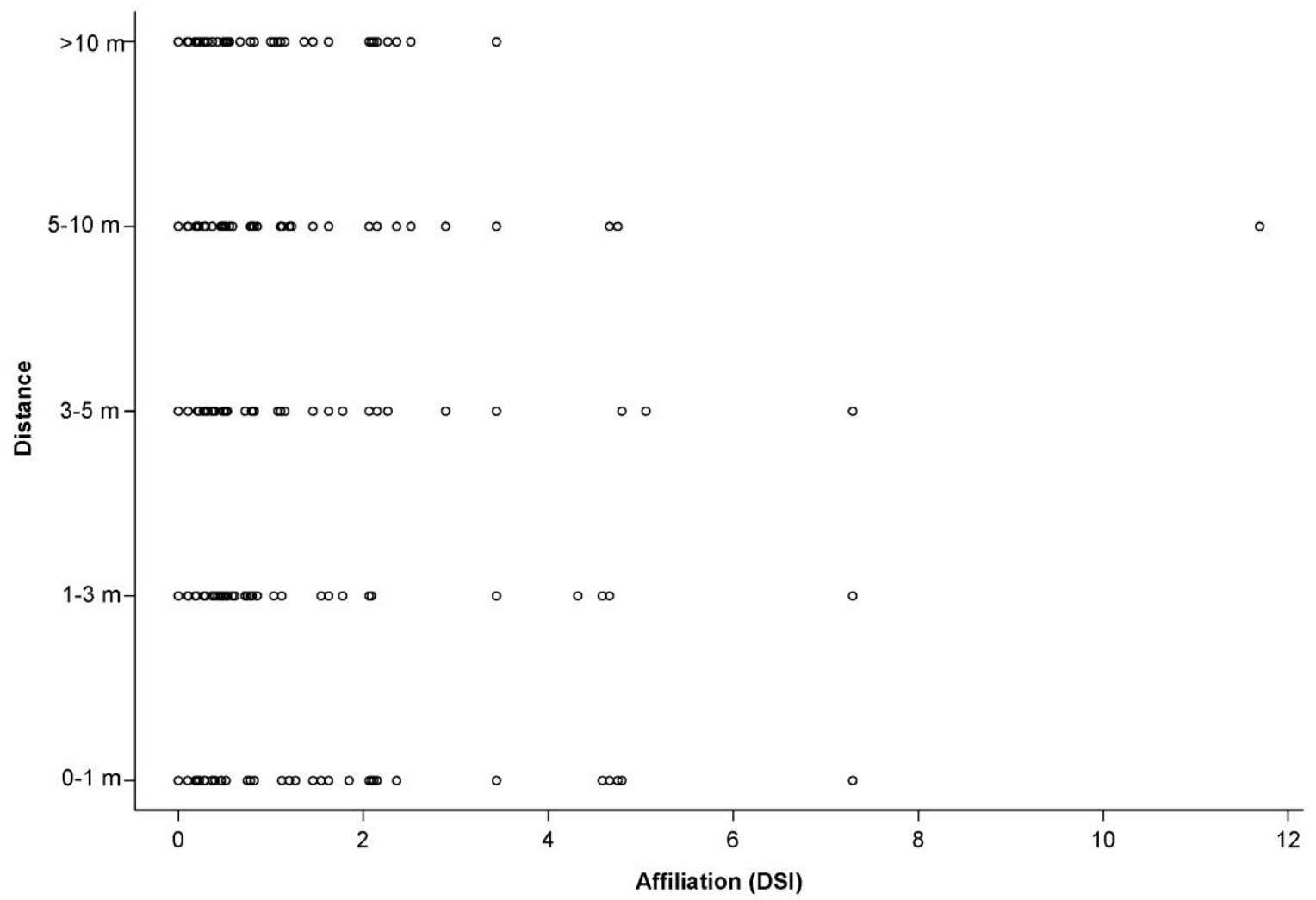

Figure S4.3: Proximity at departure depicted as a function of the affiliation index (DSI) of the dyad. Data combined from all four groups ( $n=347$ observations).

Table S4.1: Results for the MCMC GLMM regressing a dyad's distance at departure on its dyadic composite sociability index (DSI) and the dyad's age-sex combination.

$\begin{array}{lcclll} & \text { Post. mean } & \text { Cl lower } & \text { Cl upper } & \text { Eff.sample size } & \text { pMCMC } \\ \text { (Intercept) } & 4.10 & 1.86 & 6.27 & 48.42 & <0.001 \\ \text { DSI } & -0.61 & -1.10 & -0.20 & 45.50 & <0.01 \\ \text { Female-female } & 0.94 & -0.51 & 2.40 & 1000 & 0.68 \\ \text { Female-male } & 0.90 & -0.27 & 2.25 & 1000 & 0.68 \\ \text { Female-juvenile } & -0.01 & -1.21 & 1.15 & 1000 & 1.00 \\ \text { Male-male } & 1.17 & -0.42 & 2.68 & 1000 & 0.67 \\ \text { Male-juvenile } & -0.07 & -1.31 & 1.05 & 1000 & 1.00 \\ \text { Group B } & 0.58 & -0.89 & 2.32 . & 1000 & 1.00 \\ \text { Group F } & -0.29 & -1.78 & 1.39 & 826.51 & 1.00 \\ \text { Group J } & -0.02 & -1.67 & 1.52 & 764.50 & 1.00\end{array}$


Cutpoints:

$\begin{array}{lllll} & \text { Post. mean } & \text { Cl lower } & \text { Cl upper } & \text { Eff.sample size } \\ \text { Cutpoint distance 1 } & 3.80 & 2.13 & 5.65 & 22.89 \\ \text { Cutpoint distance 2 } & 6.45 & 3.70 & 9.69 & 19.28 \\ \text { Cutpoint distance 3 } & 10.19 & 6.13 & 15.41 & 18.14\end{array}$

The reference levels are age-sex combination juvenile-juvenile and group A.

Table S4.2: Effect of age class and sex on departure position. Results from multiple comparisons of the effects from the LMM.

$\begin{array}{lllllll} & \text { Estimate } & \text { Cl lower } & \text { Cl upper } & \text { Std. Error } & \mathbf{t} \text { value } & \operatorname{Pr}(>|\mathbf{t}|) \\ \text { female van-male van } & 0.12 & 0.00 & 0.24 & 0.04 & 2.81 & 0.05 \\ \text { female centre-male centre } & 0.00 & -0.12 & 0.13 & 0.04 & 0.10 & 100.00 \\ \text { female rear-male rear } & -0.13 & -0.25 & -0.01 & 0.04 & -2.99 & 0.03 \\ \text { female van-juvenile van } & 0.21 & 0.09 & 0.33 & 0.04 & 4.93 & <0.0001 \\ \text { female centre- juvenile centre } & -0.15 & -0.27 & -0.03 & 0.04 & -3.37 & 0.01 \\ \text { female rear- juvenile rear } & -0.05 & -0.17 & 0.07 & 0.04 & -1.19 & 0.84 \\ \text { male van- juvenile van } & 0.09 & -0.03 & 0.22 & 0.04 & 2.06 & 0.28 \\ \text { male centre- juvenile centre } & -0.15 & -0.27 & -0.03 & 0.04 & -3.39 & 0.01 \\ \text { male rear- juvenile rear } & 0.08 & -0.05 & 0.20 & 0.04 & 1.76 & 0.46\end{array}$

Test against null model: $F=11.09, d f=14, p<0.001$

Table S4.3: Assortativity by age and sex (juvenile, adult male, adult female. Mixing matrices and weighted assortativity coefficient (AC) by group.

\begin{tabular}{|c|c|c|c|c|c|c|c|c|c|}
\hline Group A & female & male & juvenile & $a_{i}=b_{i}$ & Group B & female & male & juvenile & $a_{i}=b_{i}$ \\
\hline female & 0.09 & 0.11 & 0.22 & 0.42 & female & 0.02 & 0.17 & 0.12 & 0.31 \\
\hline male & 0.11 & 0.05 & 0.09 & 0.25 & male & 0.17 & 0.13 & 0.11 & 0.41 \\
\hline juvenile & 0.22 & 0.09 & 0.02 & 0.33 & juvenile & 0.12 & 0.11 & 0.05 & 0.28 \\
\hline \multicolumn{5}{|c|}{$\mathrm{AC} \pm \mathrm{SE}:-0.28 \pm 0.08$} & \multicolumn{5}{|c|}{$A C \pm S E:-0.21 \pm 0.13$} \\
\hline roup F & female & male & juvenile & $a_{i}=b_{i}$ & Group J & female & male & juvenile & $a_{i}=b_{i}$ \\
\hline female & 0.02 & 0.11 & 0.28 & 0.40 & female & 0.05 & 0.17 & 0.14 & 0.36 \\
\hline male & 0.11 & 0.00 & 0.09 & 0.20 & male & 0.17 & 0.06 & 0.07 & 0.31 \\
\hline juvenile & 0.28 & 0.09 & 0.02 & 0.39 & juvenile & 0.14 & 0.07 & 0.12 & 0.33 \\
\hline \multicolumn{5}{|c|}{$\mathrm{AC} \pm \mathrm{SE}:-0.5 \pm 0.14$} & \multicolumn{5}{|c|}{$A C \pm S E:-0.16 \pm 0.08$} \\
\hline
\end{tabular}


Table S4.4: Effect of age class and sex on distance to the initiator. Results from multiple comparisons of the effects from the LMM.

$\begin{array}{lllllll} & \text { Estimate } & \text { Cl lower } & \text { Cl upper } & \text { SE } & \text { t value } & \operatorname{Pr}(>|t|) \\ \text { female }<1 \mathrm{~m}-\text { male }<1 \mathrm{~m} & 0.02 & -0.14 & 0.19 & 0.06 & 0.40 & 0.99 \\ \text { juvenile }<1 \mathrm{~m}-\text { female }<1 \mathrm{~m} & 0.04 & -0.13 & 0.20 & 0.06 & 0.62 & 0.96 \\ \text { juvenile }<1 \mathrm{~m}-\text { male }<1 \mathrm{~m} & 0.06 & -0.10 & 0.23 & 0.06 & 0.99 & 0.83 \\ \text { female }>10 \mathrm{~m}-\text { male }>10 \mathrm{~m} & -0.17 & -0.34 & -0.01 & 0.06 & -2.74 & 0.04 \\ \text { juvenile }>10 \mathrm{~m}-\text { female }>10 \mathrm{~m} & 0.06 & -0.11 & 0.22 & 0.06 & 0.93 & 0.86 \\ \text { juvenile }>10 \mathrm{~m}-\text { male }>10 \mathrm{~m} & -0.11 & -0.28 & 0.05 & 0.06 & -1.77 & 0.33\end{array}$

Test against null model: $F=2.12, \mathrm{df}=17, \mathrm{p}=0.01$

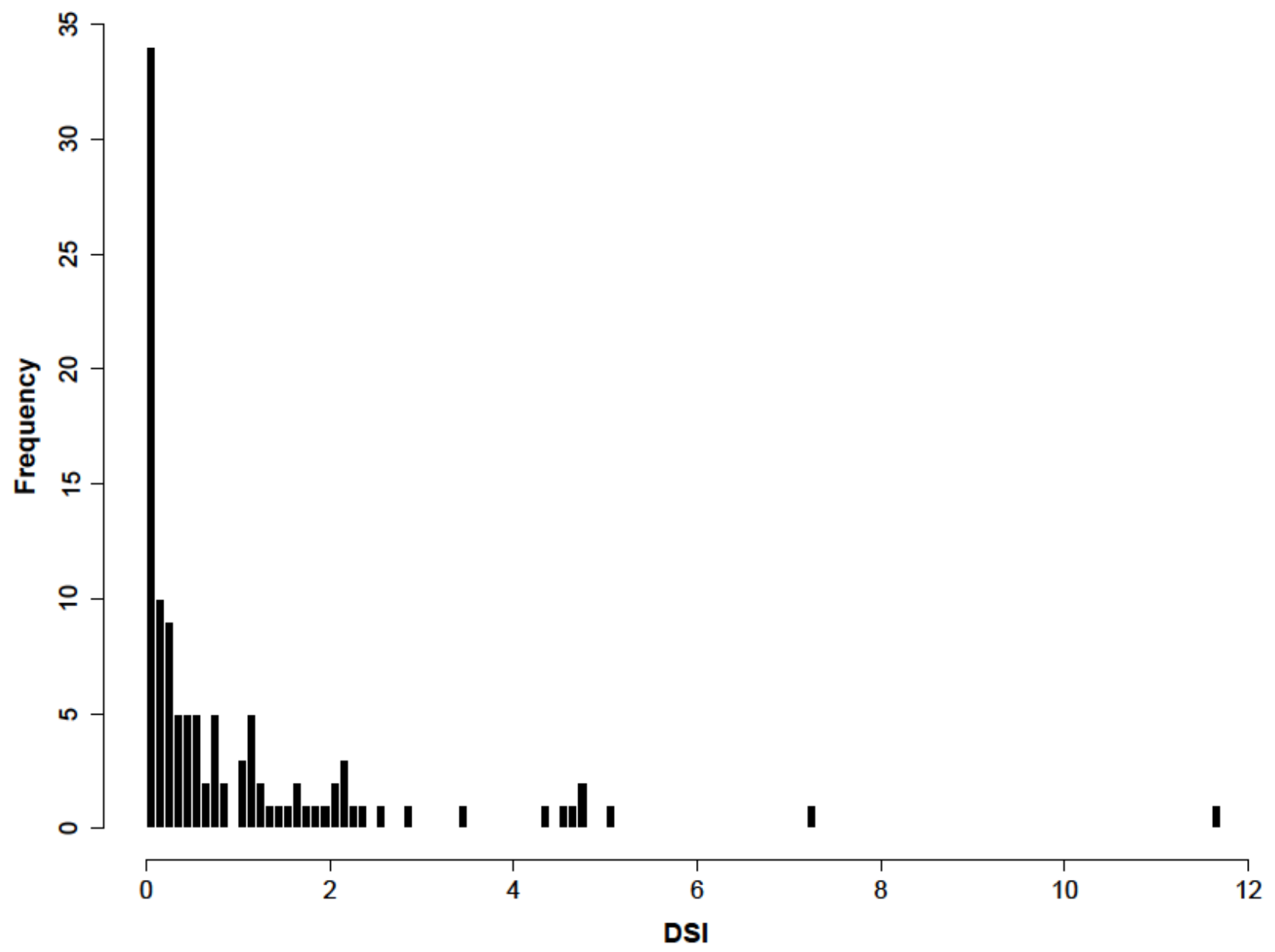

Figure S4.4: Distribution of dyadic sociability index values. Data pooled across groups ( $n=113$ dyads), but DSI calculated within groups. ( mean $=1$, median $=0.38$, range $=0-11.69$ ). 
4 Individual decisions in group departures 


\section{Chapter 5}

\section{General Discussion}

Understanding how groups achieve consensus decisions and collective actions is vital in uncovering the underlying principles of group living. In this thesis I, therefore, explored in detail the three stages of collective departures, pre-departure period, initiation and joining, in group movements of red-fronted lemurs. I found that red-fronted lemurs likely use a multi-contextual call to coordinate group departures. I confirmed the result of prior studies that adults differ in their frequency of initiating group movements and showed that an individual's initiation frequency depended on their personality. Joining was determined by sex and age but additionally affected by affiliative bonds and spatial proximity at departure time. In this final chapter I will recount my major findings and illustrate how they are embedded in the broader context of research on group movements. Moreover, I will suggest directions for future studies: On the one hand, studying group movements in the natural context could have practical applications in conservation. On the other hand, diversifying the contexts in which we study group coordination is crucial to further our understanding of collective actions.

\section{Group departures in red-fronted lemurs}

In Chapter 2, I investigated the potential use of a multi-contextual call for group coordination. Red-fronted lemurs' group movements were preceded by a pre-departure period, which, in comparison to a foraging control, was marked by both subsequent initiators and followers increasing their grunt rates significantly. Grunts can thus be classified as notifying behaviours (Black, 1988; Evans, 1982; Ramseyer et al., 2009, 2009; Sueur \& Petit, 2010) and provide a means for making a shared decision on departure time (Bourjade \& Sueur, 2010). Furthermore, grunts could have a 
recruitment function, since initiators grunted more than followers in the pre-departure period as well as at their respective departures. Such a difference is usually reported in species where recruitment success is linked to the production of notifying behaviours (Black, 1988; Evans, 1982; Ramseyer et al., 2009, 2009; Sueur \& Petit, 2010). I recommended that playback experiments similar to those conducted with meerkats (Suricata suricatta) by Gall \& Manser (2017) be used to test whether grunt rates actually affect the decision on joining the movement. Grunts were produced at elevated rates not only in the pre-departure period, but also at individual departure. This combined function of notifying behaviours has not been reported before; in other species pre-departure behaviours either stop when an individual starts moving (Black, 1988) or are replaced by specific initiation signals (Raveling, 1969; Rittschof \& Seeley, 2008). To determine whether this combined function also occurs in other species, I suggested that more studies should cover the whole departure process, reporting signalling behaviours in the pre-departure period, at individual departure and, insofar it is possible, throughout the movement. Overall, this chapter details how changes in call rate can grant multi-contextual calls a movement function, offering a way to coordinate departure time.

In Chapter 3, I identified traits influencing an individual's propensity to initiate group movements. Initiation frequency was affected by an individual's personality, namely its exploration and sociability. A higher initiation frequency was associated with higher levels of exploration. Reviewing previous studies investigating the effects of boldness, activity and exploration on leadership (Chapter 3, Table 3.1), I found that comparing across studies in personality research is complicated by the great diversity of measures and differences in definitions and labels. Despite efforts to define distinct personality traits (Réale et al., 2007; Sih \& Bell, 2008), the waters are still muddy, particularly for exploration and boldness, which are often measured using the same test but labelled differently. Carter et al. (2013) have laid the groundwork for a unified approach, which should be built upon, as it would be beneficial to establish a common framework to reference when moving forward. Boldness, activity or exploration were linked to initiation and leadership in more than half of the studies I reviewed, and the effect was always positive. My results thus fit the picture that proactive personality traits can encourage leadership. To my knowledge, my research is only the fourth study testing the effects of boldness, activity or exploration on leadership in the wild, and the first in primates. I concluded that research on leader personality would profit from more diverse study species and more studies conducted in the field.

The effect of sociability on initiation frequency depended on an individual's sex. More sociable females initiated more movements, while for males it was the less sociable ones that initiated more. My review of studies on the effects of sociability on leadership (Chapter 3, Table 3.1) 
showed that a negative effect of sociability is less common than a positive effect, but also not without precedent, as it has been reported for three-spined sticklebacks (Gasterosteus aculeatus), sheep (Ovis aries), cattle (Bos taurus) and barbary macaques (Macaca sylvanus) (Arnold, 1977; Della-Rossa et al., 2013; Jolles et al., 2015; Ramseyer et al., 2009; Seltmann et al., 2013). In groups where the costs of fission would be high and in which group members can coordinate their departure time with notifying behaviours, a high level of social power may not be needed for a successful movement initiation (Petit \& Bon, 2010).

Adult females were generally observed most often in the vanguard of a departing group (Chapter 4). This position could offer females, who, on average, have higher nutritional needs, better feeding opportunities. A higher foraging success of individuals in the vanguard of moving groups has been shown in fish and white-faced capuchin monkeys (Cebus capucinus), who have a diet similar to red-fronted lemurs (DeBlois \& Rose, 1996; Di Bitetti \& Janson, 2001; Krause, 1993; Krause, Reeves, et al., 1998). Juveniles were most likely to depart in the centre of the group, preceded by adult females and followed by adult males. This corresponds to a "protective travel order" (Wright, 1998), a common practice which places vulnerable individuals in the position of lowest predation risk (Fichtel, 2012; Holekamp et al., 2000; Prins, 1989). Ecological factors to an extent overruled affiliative bonds, as the travel order was assorted by sex, even though affiliative bonds were disassortative.

The affiliative bond of a dyad, expressed in huddling and grooming, affected their interdeparture interval, so that more strongly affiliated individuals joined a movement in faster succession. Spatial proximity also affected joining, as individuals followed the initiator and other preceding group mates more quickly when they were closer to them at the time of departure. While affiliative mimetism is common in many species, and particularly in primates (reviewed in Petit \& Bon, 2010), spatial mimetism, although rarely studied in species with differentiated social relationships, has already been reported in domestic geese (Anser domesticus) and sheep (Ramseyer et al., 2009; Ramseyer, Petit, et al., 2009a). My attempt to find independent measures of affiliation and proximity was unsuccessful, as more closely affiliated individuals were also in closer proximity to each other at their time of departure. I concluded that the affiliative mimetism observed in many studies might be explained more parsimoniously as an effect of proximity, but that, as long as proximity results from affiliation, this does not detract from the essential role affiliative relationships play in group decisions (King \& Fürtbauer, 2017). 


\section{Studying group movements in the wild}

As mentioned above, leader personality has rarely been studied in the wild. In my study, novel object tests were successful in measuring repeatable individual differences in exploratory behaviour (Chapter 3), which shows that this kind of test can also be used in the field and in the group context. FID, the reaction to an approaching threat, was also repeatable in red-fronted lemurs. This result supports the usefulness of this measure of boldness that has already been employed in a number of species (Boogert et al., 2010; Carrete \& Tella, 2010; Carter, Goldizen, et al., 2012; Carter et al., 2010; Evans et al., 2010; Seltmann et al., 2012). However, testing FID might not be practical in all species, since some animals could opt for fight instead of flight. Another promising approach to measuring boldness are predator call playbacks. Repeatable reactions to these playbacks have been observed in crested macaque males (Macaca nigra) and in grey seals (Halichoerus grypus) (Neumann, Agil, Widdig, \& Engelhardt, 2013; Twiss, Culloch, \& Pomeroy, 2012). While the playbacks for the macaques were broadcast from a manually operated hidden speaker, the speaker used for testing the seals was mounted on a remotely controlled vehicle, together with a video camera recording the animal's reaction. This setup is particularly well suited for testing animals that are not habituated to human observers. An additional way to assess boldness is evaluating naturally occurring situations that reveal individual risk-taking behaviour, such as the exposed drinking I used. However, such measures might be hard to standardise across species.

I found that spatial proximity to group mates affected individual following behaviour (Chapter 4). Distance categories were judged by eye, which was complicated by the difficult conditions of observing agile animals in a dense forest and lead to a loss of data when distances could not be reliably recorded for the whole group. These constraints may explain why the effect of distance on movement decisions has rarely been studied in the field. However, research on the effects of a group's distribution in space could in the future be facilitated by bio-loggers that record the relative distance and movements of all group members (Hughey, Hein, Strandburgpeshkin, \& Jensen, 2018). GPS-collars recording individual locations have been used with great success to reveal the effect of spatial proximity on individual movement decisions in groups of olive baboons (Papio anubis) on the move (Farine et al., 2016). Animal-borne recording devices could also be instrumental in improving the study of the use of vocalisations for group coordination. Recording several animals at once, which is vital for understanding the mechanism of a shared decision, is not always feasible by hand, since it may require more manpower than can conveniently follow a group. Audio collars have already been employed successfully to study the vocalisations of meerkats involved in collective decisions on the return to the sleeping site at dusk (Gall, Strandburg-Peshkin, Clutton-Brock, \& Manser, 2017). Meerkats in this study cooperated 
freely in having collars attached, but if other species are not as obliging, the possible detrimental effects on the animals caused by capturing and equipping must be considered and weighed with the convenience of animal-borne devices.

\section{Comparison to other species}

\section{State-of-the-art in non-human animals}

This thesis complements prior studies in painting a comprehensive picture of the group movements in red-fronted lemurs. It is an important step toward our understanding of group coordination, as in other species the picture is seldom as complete; often only isolated aspects of group movements are known. I have reviewed the information on group departures available in different species regarding the existence of notifying behaviours, characteristics of leaders, mechanisms of the joining process and the payoff for followers. I have assembled an overview of the species for which information is available in at least three of these categories (Table 5.1) to compare them with what is known in red-fronted lemurs. Although thorough work has been done on several domestic species (Ramseyer et al., 2009, 2009, 2009, Ramseyer, Petit, et al., 2009b, 2009a), groups in these studies were mostly artificially composed of only individuals of the same age-sex class and observed in a captive environment. I will therefore only discuss species studied in the wild.

Notifying behaviours are covered thoroughly; they have been described in all the included species. Leaders, however, in most of the species have only been characterised according to their age, sex and rank. When a personality trait was considered it was sociability. Even in these few species the divergent effects of sociability become apparent, as less sociable individuals initiated more movements barbary macaques but fewer movements in bottlenose dolphins (Tursiops truncatus) and chacma baboons (Papio ursinus) (King, Clark, \& Cowlishaw, 2011; Lusseau \& Conradt, 2009; Seltmann et al., 2013). The causes for these opposing effects merit more research on the possible effects of social-ecological factors and the different aspects of sociability that are measured, such as gregariousness, number of partners and social network position. The effects of boldness, activity or exploration on leadership have been investigated in none of these otherwise wellexplored species. Another point that would deserve more attention are the mechanisms and factors that determine the joining process. The payoff for group members to follow specific individuals has been investigated only in African elephants (Loxodonta africana) and bottlenose dolphins. The question of payoff is highly relevant in these species since they exhibit consistent leadership and, in the case of the dolphins, also unshared decision making. The consensus costs thus incurred by the other group members can be alleviated by everyone profiting from resources located by knowledgeable leaders (Conradt \& Roper, 2003, 2005; Foley et al., 2008; Lewis et al., 2013). 
However, the payoff for followers would also be worth investigating in species where certain individuals have more recruitment success than others. This is also a gap still left to fill in our knowledge of red-fronted lemurs.

Table 5.1 Overview of the species, in which group departures have been studies most comprehensively.

\begin{tabular}{|c|c|c|c|c|c|c|}
\hline Species & $\begin{array}{l}\text { Red-fronted le- } \\
\text { murs }\end{array}$ & $\begin{array}{l}\text { African ele- } \\
\text { phants }\end{array}$ & Meerkats & $\begin{array}{l}\text { Bottlenose dol- } \\
\text { phins }\end{array}$ & $\begin{array}{l}\text { Chacma ba- } \\
\text { boons }\end{array}$ & $\begin{array}{l}\text { Barbary ma- } \\
\text { caques }\end{array}$ \\
\hline Social structure & $\begin{array}{l}\text { egalitarian, fe- } \\
\text { males philopat- } \\
\text { ric }\end{array}$ & matriarchal & matriarchal & $\begin{array}{l}\text { fission-fusion } \\
\text { societies }\end{array}$ & $\begin{array}{l}\text { males dominant, } \\
\text { females philo- } \\
\text { patric }\end{array}$ & $\begin{array}{l}\text { males dominant, } \\
\text { females philo- } \\
\text { patric }\end{array}$ \\
\hline $\begin{array}{l}\text { Notifying be- } \\
\text { haviours }\end{array}$ & $\begin{array}{l}\text { Pre-departure \& } \\
\text { initiation: } \\
\text { "grunts" (multi- } \\
\text { contextual) }\end{array}$ & $\begin{array}{l}\text { Pre-departure, } \\
\text { possibly also ini- } \\
\text { tiating \& lead- } \\
\text { ing: } \\
\text { "rumble call" } \\
\text { (multi-contex- } \\
\text { tual) with inten- } \\
\text { tion movement, } \\
\text { lifting one leg \& } \\
\text { flapping ears }\end{array}$ & $\begin{array}{l}\text { Pre-departure: } \\
\text { quorum of } \\
\text { "moving calls" } \\
\text { (specific) } \\
\text { Initiation: } \\
\text { lead call (spe- } \\
\text { cific) } \\
\text { During move- } \\
\text { ment: } \\
\text { following } \\
\text { hotspot of close } \\
\text { calls (multi-con- } \\
\text { textual) }\end{array}$ & $\begin{array}{l}\text { Initiation: } \\
\text { side flops }\end{array}$ & $\begin{array}{l}\text { Pre-departure: } \\
\text { "grunts" (multi- } \\
\text { contextual) }\end{array}$ & $\begin{array}{l}\text { Pre-departure } \\
\text { (voting on direc- } \\
\text { tion): } \\
\text { Intention move- } \\
\text { ments, glancing } \\
\text { back }\end{array}$ \\
\hline Leadership & variable & consistent & variable & $\begin{array}{l}\text { differs between } \\
\text { groups }\end{array}$ & variable & variable \\
\hline $\begin{array}{l}\text { Leader age, sex } \\
\text { \& rank }\end{array}$ & $\begin{array}{l}\text { Anyone can initi- } \\
\text { ate, adult fe- } \\
\text { males initiate } \\
\text { more } \\
\text { males \& females } \\
\text { recruit equally, } \\
\text { adults more } \\
\text { than subadults }\end{array}$ & $\begin{array}{l}\text { Always oldest } \\
\text { female (matri- } \\
\text { arch) }\end{array}$ & $\begin{array}{l}\text { Dominant, } \\
\text { breeding female } \\
\text { or anyone who } \\
\text { initiates first, } \\
\text { rank, sex and } \\
\text { age (within } \\
\text { adults) have no } \\
\text { effect on initia- } \\
\text { tion success }\end{array}$ & $\begin{array}{l}\text { Adult males ini- } \\
\text { tiate more }\end{array}$ & $\begin{array}{l}\text { Contradictory } \\
\text { results, but } \\
\text { mostly higher } \\
\text { ranking and } \\
\text { males, especially } \\
\text { alpha male lead } \\
\text { more }\end{array}$ & $\begin{array}{l}\text { Higher ranking } \\
\text { initiate more, } \\
\text { higher ranking } \\
\text { and males re- } \\
\text { cruit more }\end{array}$ \\
\hline $\begin{array}{l}\text { Leader person- } \\
\text { ality }\end{array}$ & $\begin{array}{l}\text { More explora- } \\
\text { tory initiate } \\
\text { more, sex-de- } \\
\text { pendent effect } \\
\text { of sociability }\end{array}$ & & & $\begin{array}{l}\text { More sociable } \\
\text { initiate more }\end{array}$ & $\begin{array}{l}\text { More sociable } \\
\text { initiate and re- } \\
\text { cruit more }\end{array}$ & $\begin{array}{l}\text { Less sociable ini- } \\
\text { tiate more, but } \\
\text { recruit less }\end{array}$ \\
\hline $\begin{array}{l}\text { Joining process } \\
\text { determined by }\end{array}$ & $\begin{array}{l}\text { Protective travel } \\
\text { order, affiliation, } \\
\text { spatial proximity }\end{array}$ & & & & $\begin{array}{l}\text { Affiliation, spa- } \\
\text { tial association }\end{array}$ & Affiliation \\
\hline $\begin{array}{l}\text { Payoff for fol- } \\
\text { lowers }\end{array}$ & & $\begin{array}{l}\text { Knowledge of } \\
\text { resources, pred- } \\
\text { ators and con- } \\
\text { specifics }\end{array}$ & & $\begin{array}{l}\text { Knowledge of } \\
\text { resources }\end{array}$ & & \\
\hline References & $\begin{array}{l}\text { Erhart \& } \\
\text { Overdorff, 1999; } \\
\text { Pyritz, Kappeler, } \\
\text { et al., 2011, } \\
\text { Chapters 2-4 }\end{array}$ & $\begin{array}{l}\text { Foley et al., } \\
\text { 2008; McComb, } \\
\text { 2011; McComb } \\
\text { et al., 2001; } \\
\text { O'Connell- } \\
\text { Rodwell et al., } \\
\text { 2012; Poole et } \\
\text { al., } 1988\end{array}$ & $\begin{array}{l}\text { Bousquet \& } \\
\text { Manser, 2011; } \\
\text { Bousquet et al., } \\
\text { 2011; Gall \& } \\
\text { Manser, 2017; } \\
\text { Gall et al., } 2017\end{array}$ & $\begin{array}{l}\text { Lewis et al., } \\
\text { 2013; Lusseau \& } \\
\text { Conradt, } 2009\end{array}$ & $\begin{array}{l}\text { Fischer \& } \\
\text { Zinner, 2011; } \\
\text { King et al., 2008; } \\
\text { King, Sueur, et } \\
\text { al., 2011; } \\
\text { Rendall et al., } \\
\text { 1999; Rhine, } \\
\text { Bioland, \& } \\
\text { Lodwick, 1985; } \\
\text { Ramon J Rhine } \\
\text { \& Tilson, 1987; } \\
\text { Stueckle \& } \\
\text { Zinner, 2008; } \\
\text { Sueur, 2011 }\end{array}$ & $\begin{array}{l}\text { Seltmann et al., } \\
2016,2013\end{array}$ \\
\hline
\end{tabular}




\section{Collective decisions in humans}

Maybe not surprisingly, humans are the only other primates beside red-fronted lemurs in which the personality of leaders has been studied, albeit in different contexts. Although human societies are vastly more complex and present infinitely diverse contexts for collective decisions, many of the traits associated with leadership, such as boldness, ambition, self-esteem and extraversion, boil down to much the same principle as I have reported for red-fronted lemurs (Chapter 3): taking the initiative (Vugt, 2006). Collective movement behaviour is also being studied in humans and can provide valuable insights for controlling crowds. Observational and experimental studies have shown that different aspects of movement decisions in anonymous groups of humans are guided by simple local rules, similar to the spatial mimetism I found in lemurs (Chapter 4). Road crossing behaviour has been reported to be determined by the distance between pedestrians, as an individual's likelihood to cross the road increased when their nearest neighbour started crossing (Faria et al., 2010). Furthermore, an informed minority can lead the majority towards a spatial goal without communicating either verbally or by signs as long as the informed individuals are among the first to move and thus initiate a movement (Boos et al., 2014). Experiments have moreover identified the necessary proportion of informed individuals and the ideal positions for placing them to efficiently lead the group. These studies can help to make evacuations more efficient, for example by specifying where to place guides (Dyer et al., 2008, 2009). The fact that we can find parallels in group coordination mechanism between humans and other animals that make collective decisions in vastly different social and ecological contexts suggest that some principles of group coordination may be universally adaptive.

\section{Future perspectives}

\section{Collective movements - a topic in their own right}

Not only are group movements a fantastic model for studying the mechanism of collective decision making across species, they are also a topic in their own right. Apart from their role in basic research, knowledge of group movement mechanisms also has important real-life applications. Human-wildlife conflicts over resources, particularly crops, have been increasing and will continue to increase as humans encroach on animals' dwindling habitats. Studying group movement mechanisms can offer ways to mitigate the consequences of these conflicts and thus contribute to animal conservation. For example, chacma baboons regularly raid residential areas for food. Raid frequency was reduced by introducing artificial feeding patches that elicit despotic leadership in the dominant male. The negative effects of provisioning are minimised, as the food is monopolised by the troop leader (Kaplan, O’Riain, van Eeden, \& King, 2011; King et al., 2008). 
Identifying the rules underlying collective movement can also help to explain why animals may show maladaptive behaviours in changing environments and can inform us on how we can improve this situation. For example, killer whales (Orcinus orca) continue using polluted areas due to cultural conformism in the matrilineal groups (Osborne, 1999; Whitehead, 2010). Furthermore, climate change and other human disturbances particularly impact migratory species. Traditional migration routes and schedules often become obsolete, which can lead to dramatic population declines (Hardesty-Moore et al., 2018). However, not all species are able to alter their migration patterns as necessary (Sutherland, 2011). Behavioural manipulations can offer a solution, especially in the course of re-introductions. Successful social learning of migration routes has been achieved by introducing knowledgeable leaders in the form of foster parents for lesser whitefronted geese (Anser erythropus) (Essen, 1988; Sutherland, 1998) or an ultralight aircraft for whooping cranes (Grus americana) (Mueller, O’Hara, Converse, Urbanek, \& Fagan, 2013).

To gather the required knowledge it is necessary to "re-wild" the study of collective behaviour (King, Fehlmann, Biro, Ward, \& Fürtbauer, 2018), leaving behind the minimalist and artificial groups and controlled conditions of the lab and stepping out into the field. Of course, this step poses some challenges, such as keeping track of numerous animals at once, in habitats with often low visibility and sometimes in inaccessible environments. In this respect, the recent advances in technology and relating analytical tools are extremely helpful as they make it possible to record the location and behaviour of whole groups, in all kinds of environments using remote sensing or on-board bio-loggers (reviewed in Hughey et al., 2018)

\section{Group coordination in different contexts}

As I have discussed, group movements offer an excellent and relevant context for the study of group coordination. However, to fully understand the mechanisms underlying collective action, it is vital to branch out and explore how collective action is achieved in other contexts. Intergroup encounters and a group's reaction to the presence of a predator, such as inspection, mobbing or defence, are two contexts that would be well suited for a comparison across species. These situations can also be evoked experimentally with decoys and playbacks, making them convenient for study (Graw \& Manser, 2007; Heinsohn \& Packer, 1995; Micheletta et al., 2012; Sternalski \& Bretagnolle, 2010). These contexts show parallels to the movement context and similar aspects need to be considered.

Corresponding to notifying behaviours in group movements, individuals will recruit group mates to predator or intergroup interactions using visual or acoustic signals and can differ in their recruitment success. It is thus possible to compare recruitment mechanisms and the factors which 
influence recruitment success. For example, in communally roosting Marsh harriers (Circus aeruginosus), whether a group responds with mobbing to a predator decoy largely depends on the identity of the discovering bird. First, different colour morphs, in birds associated with individual level of aggression (Ducrest, Keller, \& Roulin, 2008), differ in their likelihood to give alarm calls. Second, a lighter colouration, associated with higher age, leads to a higher recruitment success (Sternalski \& Bretagnolle, 2010). Recruitment success can also depend on social bonds, as in crested macaques (Macaca nigra), where individuals react more strongly to the alarm calls of closely affiliated group members (Micheletta et al., 2012).

The topic of leadership can also be addressed. An interaction can simply be initiated by the individual who discovers the threat. If several group members are aware of a potential threat, one must be the first to initiate a response. In a study on female lions, some individuals consistently led the approach towards the playbacks of aggressive vocalisations of conspecifics, while others always lagged behind. These different strategies could not be explained by age, size and body condition, and also not by rank, since female lions are egalitarian (Heinsohn \& Packer, 1995). To my knowledge, the role of individual personality in leadership has not been considered outside the movement context, but these results show that it might hold explanatory power. The appropriateness of the leader's response can depend on leader characteristics and affect the costs for the group. The effect that a leader's age, and thus experience, has on the group's fitness has been demonstrated in African elephants. The age of a matriarch is crucial for an appropriate defence reaction towards predators, as young matriarchs showed little reaction to playbacks of lion calls, indicators of a serious threat to the herd (McComb, 2011). Similarly, a matriarch's age determines their social knowledge, which is important for the regulation of interactions outside the family unit (McComb et al., 2001).

When we consider leadership in different contexts, the next step is to investigate the generality of leadership, i.e. does leadership in one context predict leadership in another? This question has been addressed in a survey by Smith et al. (2015). They compared eight non-human mammalian species with human small-scale societies in their leadership in four contexts: group movement, food acquisition, within-group conflict mediation, and between-group interactions. They concluded that generality was higher in species where leadership is associated with a high rank in strict dominance hierarchies (Smith, Gavrilets, et al., 2015). To understand leadership beyond dominance, species with low generality are of great interest, since they can help us deduce which qualities the different contexts demand of a leader. Moving forward, it would be beneficial to study group coordination across different contexts, using the same measures or comparable measures throughout to facilitate comparisons. 


\section{General conclusions}

This thesis constitutes an important step towards understanding collective decisions, as it chronicles the whole process of group departures in red-fronted lemurs, spanning from the pre-departure period across the time of initiation up to the departure of the last individual joining the movement. I provide support for the hypothesis that an egalitarian social system is usually associated with shared decision making, here in the form of pre-departure period with increased call rates and variable leadership, with all group members able to initiate a movement. Furthermore, the identified characteristics of frequent initiators hint that the most important trait to achieve leadership can simply be the willingness to leave the group at the risk of (temporary) isolation. The opposing effects that sociability has on leadership likelihood in different species still merits research, particularly regarding the connection to the role of social power and group cohesion. My findings on the factors determining the joining process illustrate that individual departure decisions can simultaneously be guided by local rules and individual traits. These findings provide further support for the approach to consider the needs of individuals in research on collective decisions. This thesis demonstrates that experimental methods and technologies to study group movements in the wild are available and that our understanding of group coordination and collective decision making can greatly benefit from such research. I show that, on the whole, redfronted lemurs, despite their isolated evolution, have arrived at collective decision processes and determinants which closely resemble those of anthropoid primates and many species from diverse taxa. These finding suggests that some mechanisms of collective decision making can be universally adaptive, across a huge variety of group sizes, compositions and organisations as well as ecological contexts. 


\section{Bibliography}

Akaike, H. (1973). Information theory and an extension of the maximum likelihood principle. In B. N. Petrov \& F. Csaki (Eds.), Second International Symposium on Information Theory (pp. 267281). Budapest: Akadémiai Kiado.

Alexander, R. D. (1974). The evolution of social behavior. Annual Review of Ecology and Systematics, 5, 325-383.

Alonso, J. A., \& Alonso, J. C. (1993). Age-related differences in time budgets and parental care in wintering common cranes. The Auk, 110(1), 78-88.

Andrieu, J., Henry, S., Hausberger, M., \& Thierry, B. (2015). Informed horses are influential in group movements, but they may avoid leading. Animal Cognition. https://doi.org/10.1007/s10071015-0945-2

Arnold, G. W. (1977). An analysis of spatial leadership in a small field in a small flock of sheep. Applied Animal Ethology, 3(3), 263-270. https://doi.org/https://doi.org/10.1016/03043762(77)90007-4

Barelli, C., Boesch, C., Heistermann, M., \& Reichard, U. H. (2008). Female white-handed gibbons (Hylobates lar) lead group movements and have priority of access to food resources. Behaviour, 145(7), 965-981. https://doi.org/10.1163/156853908784089243

Bates, D., Mächler, M., Bolker, B., \& Walker, S. (2015). Fitting Linear Mixed-Effects Models Using Ime4. Journal of Statistical Software, 67(1), 1-48. https://doi.org/10.18637/jss.v067.i01

Bates, D., Maechler, M., Bolker, B., \& Walker, S. (2015). Fitting linear mixed-effects models using Ime4. Journal of Statistical Software, 67(1), 1-48.

Beauchamp, G. (2000). Individual differences in activity and exploration influence leadership in pairs of foraging zebra finches. Behaviour, 137(3), 301-314.

Bell, A., Hankison, S., \& Laskowski, K. (2009). The repeatability of behaviour: a meta-analysis. Animal Behaviour, 77(4), 771-783. https://doi.org/10.1016/j.anbehav.2008.12.022.Bell

Berger, J. (1977). Organizational systems and dominance in feral horses in the Grand Canyon. Behavioral Ecology and Sociobiology, 146, 131-146.

Bergman, T. J., \& Kitchen, D. M. (2009). Comparing responses to novel objects in wild baboons (Papio ursinus) and geladas (Theropithecus gelada). Animal Cognition, 12(1), 63-73. https://doi.org/10.1007/s10071-008-0171-2

Bergmüller, R., \& Taborsky, M. (2010). Animal personality due to social niche specialisation. Trends in Ecology \& Evolution, 25(9), 504-11. https://doi.org/10.1016/j.tree.2010.06.012

Berry, P. S. M., \& Bercovitch, F. B. (2014). Leadership of herd progressions in the Thornicroft's giraffe of Zambia. African Journal of Ecology, n/a-n/a. https://doi.org/10.1111/aje.12173

Bertram, B. (1978). Living in groups: predators and prey. In J. R. Krebs \& N. B. Davies (Eds.), Behavioural Ecology: An Evolutionary Approach (pp. 64-96). Oxford: Blackwell Scientific Publications.

Bisazza, A., Butterworth, B., Piffer, L., Bahrami, B., Petrazzini, M. E. M., \& Agrillo, C. (2014). Collective enhancement of numerical acuity by meritocratic leadership in fish. Scientific Reports, 4(49), 4560. https://doi.org/10.1038/srep04560

Black, J. M. (1988). Preflight signalling in swans: A mechanism for group cohesion and flock formation. Ethology, 79(2), 143-157. https://doi.org/10.1111/j.1439-0310.1988.tb00707.x

Blumstein, D. T. (2003). Flight-initiation distance in birds is dependent on intruder starting distance. The Journal of Wildlife Management, 67(4), 852-857.

Boinski, S. (1988). Sex differences in the foraging behavior of squirrel monkeys in a seasonal habitat. Behavioral Ecology and Sociobiology, 23(3), 177-186. https://doi.org/10.1007/BF00300352 
Boinski, S. (1991). The coordination of spatial position: a field study of the vocal behaviour of adult female squirrel monkeys. Animal Behaviour, 41, 89-102.

Boinski, S. (1993). Vocal coordination of troop movement among white-faced capuchin monkeys, Cebus capucinus. American Journal of Primatology, 30(2), 85-100. https://doi.org/10.1002/ajp.1350300202

Boinski, S. (1996). Vocal Coordination of Troop Movement in Squirrel Monkeys (Saimiri oerstedi and S. sciureus) and White-Faced Capuchins (Cebus capucinus). In M. A. Norconk, A. L. Rosenberger, \& P. A. Garber (Eds.), Adaptive Radiations of Neotropical Primates (pp. 251269). Boston, MA: Springer US. https://doi.org/10.1007/978-1-4419-8770-9_15

Boinski, S., \& Campbell, A. F. (1995). Use of trill vocalizations to coordinate troop movement among white-faced capuchins: a second field test. Behaviour, 132(11-12), 875-901.

Boinski, S., \& Garber, P. A. (2000). On the Move: How and Why Animals Travel in Groups. Chicago, IL: University of Chicago Press.

Boinski, S., Moraes, E., Kleiman, D. G., Dietz, J. M., \& Baker, A. J. (1994). Intra-group vocal behaviour in wild golden lion tamarins, Leontopithecus rosalia: honest communication of individual activity. Behaviour, 130(1), 53-75.

Bonanni, R., Cafazzo, S., Valsecchi, P., \& Natoli, E. (2010). Effect of affiliative and agonistic relationships on leadership behaviour in free-ranging dogs. Animal Behaviour, 79(5), 981991. https://doi.org/10.1016/j.anbehav.2010.02.021

Boogert, N. J., Monceau, K., \& Lefebvre, L. (2010). A field test of behavioural flexibility in Zenaida doves (Zenaida aurita). Behavioural Processes, 85(2), 135-41. https://doi.org/10.1016/j.beproc.2010.06.020

Boos, M., Pritz, J., Lange, S., \& Belz, M. (2014). Leadership in moving human groups. PLoS Computational Biology, 10(4), e1003541. https://doi.org/10.1371/journal.pcbi.1003541

Bourjade, M., \& Sueur, C. (2010). Shared or unshared consensus for collective movement? Towards methodological concerns. Behavioural Processes, 84(3), 648-52. https://doi.org/10.1016/j.beproc.2010.02.027

Bourjade, M., Thierry, B., Maumy, M., \& Petit, O. (2009). Decision-making in Przewalski horses (Equus ferus przewalskii) is driven by the ecological contexts of collective movements. Ethology, 115(4), 321-330. https://doi.org/10.1111/j.1439-0310.2009.01614.x

Bousquet, C. A. H., \& Manser, M. B. (2011). Resolution of experimentally induced symmetrical conflicts of interest in meerkats. Animal Behaviour, 81(6), 1101-1107. https://doi.org/10.1016/j.anbehav.2011.02.030

Bousquet, C. A. H., Sumpter, D. J. T., \& Manser, M. B. (2011). Moving calls: a vocal mechanism underlying quorum decisions in cohesive groups. Proceedings of the Royal Society $B$ : Biological Sciences, 278(1711), 1482-8. https://doi.org/10.1098/rspb.2010.1739

Bradbury, J. W., \& Vehrencamp, S. L. (2011). Principles of Animal Communication (2nd ed.). Sunderland MA: Sinauer Associates.

Braune, P., Schmidt, S., \& Zimmermann, E. (2005). Spacing and group coordination in a nocturnal primate, the golden brown mouse lemur (Microcebus ravelobensis): the role of olfactory and acoustic signals. Behavioral Ecology and Sociobiology, 58(6), 587-596. https://doi.org/10.1007/s00265-005-0944-4

Brent, L. J. N., Franks, D. W., Foster, E. A., Balcomb, K. C., Cant, M. A., \& Croft, D. P. (2015). Ecological knowledge, leadership, and the evolution of menopause in killer whales. Current Biology, 25(6), 746-750. https://doi.org/10.1016/j.cub.2015.01.037

Bretz, F., Hothorn, T., \& Westfall, P. (2010). Multiple comparisons using R. Boca Raton, Florida, USA: CRC Press.

Briard, L., Dorn, C., \& Petit, O. (2015). Personality and affinities play a key role in the organisation of collective movements in a group of domestic horses. Ethology, 121(9), 888-902. https://doi.org/10.1111/eth.12402

Bumann, D., Krause, J., \& Rubenstein, D. I. (1997). Mortality risk of spatial positions in animal 
groups: the danger of being in the front. Behaviour, 134(13), 1063-1076.

Burns, A. L. J., Herbert-Read, J. E., Morrell, L. J., \& Ward, A. J. W. (2012). Consistency of leadership in shoals of mosquitofish (Gambusia holbrooki) in novel and in familiar environments. PLoS ONE, $7(5), \quad$ e36567. doi:10.1371/journal.pone.0036567. https://doi.org/10.1371/journal.pone.0036567

Byrne, R. W., Whiten, A., \& Henzi, S. P. (1990). Social relationships of mountain baboons: Leadership and affiliation in a non-female-bonded monkey. American Journal of Primatology, 20(4), 313-329. https://doi.org/10.1002/ajp.1350200409

Carrete, M., \& Tella, J. L. (2010). Individual consistency in flight initiation distances in burrowing owls: a new hypothesis on disturbance-induced habitat selection. Biology Letters, 6(2), 16770. https://doi.org/10.1098/rsbl.2009.0739

Carter, A. J., Feeney, W. E., Marshall, H. H., Cowlishaw, G., \& Heinsohn, R. (2013). Animal personality: what are behavioural ecologists measuring? Biological Reviews of the Cambridge Philosophical Society, 88(2), 465-75. https://doi.org/10.1111/brv.12007

Carter, A. J., Goldizen, A., \& Heinsohn, R. (2012). Personality and plasticity: temporal behavioural reaction norms in a lizard, the Namibian rock agama. Animal Behaviour, 84(2), 471-477. https://doi.org/10.1016/j.anbehav.2012.06.001

Carter, A. J., Goldizen, A. W., \& Tromp, S. A. (2010). Agamas exhibit behavioral syndromes: bolder males bask and feed more but may suffer higher predation. Behavioral Ecology, 21(3), 655661. https://doi.org/10.1093/beheco/arq036

Carter, A. J., Marshall, H. H., Heinsohn, R., \& Cowlishaw, G. (2012). How not to measure boldness: novel object and antipredator responses are not the same in wild baboons. Animal Behaviour, 84(3), 603-609. https://doi.org/10.1016/j.anbehav.2012.06.015

Conradt, L., Krause, J., Couzin, I. D., \& Roper, T. J. (2009). "Leading according to need" in selforganizing groups. The American Naturalist, 173(3), 304-12. https://doi.org/10.1086/596532

Conradt, L., \& Roper, T. J. (2003). Group decision-making in animals. Nature, 421(6919), 155-8. https://doi.org/10.1038/nature01294

Conradt, L., \& Roper, T. J. (2005). Consensus decision making in animals. Trends in Ecology \& Evolution, 20(8), 449-456. https://doi.org/10.1016/j.tree.2005.05.008

Conradt, L., \& Roper, T. J. (2007). Democracy in animals: the evolution of shared group decisions. Proceedings of the Royal Society B: Biological Sciences, 274(1623), 2317-26. https://doi.org/10.1098/rspb.2007.0186

Conradt, L., \& Roper, T. J. (2009). Conflicts of interest and the evolution of decision sharing. Philosophical Transactions of the Royal Society B, 364(1518), 807-819. https://doi.org/10.1098/rstb.2008.0257

Cooper Jr, W. E. (2003). Effect of risk on aspects of escape behavior by a lizard, <i>Holbrookia propinqua</, in relation to optimal escape theory. Ethology, 109(8), 617-626. https://doi.org/https://doi.org/10.1046/j.1439-0310.2003.00912.x

Couzin, I. D., \& Krause, J. (2003). Self-organization and collective behavior in vertebrates. Advances in the Study of Behavior, 32, 1-75. https://doi.org/10.1016/S0065-3454(03)01001-5

Couzin, I. D., Krause, J., Franks, N. R., \& Levin, S. A. (2005). Effective leadership and decisionmaking in animal groups on the move. Nature, 433(7025), 513-516.

Dammhahn, M. (2012). Are personality differences in a small iteroparous mammal maintained by a life-history trade-off? Proceedings of the Royal Society B: Biological Sciences, 279(1738), 2645-51. https://doi.org/10.1098/rspb.2012.0212

Dammhahn, M., \& Almeling, L. (2012). Is risk taking during foraging a personality trait? A field test for cross-context consistency in boldness. Animal Behaviour, 84(5), 1131-1139. https://doi.org/10.1016/j.anbehav.2012.08.014

DeBlois, E. M., \& Rose, G. A. (1996). Cross-shoal variability in the feeding habits of migrating Atlantic cod (Gadus morhua). Oecologia, 108, 192-196. 
Della-Rossa, L., Chadœuf, J., Boissy, A., \& Dumont, B. (2013). Leaders of spontaneous group movements influence whole-group social organization: an experimental study on grazing heifers. Behaviour, 150(2), 153-173. https://doi.org/10.1163/1568539X-00003043

Deneubourg, J., \& Goss, S. (1989). Collective patterns and decision-making. Ethology Ecology \& Evolution, 1, 295-311.

Di Bitetti, M. S., \& Janson, C. H. (2001). Social foraging and the finder's share in capuchin monkeys, Cebus apella. Animal Behaviour, 62(1), 47-56. https://doi.org/10.1006/anbe.2000.1730

Ducrest, A.-L., Keller, L., \& Roulin, A. (2008). Pleiotropy in the melanocortin system, coloration and behavioural syndromes. Trends in Ecology \& Evolution, 23(9), 502-510.

Dumont, B., \& Boissy, A. (2000). Grazing behaviour of sheep in a situation of conflict between feeding and social motivations, 49, 131-138.

Duplaix, N. (1980). Observations on the ecology and behavior of the giant river otter Pteronura brasiliensis in Suriname. Rev. Ecol. (Terre Vie), 34, 495--620.

Dyer, J. R. G., loannou, C. C., Morrell, L. J., Croft, D. P., Couzin, I. D., Waters, D. A., \& Krause, J. (2008). Consensus decision making in human crowds. Animal Behaviour, 75(2), 461-470. https://doi.org/10.1016/j.anbehav.2007.05.010

Dyer, J. R. G., Johansson, A., Helbing, D., Couzin, I. D., \& Krause, J. (2009). Leadership, consensus decision making and collective behaviour in humans. Proceedings of the Royal Society $B$ : Biological Sciences, 364, 781-789. https://doi.org/10.1098/rstb.2008.0233

Erhart, E. M., \& Overdorff, D. J. (1999). Female coordination of group travel in wild Propithecus and Eulemur. International Journal of Primatology, 20(6), 927-940.

Essen, L. von. (1988). A note on the lesser white-fronted goose Anser erythropus in Sweden and the result of a re-introduction scheme, 305-306.

Evans, J., Boudreau, K., \& Hyman, J. (2010). Behavioural syndromes in urban and rural populations of song sparrows. Ethology, 116, 588-595. https://doi.org/10.1111/j.14390310.2010.01771.x

Evans, R. M. (1982). Foraging-flock recruitment at a black-billed gull colony: implications for the information center hypothesis. The Auk, 99, 24-30.

Fairbanks, B., \& Dobson, F. (2007). Mechanisms of the group-size effect on vigilance in Columbian ground squirrels: dilution versus detection. Animal Behaviour, 73(1), 115-123. https://doi.org/10.1016/j.anbehav.2006.07.002

Faria, J. J., Krause, S., \& Krause, J. (2010). Collective behavior in road crossing pedestrians: The role of social information. Behavioral Ecology, 21(6), 1236-1242. https://doi.org/10.1093/beheco/arq141

Farine, D. R. (2014). Measuring phenotypic assortment in animal social networks: Weighted associations are more robust than binary edges. Animal Behaviour, 89, 141-153. https://doi.org/10.1016/j.anbehav.2014.01.001

Farine, D. R., Strandburg-Peshkin, A., Berger-Wolf, T., Ziebart, B., Brugere, I., Li, J., \& Crofoot, M. C. (2016). Both nearest neighbours and long-term affiliates predict individual locations during collective movement in wild baboons. Scientific Reports, 6(February), 27704. https://doi.org/10.1038/srep27704

Farine D. R., Strandburg-Peshkin, A., Couzin, I. D., Berger-Wolf, T., Crofoot, M. C. (2017) Individual variation in local interaction rules can explain emergent patterns of spatial organization in wild baboons. Proceedings of the Royal Society B: Biological Sciences, 284(1853), 20162243. https://doi:10.1098/rspb.2016.2243)

Fernández, V. a, Kowalewski, M., \& Zunino, G. E. (2013). Who is coordinating collective movements in black and gold howler monkeys? Primates, 54(2), 191-9. https://doi.org/10.1007/s10329-013-0342-x

Fichtel, C. (2012). Predation. In The Evolution of Primate Societies.

Fichtel, C., \& Hilgartner, R. (2013). Noises in the dark: Vocal communication in Lepilemur ruficaudatus and other nocturnal pair-living primates. In J. Masters, M. Gamba, \& F. Génin 
(Eds.), Leaping Ahead (pp. 297-304). New York, NY: Springer. https://doi.org/10.1007/9781-4614-4511-1

Fichtel, C., \& Kappeler, P. M. (2002). Anti-predator behavior of group-living Malagasy primates: mixed evidence for a referential alarm call system. Behavioral Ecology and Sociobiology, 51(3), 262-275. https://doi.org/10.1007/s00265-001-0436-0

Fichtel, C., \& Manser, M. (2010). Vocal communication in social groups. In P. M. Kappeler (Ed.), Animal behaviour: Evolution and mechanisms (pp. 29-54). Springer Berlin Heidelberg.

Fichtel, C., Pyritz, L. W., \& Kappeler, P. M. (2011). Coordination of group movements in non-human primates. In M. Boos, M. Kolbe, P. M. Kappeler, \& T. Ellwart (Eds.), Coordination in Human and Primate Groups (pp. 37-56). Berlin, Heidelberg: Springer-Verlag. https://doi.org/10.1007/978-3-642-15355-6

Fichtel, C., Schnoell, A. V, \& Kappeler, P. M. (2018). Measuring social tolerance: An experimental approach in two lemurid primates. Ethology, 124(1), 65-73. https://doi.org/10.1111/eth.12706

Fischer, J., \& Zinner, D. (2011). Communication and cognition in primate group movement. International Journal of Primatology, 32, 1279-1295. https://doi.org/10.1007/s10764-0119542-7

Fischhoff, I. R., Sundaresan, S. R., Cordingley, J., Larkin, H. M., Sellier, M.-J., \& Rubenstein, D. I. (2007). Social relationships and reproductive state influence leadership roles in movements of plains zebra, Equus burchellii. Animal Behaviour, 73(5), 825-831. https://doi.org/10.1016/j.anbehav.2006.10.012

Flack, A., Pettit, B., Freeman, R., Guilford, T., \& Biro, D. (2012). What are leaders made of? The role of individual experience in determining leader-follower relations in homing pigeons. Animal Behaviour, 83(3), 703-709. https://doi.org/10.1016/j.anbehav.2011.12.018

Foley, C., Pettorelli, N., \& Foley, L. (2008). Severe drought and calf survival in elephants. Biology Letters, 4(5), 541-544. https://doi.org/10.1098/rsbl.2008.0370

Fragaszy, D. M. (1990). Sex and age differences in the organization of behavior in wedge-capped capuchins, Cebus olivaceus. Behavioral Ecology, 1(1), 81-94.

Freeman, R., Mann, R., Guilford, T., \& Biro, D. (2011). Group decisions and individual differences: route fidelity predicts flight leadership in homing pigeons (Columba livia). Biology Letters, 7(1), 63-66. https://doi.org/10.1098/rsbl.2010.0627

Friard, O., \& Gamba, M. (2016). BORIS: a free, versatile open-source event-logging software for video/audio coding and live observations. Methods in Ecology and Evolution, 7(11), 13251330. https://doi.org/10.1111/2041-210X.12584

Frid, A., \& Dill, L. (2002). Human-caused disturbance stimuli as a form of predation risk. Conservation Ecology, 6(1), 16.

Furrer, R. D., Kunc, H. P., \& Manser, M. B. (2012). Variable initiators of group departure in a cooperative breeder: The influence of sex, age, state and foraging success. Animal Behaviour, 84(1), 205-212. https://doi.org/10.1016/j.anbehav.2012.04.034

Gall, G. E. C., \& Manser, M. B. (2017). Group cohesion in foraging meerkats: follow the moving 'vocal hot spot.' Royal Society Open Science, 4(4), 170004. https://doi.org/10.1098/rsos.170004

Gall, G. E. C., Strandburg-Peshkin, A., Clutton-Brock, T., \& Manser, M. B. (2017). As dusk falls: collective decisions about the return to sleeping sites in meerkats. Animal Behaviour, 132, 91-99.

Ginnett, T. F., \& Demment, M. W. (1997). Sex differences in giraffe foraging behavior at two spatial scales. Oecologia, 110(2), 291-300.

Graw, B., \& Manser, M. B. (2007). The function of mobbing in cooperative meerkats. Animal Behaviour, 74(3), 507-517. https://doi.org/10.1016/j.anbehav.2006.11.021

Hadfield, J. D. (2010). MCMC methods for multi-response generalized linear mixed models: the MCMCgImm R package. Journal of Statistical Software, 33(22), 1--22. 
Harcourt, J. L., Ang, T. Z., Sweetman, G., Johnstone, R. A., \& Manica, A. (2009). Social feedback and the emergence of leaders and followers. Current Biology, 19(3), 248-252. https://doi.org/10.1016/j.cub.2008.12.051

Hardesty-Moore, M., Deinet, S., Freeman, R., Titcomb, G. C., Dillon, E. M., Stears, K., ... Hardestymoore, M. (2018). Migration in the Anthropocene: how collective navigation , environmental system and taxonomy shape the vulnerability of migratory species. Phil Trans $R$ Soc B, 373(20170017).

Hass, C., \& Valenzuela, D. (2002). Anti-predator benefits of group living in white-nosed coatis (Nasua narica). Behavioral Ecology and Sociobiology, 51(6), 570-578. https://doi.org/10.1007/s00265-002-0463-5

Haunhorst, C. B., Schülke, O., \& Ostner, J. (2016). Opposite-sex social bonding in wild Assamese macaques. American Journal of Primatology, 882(April), 1-11. https://doi.org/10.1002/ajp.22554

Heinsohn, R., \& Packer, C. (1995). Complex cooperative strategies in group-territorial African lions. Science, 269(5228), 1260-1262.

Herbert-Read, J. E., Perna, A., Mann, R. P., Schaerf, T. M., Sumpter, D. J. T., \& Ward, A. J. W. (2011). Inferring the rules of interaction of shoaling fish. Proceedings of the National Academy of Sciences of the United States of America, 108(46), 18726-31. https://doi.org/10.1073/pnas.1109355108

Hewitson, L., Gordon, I. J., \& Dumont, B. (2007). Social context affects patch-leaving decisions of sheep in a variable environment. Animal Behaviour, 74(2), 239-246. https://doi.org/10.1016/j.anbehav.2006.07.020

Hockings, K. J., Anderson, J. R., \& Matsuzawa, T. (2006). Road crossing in chimpanzees: a risky business. Current Biology, 16(17), R668-70. https://doi.org/10.1016/j.cub.2006.08.019

Holekamp, K. E., Boydston, E. E., \& Smale, L. (2000). Group travel in social carnivores. In S. Boinski \& P. A. Garber (Eds.), On the Move: How and Why Animals Travel in Groups (pp. 587-627). Chicago: University of Chicago Press.

Holm, S. (1979). A simple sequentially rejective multiple test procedure. Scandinavian Journal of Statistics, 6, 65-70.

Hongo, S. (2014). New evidence from observations of progressions of mandrills (Mandrillus sphinx): a multilevel or non-nested society? Primates, 55(4), 473-481. https://doi.org/10.1017/CBO9781107415324.004

Hothorn, T. (2016). Additional multcomp examples.

Hothorn, T., Bretz, F., \& Westfall, P. (2008). Simultaneous inference in general parametric models. Biometrical Journal, 50(3), 346-363.

Huebner, F., \& Fichtel, C. (2015). Innovation and behavioral flexibility in wild red-fronted lemurs (Eulemur rufifrons). Animal Cognition, 18(3), 777-787. https://doi.org/10.1007/s10071-0150844-6

Hughey, L. F., Hein, A. M., Strandburg-peshkin, A., \& Jensen, F. (2018). Challenges and solutions for studying collective animal behavior in the wild.

Ihl, C., \& Bowyer, R. T. (2011). Leadership in mixed-sex groups of muskoxen during the snow-free season. Journal of Mammalogy, 92(4), 819-827. https://doi.org/10.1644/10-MAMM-A109.1

Jacobs, A. T., Sueur, C., Deneubourg, J.-L., \& Petit, O. (2011). Social network influences decision making during collective movements in brown lemurs (Eulemur fulvus fulvus). International Journal of Primatology, 32(3), 721-736. https://doi.org/10.1007/s10764-011-9497-8

Jacobs, A. T., Watanabe, K., \& Petit, O. (2011). Social structure affects initiations of group movements but not recruitment success in Japanese macaques (Macaca fuscata). International Journal of Primatology, 32(6), 1311-1324. https://doi.org/10.1007/s10764011-9554-3

Jolles, J. W., Fleetwood-Wilson, A., Nakayama, S., Stumpe, M. C., Johnstone, R. A., \& Manica, A. 
(2015). The role of social attraction and its link with boldness in the collective movements of three-spined sticklebacks. Animal Behaviour, 99, 147-153. https://doi.org/10.1016/j.anbehav.2014.11.004

Joubert, A., \& Vauclair, J. (1986). Reaction to novel objects in a troop of Guinea baboons: Approach and manipulation. Behaviour. https://doi.org/10.1163/156853986X00234

Kalbitz, J., Ostner, J., \& Schülke, O. (2016). Strong, equitable and long-term social bonds in the dispersing sex in Assamese macaques. Animal Behaviour, 113, 13-22. https://doi.org/10.1016/j.anbehav.2015.11.005

Kaplan, B. S., O'Riain, M. J., van Eeden, R., \& King, A. J. (2011). A low-cost manipulation of food resources reduces spatial overlap between baboons (Papio ursinus) and humans in conflict. International Journal of Primatology, 32(6), 1397-1412. https://doi.org/10.1007/s10764011-9541-8

Kappeler, P. M. (1999). Convergence and divergence in primate social systems. In J. G. Fleagle, C. Janson, \& K. E. Reed (Eds.), Primate Communities. Cambridge: Cambridge University Press.

Kappeler, P. M., \& Erkert, H. G. (2003). On the move around the clock: correlates and determinants of cathemeral activity in wild red-fronted lemurs (Eulemur fulvus rufus). Behavioral Ecology and Sociobiology, 54(4), 359-369. https://doi.org/10.1007/s00265-003-0652-x

Kappeler, P. M., \& Fichtel, C. (2012a). A 15-Year Perspective on the Social Organization and Life History of Sifaka in Kirindy Forest. In P. M. Kappeler \& D. P. Watts (Eds.), Long-Term Field Studies of Primates (pp. 101-121). Berlin Heidelberg: Springer. https://doi.org/10.1007/9783-642-22514-7

Kappeler, P. M., \& Fichtel, C. (2012b). Female reproductive competition in Eulemur rufifrons: eviction and reproductive restraint in a plurally breeding Malagasy primate. Molecular Ecology, 21(3), 685-98. https://doi.org/10.1111/j.1365-294X.2011.05255.x

Kerth, G., Ebert, C., \& Schmidtke, C. (2006). Group decision making in fission-fusion societies: evidence from two-field experiments in Bechstein's bats. Proceedings of the Royal Society B: Biological Sciences, 273(1602), 2785-90. https://doi.org/10.1098/rspb.2006.3647

King, A. J. (2010). Follow me! I'm a leader if you do; I'm a failed initiator if you don't? Behavioural Processes, 84(3), 671-4. https://doi.org/10.1016/j.beproc.2010.03.006

King, A. J., Clark, F. E., \& Cowlishaw, G. (2011). The dining etiquette of desert baboons: the roles of social bonds, kinship, and dominance in co-feeding networks. American Journal of Primatology, 73(8), 768-74. https://doi.org/10.1002/ajp.20918

King, A. J., Douglas, C. M. S., Huchard, E., Isaac, N. J. B., \& Cowlishaw, G. (2008). Dominance and affiliation mediate despotism in a social primate. Current Biology, 18(23), 1833-8. https://doi.org/10.1016/j.cub.2008.10.048

King, A. J., Fehlmann, G., Biro, D., Ward, A. J., \& Fürtbauer, I. (2018). Re-wilding Collective Behaviour: An Ecological Perspective. Trends in Ecology \& Evolution, 33(5), 347-357. https://doi.org/10.1016/j.tree.2018.03.004

King, A. J., \& Fürtbauer, I. (2017). Collective Decision Making. In A. Fuentes (Ed.), The International Encyclopedia of Primatology (pp. 1-5). John Wiley \& Sons, Inc. https://doi.org/10.1007/9783-642-02865-6

King, A. J., Johnson, D. D. P., \& Van Vugt, M. (2009). The origins and evolution of leadership. Current Biology, 19(19), R911-916. https://doi.org/10.1016/j.cub.2009.07.027

King, A. J., \& Sueur, C. (2011). Where next? Group coordination and collective decision making by primates. International Journal of Primatology, 32(6), 1245-1267. https://doi.org/10.1007/s10764-011-9526-7

King, A. J., Sueur, C., Huchard, E., \& Cowlishaw, G. (2011). A rule-of-thumb based on social affiliation explains collective movements in desert baboons. Animal Behaviour, 82(6), 13371345. https://doi.org/10.1016/j.anbehav.2011.09.017

Köhler, D. (1976). The interaction between conditioned fish and naive schools of juvenile carp (Cyprinus carpio, pisces). Behavioural Processes, 1(3), 267-275. 
Koolhaas, J. M., Korte, S. M., De Boer, S. F., Van Der Vegt, B. J., Van Reenen, C. G., Hopster, H., ... Blokhuis, H. J. (1999). Coping styles in animals: current status in behavior and stressphysiology. Neuroscience \& Biobehavioral Reviews, 23(7), 925-35.

Krause, J. (1993). The relationship between foraging and shoal position in a mixed shoal of roach (Rutilus rutilus) and chub (Leuciscus cephalus): a field study. Oecologia, 93, 356-359.

Krause, J., Reeves, P., \& Hoare, D. (1998). Positioning behaviour in roach shoals: the role of body length and nutritional state. Behaviour, 135(8), 1031-1039.

Krause, J., \& Ruxton, G. D. (2002). Living in groups. Oxford, England: Oxford University Press.

Krause, J., Ruxton, G. D., \& Rubenstein, D. I. (1998). Is there always an influence of shoal size on predator hunting success? Journal of Fish Biology, 52, 494-501.

Krebs, J. R., MacRoberts, M. H., \& Cullen, J. M. (1972). Flocking and feeding in the great tit Parus major - an experimental study. Ibis, 114(4), 507-530. https://doi.org/10.1111/j.1474919X.1972.tb00852.x

Kulahci, I. G., Rubenstein, D. I., \& Ghazanfar, A. A. (2015). Lemurs groom-at-a-distance through vocal networks. Animal Behaviour, 110, 179-186. https://doi.org/10.1016/j.anbehav.2015.09.016

Kummer, H. (1968). Social organization of hamadryas baboons. Chicago: University of Chicago Press.

Kurvers, R. H. J. M., Adamczyk, V. M. a P., van Wieren, S. E., \& Prins, H. H. T. (2011). The effect of boldness on decision-making in barnacle geese is group-size-dependent. Proceedings of the Royal Society B: Biological Sciences, 278(1714), 2018-24. https://doi.org/10.1098/rspb.2010.2266

Kurvers, R. H. J. M., Eijkelenkamp, B., van Oers, K., van Lith, B., van Wieren, S. E., Ydenberg, R. C., \& Prins, H. H. T. (2009). Personality differences explain leadership in barnacle geese. Animal Behaviour, 78(2), 447-453. https://doi.org/10.1016/j.anbehav.2009.06.002

Kuznetsova, A., Bruun Brockhoff, P., \& Haubo Bojesen Christensen, R. (2015). ImerTest: Tests in Linear Mixed Effects Models. R package version 2.0-29.

Landeau, L., \& Terborgh, J. (1986). Oddity and the "confusion effect" in predation. Animal Behaviour, 34, 1372-1380.

Leblond, C., \& Reebs, S. G. (2006). Individual leadership and boldness in shoals of golden shiners (Notemigonus crysoleucas). Behaviour, 143(10), 1263-1280.

Leca, J.-B., Gunst, N., Thierry, B., \& Petit, O. (2003). Distributed leadership in semifree-ranging white-faced capuchin monkeys. Animal Behaviour, 66(6), 1045-1052. https://doi.org/10.1006/anbe.2003.2276

Lee, H. C., \& Teichroeb, J. A. (2016). Partially shared consensus decision making and distributed leadership in vervet monkeys: Older females lead the group to forage. American Journal of Physical Anthropology, (November 2015), 1-11. https://doi.org/10.1002/ajpa.23058

Lewis, J. S., Wartzok, D., \& Heithaus, M. R. (2013). Individuals as information sources: Could followers benefit from leaders' knowledge? Behaviour, 150(6), 635-657. https://doi.org/10.1163/1568539X-00003075

Lusseau, D. (2006). Why do dolphins jump? Interpreting the behavioural repertoire of bottlenose dolphins (Tursiops sp.) in Doubtful Sound, New Zealand. Behavioural Processes, 73(3), 257265. https://doi.org/10.1016/j.beproc.2006.06.006

Lusseau, D., \& Conradt, L. (2009). The emergence of unshared consensus decisions in bottlenose dolphins. Behavioral Ecology and Sociobiology, 63(7), 1067-1077.

McComb, K. (2011). Leadership in elephants: the adaptive value of age. Proceedings of the Royal Society B: Biological Sciences, 278(1722), 3270-6. https://doi.org/10.1098/rspb.2011.0168

McComb, K., Moss, C., Durant, S. M., Baker, L., \& Sayialel, S. (2001). Matriarchs as repositories of social knowledge in African elephants. Science, 292(5516), 491-4. https://doi.org/10.1126/science.1057895

Meunier, H., Leca, J.-B., Deneubourg, J.-L., \& Petit, O. (2006). Group movement decisions in 
capuchin monkeys: the utility of an experimental study and a mathematical model to explore the relationship between individual and collective behaviours. Behaviour, 143(12), 15111528.

Micheletta, J., Waller, B. M., Panggur, M. R., Neumann, C., Duboscq, J., Agil, M., \& Engelhardt, A. (2012). Social bonds affect anti-predator behaviour in a tolerant species of macaque, Macaca nigra. Proceedings of the Royal Society B: Biological Sciences, 279(1744), 4042-50. https://doi.org/10.1098/rspb.2012.1470

Mittermeier, R. A., Louis Jr., E. E., Richardson, M., Schwitzer, C., Langrand, O., Rylands, A. B., ... Mackinnon, J. (2010). Lemurs of Madagascar (3rd ed.). Arlington, VA: Conservation International.

Morrell, L. J., \& Romey, W. L. (2008). Optimal individual positions within animal groups. Behavioral Ecology, 19(4), 909-919. https://doi.org/10.1093/beheco/arn050

Mueller, T., O'Hara, R. B., Converse, S. J., Urbanek, R. P., \& Fagan, W. F. (2013). Social learning of migratory performance. Science, 341, 999-1003.

Nakagawa, S., \& Schielzeth, H. (2010). Repeatability for Gaussian and non-Gaussian data: a practical guide for biologists. Biological Reviews of the Cambridge Philosophical Society, 85(4), 935-56. https://doi.org/10.1111/j.1469-185X.2010.00141.x

Nakayama, S., Johnstone, R. A., \& Manica, A. (2012). Temperament and hunger interact to determine the emergence of leaders in pairs of foraging fish. PLOS ONE, 7(8), e43747. https://doi.org/10.1371/journal.pone.0043747

Neumann, C., Agil, M., Widdig, A., \& Engelhardt, A. (2013). Personality of wild male crested macaques (Macaca nigra). PLOS ONE, 8(8), e69383. https://doi.org/10.1371/journal.pone.0069383

O'Connell-Rodwell, C. E., Wood, J. D., Wyman, M., Redfield, S., Puria, S., \& Hart, L. a. (2012). Antiphonal vocal bouts associated with departures in free-ranging African elephant family groups (Loxodonta africana). Bioacoustics: The International Journal of Animal Sound and Its Recording, 21(3), 215-224. https://doi.org/10.1080/09524622.2012.686166

Osborne, R. W. (1999). A historical ecology of Salish Sea 'resident' killer whales (Orcinus orca): with implications for management. University of Victoria.

Öst, M., \& Jaatinen, K. (2013). Relative importance of social status and physiological need in determining leadership in a social forager. PLOS ONE, 8(5), e64778. https://doi.org/10.1371/journal.pone.0064778

Patel, E. R., \& Owren, M. J. (2012). Silky sifaka (Propithecus candidus) "zzuss" vocalizations: sexual dimorphism, individuality, and function in the alarm call of a monomorphic lemur. The Journal of the Acoustical Society of America, 132(3), 1799-810. https://doi.org/10.1121/1.4740475

Pereira, M. E., \& Kappeler, P. M. (1997). Divergent systems of agonistic behaviour in lemurid primates. Behaviour, 134(3-4), 225-274.

Pereira, M. E., Kaufman, R., Kappeler, P. M., \& Overdorff, D. J. (1990). Female dominance does not characterize all of the Lemuridae. Folia Primatologica, 55(2), 96-103. https://doi.org/10.1159/000156505

Péter, A. (2017). Solomon Coder: A simple and free solution for behavior coding.

Peterson, R. O., Jacobs, A. K., Drummer, T. D., Mech, L. D., \& Smith, D. W. (2002). Leadership behavior in relation to dominance and reproductive status in gray wolves, Canis lupus. Canadian Journal of Zoology, 80(8), 1405-1412. https://doi.org/10.1139/Z02-124

Petit, O., \& Bon, R. (2010). Decision-making processes: The case of collective movements. Behavioural Processes, 84, 635-647.

Petit, O., Gautrais, J., Leca, J.-B., Theraulaz, G., \& Deneubourg, J.-L. (2009). Collective decisionmaking in white-faced capuchin monkeys. Proceedings of the Royal Society B: Biological Sciences, 276(1672), 3495-503. https://doi.org/10.1098/rspb.2009.0983

Pflüger, F. J., \& Fichtel, C. (2012). On the function of red-fronted lemur's close calls. Animal 
Cognition, 15(5), 823-31. https://doi.org/10.1007/s10071-012-0507-9

Pillot, M. H., Gautrais, J., Gouello, J., Michelena, P., Sibbald, A. M., \& Bon, R. (2010). Moving together: Incidental leaders and naïve followers. Behavioural Processes, 83(3), 235-41. https://doi.org/10.1016/j.beproc.2009.11.006

Poole, J. H., Payne, K., Langbauer Jr., W. R., \& Moss, C. J. (1988). The social contexts of some very low frequency calls of African elephants. Behavioral Ecology and Sociobiology, 22, 385-392.

Prins, H. H. T. (1989). Buffalo herd structure and its repercussions for condition of individual African buffalo cows. Ethology, 81, 47-71.

Prins, H. H. T. (1996). Ecology and behaviour of the African buffalo: social inequality and decision making. Springer.

Pulliam, H. R. (1973). On the advantages of flocking. Journal of Theoretical Biology, 38(2), 419422.

Pyritz, L. W., Fichtel, C., Huchard, E., \& Kappeler, P. M. (2013). Determinants and outcomes of decision-making, group coordination and social interactions during a foraging experiment in a wild primate. PLOS ONE, 8(1), e53144. https://doi.org/10.1371/journal.pone.0053144

Pyritz, L. W., Kappeler, P. M., \& Fichtel, C. (2011). Coordination of group movements in wild redfronted lemurs (Eulemur rufifrons): Processes and influence of ecological and reproductive seasonality. International Journal of Primatology, 32(6), 1325-1347. https://doi.org/10.1007/s10764-011-9549-0

Pyritz, L. W., King, A. J., Sueur, C., \& Fichtel, C. (2011). Reaching a consensus: Terminology and concepts used in coordination and decision-making research. International Journal of Primatology, 32(6), 1268-1278. https://doi.org/10.1007/s10764-011-9524-9

R Core Team. (2014). R: A language and environment for statistical computing. Vienna, Austria: R Foundation for Statistical Computing.

Radford, A. N. (2004). Vocal coordination of group movement by green woodhoopoes (Phoeniculus purpureus). Ethology, 110(1), 11-20. https://doi.org/10.1046/j.14390310.2003.00943.x

Ramanankirahina, R., Joly, M., Scheumann, M., \& Zimmermann, E. (2016). The role of acoustic signaling for spacing and group coordination in a nocturnal, pair-living primate, the western woolly lemur (Avahi occidentalis). American Journal of Physical Anthropology, 159(6), 466477. https://doi.org/10.1002/ajpa.22898

Ramos, A., Petit, O., Longour, P., Pasquaretta, C., \& Sueur, C. (2015). Collective decision making during group movements in European bison, Bison bonasus. Animal Behaviour, 109(January 2016), 149-160. https://doi.org/10.1016/j.anbehav.2015.08.016

Ramseyer, A., Boissy, A., Dumont, B., \& Thierry, B. (2009). Decision making in group departures of sheep is a continuous process. Animal Behaviour, 78(1), 71-78. https://doi.org/10.1016/j.anbehav.2009.03.017

Ramseyer, A., Boissy, A., Thierry, B., \& Dumont, B. (2009). Individual and social determinants of spontaneous group movements in cattle and sheep. Animal, 3(9), 1319-26. https://doi.org/10.1017/S1751731109004790

Ramseyer, A., Petit, O., \& Thierry, B. (2009a). Decision-making in group departures of female domestic geese. Behaviour, 146(3), 351-371(21). https://doi.org/10.1163/156853909X410955

Ramseyer, A., Petit, O., \& Thierry, B. (2009b). Patterns of group movements in juvenile domestic geese. Journal of Ethology, 27(3), 369-375. https://doi.org/10.1007/s10164-008-0128-6

Ramseyer, A., Thierry, B., Boissy, A., \& Dumont, B. (2009). Decision-making processes in group departures of cattle. Ethology, 115(10), 948-957. https://doi.org/10.1111/j.14390310.2009.01686.x

Rasa, O. A. E. (1987). The dwarf mongoose: a study of behavior and social structure in relation to ecology in a small, social carnivore. In J. S. Rosenblatt (Ed.), Advances in the Study of Behavior Volume 17 (pp. 121-163). Academic Press. 
Rasoloharijaona, S., Randrianambinina, B., Braune, P., \& Zimmermann, E. (2006). Loud calling, spacing, and cohesiveness in a nocturnal primate, the Milne Edwards' sportive lemur (Lepilemur edwardsi). American Journal of Physical Anthropology, 129(4), 591-600. https://doi.org/10.1002/ajpa

Raveling, D. G. (1969). Preflight and flight behavior of Canada geese. Auk, 86, 671-681.

Réale, D., \& Festa-Bianchet, M. (2003). Predator-induced natural selection on temperament in bighorn ewes. Animal Behaviour, 65, 463-470. https://doi.org/10.1006/anbe.2003.2100

Réale, D., Reader, S. M., Sol, D., McDougall, P. T., \& Dingemanse, N. J. (2007). Integrating animal temperament within ecology and evolution. Biological Reviews, 82(2), 291-318. https://doi.org/10.1111/j.1469-185X.2007.00010.x

Reebs, S. G. (2000). Can a minority of informed leaders determine the foraging movements of a fish shoal? Animal Behaviour, 59, 403-409. https://doi.org/10.1006/anbe.1999.1314

Reinhardt, V., \& Reinhardt, A. (1981). Cohesive relationships in a cattle herd (Bos indicus). Behaviour, 77(3), 121-151.

Rendall, D., Seyfarth, R., Cheney, D., \& Owren, M. (1999). The meaning and function of grunt variants in baboons. Animal Behaviour, 57(3), 583-592. https://doi.org/10.1006/anbe.1998.1031

Rhine, R. J. (1975). The order of movement of yellow baboons (Papio cynocephalus). Folia Primatologica, 23(1-2), 72-104. https://doi.org/10.1159/000155662

Rhine, R. J., Bioland, P., \& Lodwick, L. (1985). Progressions of adult male chacma baboons (Papio ursinus) in the Moremi Wildlife Reserve. International Journal of Primatology, 6(2), 115-122. https://doi.org/10.1007/BF02693649

Rhine, R. J., \& Tilson, R. (1987). Reactions to fear as a proximate factor in the sociospatial organization of baboon progressions. American Journal of Primatology, 13, 119-128.

Rittschof, C. C., \& Seeley, T. D. (2008). The buzz-run: how honeybees signal "Time to go!" Animal Behaviour, 75(1), 189-197. https://doi.org/10.1016/j.anbehav.2007.04.026

Rothman, J. M., Dierenfeld, E. S., Hintz, H. F., \& Pell, A. N. (2008). Nutritional quality of gorilla diets: Consequences of age, sex, and season. Oecologia, 155(1), 111-122. https://doi.org/10.1007/s00442-007-0901-1

Rout, P. ., Mandal, A., Singh, L. ., \& Roy, R. (2002). Studies on behavioral patterns in Jamunapari goats. Small Ruminant Research, 43(2), 185-188. https://doi.org/10.1016/s09214488(02)00011-1

Sapolsky, R. M., Alberts, S. C., \& Altmann, J. (1997). Hypercortisolism associated with social subordinace or social isolation among wild baboons. Archives of General Psychiatry, 54(12), 1137-1143. https://doi.org/10.1001/archpsyc.1997.01830240097014

Sasaki, T., Mann, R. P., Warren, K. N., Herbert, T., Wilson, T., \& Biro, D. (2018). Personality and the collective: bold homing pigeons occupy higher leadership ranks in flocks. Phil Trans $R \operatorname{Soc} B$, 373(20170017).

Sauther, M. L. (1994). Wild plant use by pregnant and lactating ringtailed lemurs, with implications for early hominid foraging. In N. L. Etkin (Ed.), Eating on the Wild Side: The Pharmacologic, Ecologic and Social Implications of Using Noncultigens (pp. 240-256). Tucson, Arizona: University of Arizona Press.

Sauther, M. L., \& Sussman, R. W. (1993). A new interpretation of the social organization and mating system of the ringtailed lemur (Lemur catta). In J. Ganzhorn \& P. M. Kappeler (Eds.), Lemur Social Systems and their Ecological Basis (pp. 111-121). New York: Plenum Press. https://doi.org/10.1007/978-1-4899-2412-4_8

Scantlebury, M., Russell, A. F., Mcllrath, G. M., Speakman, J. R., \& Clutton-Brock, T. H. (2002). The energetics of lactation in cooperatively breeding meerkats, Suricata suricatta. Proceedings of the Royal Society of London Series B-Biological Sciences, 269(1505), 2147-2153. https://doi.org/10.1098/rspb.2002.2108

Schaller, G. B. (1963). The mountain gorilla: Ecology and behavior. Chicago, IL: University of 
Chicago Press.

Schnoell, A. V., \& Fichtel, C. (2012). Wild red-fronted lemurs (Eulemur rufifrons) use social information to learn new foraging techniques. Animal Cognition, 15(4), 505-16. https://doi.org/10.1007/s10071-012-0477-y

Schuett, W., \& Dall, S. R. X. (2009). Sex differences, social context and personality in zebra finches, Taeniopygia guttata. Animal Behaviour, 77(5), 1041-1050. https://doi.org/10.1016/j.anbehav.2008.12.024

Seeley, T. D., \& Tautz, J. (2001). Worker piping in honey bee swarms and its role in preparing for liftoff. Journal of Comparative Physiology - A Sensory, Neural, and Behavioral Physiology, 187(8), 667-676. https://doi.org/10.1007/s00359-001-0243-0

Seltmann, A., Franz, M., Majolo, B., Qarro, M., Ostner, J., \& Schülke, O. (2016). Recruitment and monitoring behaviors by leaders predict following in wild Barbary macaques (Macaca sylvanus). Primate Biology, 3(2), 23-31. https://doi.org/10.5194/pb-3-23-2016

Seltmann, A., Majolo, B., Schülke, O., \& Ostner, J. (2013). The organization of collective group movements in wild Barbary macaques (Macaca sylvanus): Social structure drives processes of group coordination in macaques. PLOS ONE, 8(6), e67285. https://doi.org/10.1371/journal.pone.0067285

Seltmann, M. W., Öst, M., Jaatinen, K., Atkinson, S., Mashburn, K., \& Hollmén, T. (2012). Stress responsiveness, age and body condition interactively affect flight initiation distance in breeding female eiders. Animal Behaviour, 84(4), 889-896. https://doi.org/10.1016/j.anbehav.2012.07.012

Sih, A., \& Bell, A. M. (2008). Insights for behavioral ecology from behavioral syndromes. Advances in the Study of Behavior, 38, 227-281. https://doi.org/10.1016/S0065-3454(08)00005-3

Sih, A., Bell, A. M., \& Johnson, J. C. (2004). Behavioral syndromes: an ecological and evolutionary overview. Trends in Ecology \& Evolution, 19(7), 372-8.

https://doi.org/10.1016/j.tree.2004.04.009

Silk, J. B. (2007). The adaptive value of sociality in mammalian groups. Philosophical Transactions of the Royal Society of London B, 362(1480), 539-59. https://doi.org/10.1098/rstb.2006.1994

Silk, J. B., Altmann, J., \& Alberts, S. C. (2006). Social relationships among adult female baboons (Papio cynocephalus) I. Variation in the strength of social bonds. Behavioral Ecology and Sociobiology, 61(2), 183-195. https://doi.org/10.1007/s00265-006-0249-2

Silk, J., Cheney, D., \& Seyfarth, R. (2013). A practical guide to the study of social relationships. Evolutionary Anthropology, 22(5), 213-225. https://doi.org/10.1002/evan.21367

Smith, A. C., Buchanan-Smith, H. M., Surridge, A. K., \& Mundy, N. I. (2003). Leaders of progressions in wild mixed-species troops of saddleback (Saguinus fuscicollis) and mustached tamarins (S. mystax), with emphasis on color vision and sex. American Journal of Primatology, 61(4), 14557. https://doi.org/10.1002/ajp.10117

Smith, J. E., Estrada, J. R., Richards, H. R., Dawes, S. E., Mitsos, K., \& Holekamp, K. E. (2015). Collective movements, leadership and consensus costs at reunions in spotted hyaenas. Animal Behaviour, 105, 187-200. https://doi.org/10.1016/j.anbehav.2015.04.023

Smith, J. E., Gavrilets, S., Mulder, M. B., Hooper, P. L., Mouden, C. El, Nettle, D., ... Smith, E. A. (2015). Leadership in Mammalian Societies: Emergence, Distribution, Power, and Payoff. Trends in Ecology \& Evolution, xx(1), 1-13. https://doi.org/10.1016/j.tree.2015.09.013

Sperber, A. L., Werner, L. M., Kappeler, P. M., \& Fichtel, C. (2017). Grunt to go - Vocal coordination of group movements in redfronted lemurs. Ethology, 123(12), 894-905.

https://doi.org/10.1111/eth.12663

Spiegelhalter, D. J., Best, N. G., Carlin, B. P., \& Van Der Linde, A. (2002). Bayesian measures of model complexity and fit. Journal of the Royal Statistical Society. Series B: Statistical Methodology, 64(4), 583-616. https://doi.org/10.1111/1467-9868.00353

Sternalski, A., \& Bretagnolle, V. (2010). Experimental evidence of specialised phenotypic roles in a 
mobbing raptor. Behavioral Ecology and Sociobiology, 64(8), 1351-1361. https://doi.org/10.1007/s00265-010-0950-z

Stewart, K. J., \& Harcourt, A. H. (1994). Gorillas' vocalizations during rest periods: Signals of impending departure? Behaviour, 130(1-2), 29-40.

Stöwe, M., Bugnyar, T., Heinrich, B., \& Kotrschal, K. (2006). Effects of group size on approach to novel objects in ravens (Corvus corax). Ethology, 112(11), 1079-1088. https://doi.org/10.1111/j.1439-0310.2006.01273.x

Stueckle, S., \& Zinner, D. (2008). To follow or not to follow: decision making and leadership during the morning departure in chacma baboons. Animal Behaviour, 75(6), 1995-2004. https://doi.org/10.1016/j.anbehav.2007.12.012

Sueur, C. (2011). Group decision-making in chacma baboons: leadership, order and communication during movement. BMC Ecology, 11(1), 26. https://doi.org/10.1186/14726785-11-26

Sueur, C., Deneubourg, J.-L., \& Petit, O. (2010). Sequence of quorums during collective decision making in macaques. Behavioral Ecology and Sociobiology, 64(11), 1875-1885. https://doi.org/10.1007/s00265-010-0999-8

Sueur, C., Deneubourg, J.-L., \& Petit, O. (2011). From the first intention movement to the last joiner: macaques combine mimetic rules to optimize their collective decisions. Proceedings of the Royal Society B: Biological Sciences, 278(1712), 1697-704. https://doi.org/10.1098/rspb.2010.2084

Sueur, C., MacIntosh, A. J. J., Jacobs, A. T., Watanabe, K., \& Petit, O. (2013). Predicting leadership using nutrient requirements and dominance rank of group members. Behavioral Ecology and Sociobiology, 67(3), 457-470. https://doi.org/10.1007/s00265-012-1466-5

Sueur, C., \& Petit, O. (2008a). Organization of group members at departure is driven by social structure in Macaca. International Journal of Primatology, 29, 1085-1098. https://doi.org/10.1007/s10764-008-9262-9

Sueur, C., \& Petit, O. (2008b). Shared or unshared consensus decision in macaques? Behavioural Processes, 78(1), 84-92. https://doi.org/10.1016/j.beproc.2008.01.004

Sueur, C., \& Petit, O. (2010). Signals use by leaders in Macaca tonkeana and Macaca mulatta: group-mate recruitment and behaviour monitoring. Animal Cognition, 13(2), 239-48. https://doi.org/10.1007/s10071-009-0261-9

Sueur, C., Petit, O., \& Deneubourg, J.-L. (2009). Selective mimetism at departure in collective movements of Macaca tonkeana: an experimental and theoretical approach. Animal Behaviour, 78(5), 1087-1095. https://doi.org/10.1016/j.anbehav.2009.07.029

Sutherland, W. J. (1998). The importance of behavioural studies in conservation biology. Animal Behaviour, 56(4), 801-809. https://doi.org/10.1006/anbe.1998.0896

Sutherland, W. J. (2011). Evidence for Flexibility and Constraint in Migration Systems, 29(4), 441446.

Team, R. C. (2014). R: A language and environment for statistical computing. Vienna, Austria: R Foundation for Statistical Computing.

Tecot, S. R., \& Romine, N. K. (2012). Leading ladies: leadership of group movements in a pair-living, co-dominant, monomorphic primate across reproductive stages and fruit availability seasons. American Journal of Primatology, 74(7), 591-601. https://doi.org/10.1002/ajp.22011

Terborgh, J. (1983). Five New World Primates: A Study in Comparative Ecology. Princeton, New Jersey: Princeton University Press.

Thornton, A., \& Malapert, A. (2009). Experimental evidence for social transmission of food acquisition techniques in wild meerkats. Animal Behaviour, 78(2), 255-264. https://doi.org/10.1016/j.anbehav.2009.04.021

Tokuyama, N., \& Furuichi, T. (2017). Leadership of old females in collective departures in wild bonobos (Pan paniscus) at Wamba. Behavioral Ecology and Sociobiology, 71(3), 55. 
https://doi.org/10.1007/s00265-017-2277-5

Tóth, Z., Bókony, V., Lendvai, A. Z., Szabó, K., Pénzes, Z., \& Liker, A. (2009). Whom do the sparrows follow? The effect of kinship on social preference in house sparrow flocks. Behavioural Processes, 82(2), 173-177. https://doi.org/10.1016/j.beproc.2009.06.003

Trillmich, J., Fichtel, C., \& Kappeler, P. M. (2004). Coordination of group movements in wild Verreaux's sifakas (Propithecus verreauxi). Behaviour, 141(9), 1103-1120.

Twiss, S. D., Culloch, R., \& Pomeroy, P. P. (2012). An in-field experimental test of pinniped behavioral types. Marine Mammal Science, 28(3), 415-429. https://doi.org/10.1111/j.1748-7692.2011.00523.x

Van Belle, S., Estrada, A., \& Garber, P. A. (2013). Collective group movement and leadership in wild black howler monkeys (Alouatta pigra). Behavioral Ecology and Sociobiology, 67(1), 31-41. https://doi.org/10.1007/s00265-012-1421-5

van Oers, K., Klunder, M., \& Drent, P. J. (2005). Context dependence of personalities: risk-taking behavior in a social and a nonsocial situation. Behavioral Ecology, 16(4), 716-723. https://doi.org/10.1093/beheco/ari045

van Schaik, C. P. (1983). Why are diurnal primates living in groups? Behaviour, 87(1), 120-144.

Verdolin, J. L., \& Harper, J. (2013). Are shy individuals less behaviorally variable? Insights from a captive population of mouse lemurs. Primates. https://doi.org/10.1007/s10329-013-0360-8

Vickery, W. L., Giraldeau, L.-A., Templeton, J. J., Kramer, D. L., \& Chapman, C. A. (1991). Producers, scroungers, and group foraging. The American Naturalist, 137(6), 847-863.

Visscher, P. K., \& Seeley, T. D. (2007). Coordinating a group departure: who produces the piping signals on honeybee swarms? Behavioral Ecology and Sociobiology, 61(10), 1615-1621. https://doi.org/10.1007/s00265-007-0393-3

Volampeno, M. S. N., Masters, J. C., \& Downs, C. T. (2011). Life history traits, maternal behavior and infant development of blue-eyed black lemurs (Eulemur flavifrons). American Journal of Primatology, 73(5), 474-84. https://doi.org/10.1002/ajp.20925

Vugt, M. Van. (2006). Evolutionary Origins of Leadership and Followership. Personality and Social Psychology Review, 10(4), 354-371. https://doi.org/10.1207/s15327957pspr1004

Walker, R. H., King, A. J., McNutt, J. W., \& Jordan, N. R. (2017). Sneeze to leave: African wild dogs (Lycaon pictus) use variable quorum thresholds facilitated by sneezes in collective decisions. Proceedings of the Royal Society B: Biological Sciences, 284(1862), 20170347. https://doi.org/10.1098/rspb.2017.0347

Wang, X., Sun, L., Sheeran, L. K., Sun, B.-H., Zhang, Q.-X., Zhang, D., ... Li, J.-H. (2016). Social rank versus affiliation: Which is more closely related to leadership of group movements in Tibetan macaques (Macaca thibetana)? American Journal of Primatology, 78(8), 816-824. https://doi.org/10.1002/ajp.22546

Ward, A. J. W., Herbert-Read, J. E., Jordan, L. a, James, R., Krause, J., Ma, Q., ... Morrell, L. J. (2013). Initiators, leaders, and recruitment mechanisms in the collective movements of damselfish. The American Naturalist, 181(6), 748-60. https://doi.org/10.1086/670242

Ward, A. J. W., Thomas, P., Hart, P. J. B., \& Krause, J. (2004). Correlates of boldness in three-spined sticklebacks (Gasterosteus aculeatus). Behavioral Ecology and Sociobiology, 55(6), 561-568. https://doi.org/10.1007/s00265-003-0751-8

Warrington, M. H., McDonald, P. G., Sager, A. K., \& Griffith, S. C. (2014). The vocal repertoire of the cooperatively breeding apostlebird (Struthidea cinerea). Emu, 114(3), 206-221. https://doi.org/10.1071/MU13051

Watts, D. (2000). Mountain gorilla habitat use strategies and group movements. In S. Boinski \& P. A. Garber (Eds.), On the Move: How and Why Animals Travel in Groups (pp. 351-374). Chicago, IL: University of Chicago Press.

Webster, M. M., \& Ward, A. J. W. (2011). Personality and social context. Biological Reviews of the Cambridge Philosophical Society, 86(4), 759-73. https://doi.org/10.1111/j.1469185X.2010.00169.X 
Webster, M. M., Ward, A. J. W., \& Hart, P. J. B. (2007). Boldness is influenced by social context in threespine sticklebacks (Gasterosteus aculeatus). Behaviour, (February), 351-371.

Whitehead, H. (2010). Conserving and managing animals that learn socially and share cultures. Learning \& Behavior, 38(3), 329-336. https://doi.org/10.3758/LB.38.3.329

Wolf, M., \& Krause, J. (2014). Why personality differences matter for social functioning and social structure. Trends in Ecology \& Evolution, 29(6), 306-308. https://doi.org/10.1016/j.tree.2014.03.008

Wolf, M., \& Weissing, F. J. (2012). Animal personalities : consequences for ecology and evolution. Trends in Ecology \& Evolution, 27(8), 452-461.

Wrangham, R. (1980). An ecological model of female-bonded primate groups. Behaviour, 75(3), 262-300.

Wright, P. C. (1998). Impact of predation risk on the behaviour of Propithecus diadema edwardsi in the rain forest of Madagascar. Behaviour, 135(4), 483-512.

Zemel, A., \& Lubin, Y. (1995). Inter-group competition and stable group sizes. Animal Behaviour, 50(2), 485-488. https://doi.org/10.1006/ANBE.1995.0262 


\section{Acknowledgments}

I want to thank my supervisor Claudia Fichtel and Peter Kappeler for giving me the opportunity to conduct this project, for their guidance and support. Thank you, Claudia, for sticking this through with me! My thanks also go to Oliver Schülke and Margarete Boos for lending their advice as part of my thesis committee and to Margarete for evaluating my thesis as well. In addition, I am thankful to Julia Ostner, Eckhard Heymann and Christian Roos for agreeing to be part of my examination board.

Misaotra betsaka to the Équipe de Kirindy, particularly thanks to Mamy Razafindrasamba and Jean-Pierre Tolojanahary for supporting me in my studies and to Tianasoa Andrianjanahary, who is always there to help! Thank you to my students Hannah Kleine-Weber, Sophie Kirberg, Heather Sanders, Lynne Werner and Bianca Koegl for helping me with data collection and being such wonderful company in the forest! Also, thank you to Holger Sennhenn-Reulen, for his statistical advice and help. And a special thank you to Rebecca Jürgens for being an amazing administrator and giving advice and encouragement!

I would like to thank the whole Sobi research group, especially Ulrike Walbaum, Christina Glaschke and Anja Cziommer for their support and always having an open ear. Furthermore, super-thanks to Klara Kittler, Nicola Campbell and Johannes Schumacher for proof-reading this thesis!

Lots of love and thanks to the friends I've made here: Darja Slana, Hanitra Rakotonirina, Klara Kittler, Franziska Hübner, Charlotte Defolie and Federica Dal Pesco. Thank you for sharing this chapter of my life with me; you were the best thing about it! I don't know if I'd have made it through without our talks, hugs and laughter! Thank you for sharing the highs and lows! Let me quote George R. R. Martin here: "Summer friends will melt away like summer snows, but winter friends are friends forever."

Finally, thanks a million to my family and Johannes and the rabbits for always being there for me to cuddle. You are amazing. 


\section{Declaration}

I hereby confirm that this thesis entitled "Group coordination processes and determinants of leadership in red-fronted lemurs (Eulemur rufifrons)" is my own work. It was conducted and composed independently, without the use of any resources other than those specified in the text.

Göttingen, $29^{\text {th }}$ of September 2018

Anna Sperber 